\title{
Between Dominance and Demise: The Revitalization of the Former St. Mary's Paper Mill
}

by

\author{
Kasey Marie Camire \\ A thesis submitted to the Faculty of Graduate and Postdoctoral \\ Affairs in partial fulfillment of the requirements for the degree of \\ Master of Architecture Professional \\ Carleton University \\ Ottawa, Ontario
}

(C) 2014

Kasey Camire 


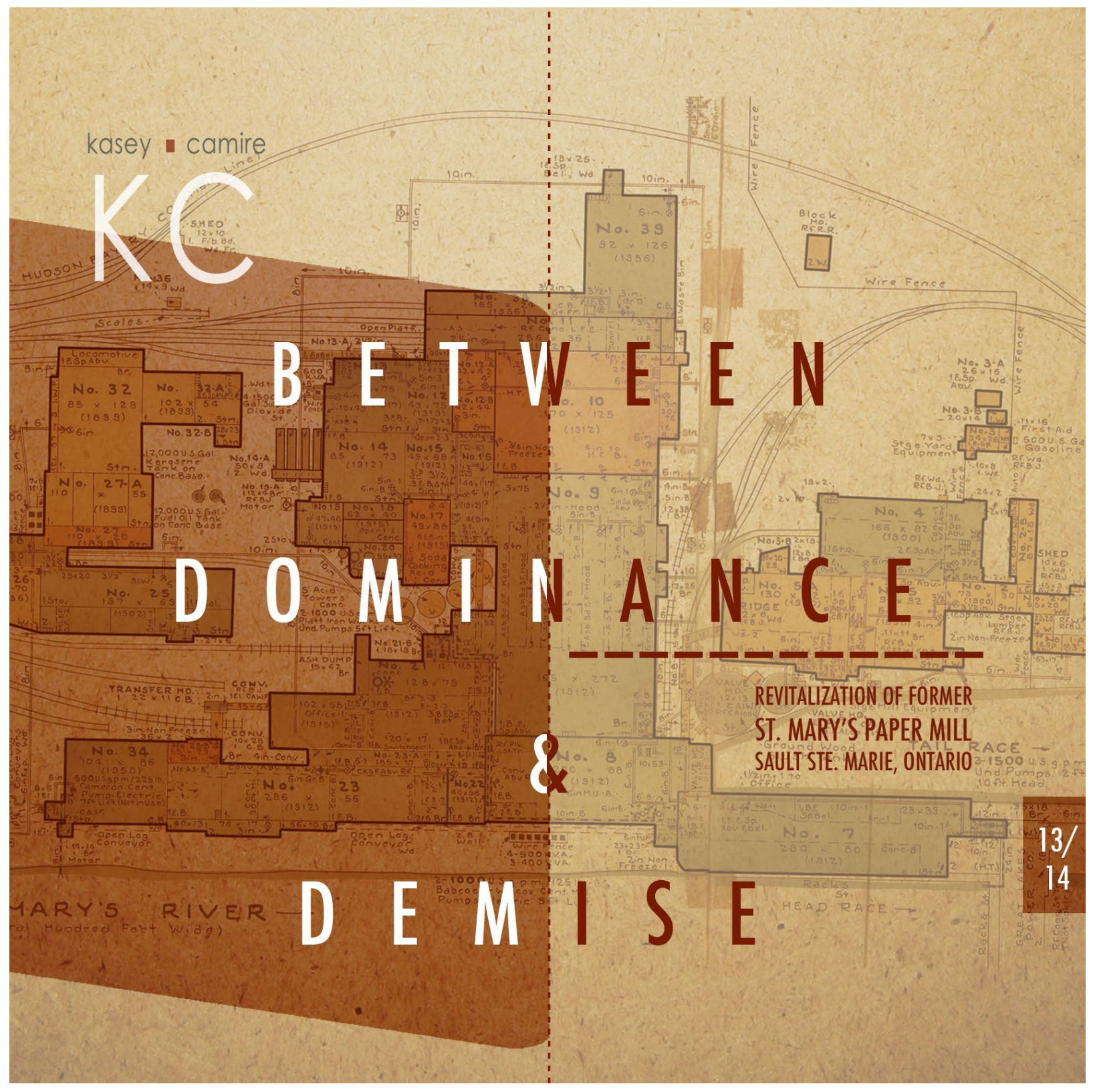


Abstract

Between Dominance and Demise speaks of the industrial ruin as an entity that is in the state of the in-between, which will be elaborated in this thesis. Due to the inevitability of immense changes in technological advancements, the industrial complex is suspended from regular activity. Such an uncertain position is considered to be in a state of transformation for both the physical construct and the community to which it pertains. For many communities, the struggles of adapting to the uncertainty of the post-industrial landscape can often inhibit their regeneration. Many elements must be addressed when re-purposing the industrial ruin, including a sensitivity to social, physical and architectural histories. Consequently, these landscapes are often replaced by contemporary modes of construction that do not consider the past or remain vacant. How do we maintain connections to our industrial heritage, to the memory of place, if it no longer appears to be embedded in the social and physical networks of surrounding communities?

Growing up in small and heavily industrial cities, I have witnessed the psychological and morphological impact of industrial decline on a community. This thesis will focus on the utilization of the former St. Mary's Paper Mill, located in my hometown of Sault. Ste. Marie. The premise of the thesis is to challenge manners to dissociate the modernist understanding of the industrial ruin as a plague to future progress and will propose the importance of maintaining the industrial phantom as a foundation for future growth. The thesis emphasizes that it is only until people see the potential of the past and its persistence in the present state that they begin to comprehend that life does not end with production. 
Contents

Abstract

Acknowledgements

Prologue

I. Avant Propos - $\ldots-\ldots$

II. Clergue's Legacy - _ _ _ _ _ $\ldots \ldots$

Introduction

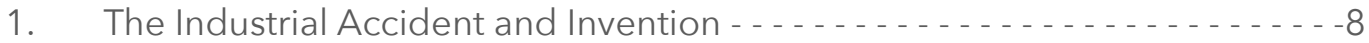

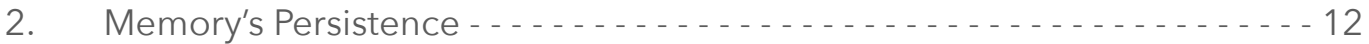

3. The Phantom and Its Mirror Form $\ldots \ldots$

The Architectural Intervention

4. Reviving Phantom Networks: Biomass Facility Proposal - - - - - - - - - - - 25

5. Mediating The Toxic Image: Phytoremediation Landscape - . . . . - . - . 41

6. Consolidating The Void: Institute of Energy and Environmental Studies - - -53

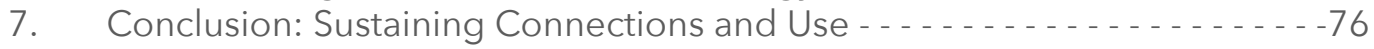

List of Illustrations -

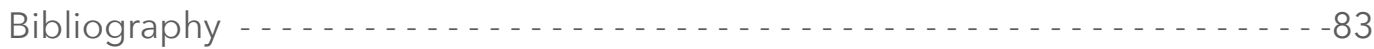

Appendix 
Acknowledgements

First, I would like to express my sincerest gratitude toward my thesis advisor Sheryl Boyle. In my third year of the undergraduate Architectural Studies program at Carleton University, I attended Sheryl's exhilarating class "Recycling Architecture". She expressed her passion of post-industrial developments and brownfield sites very vividly to students, to which has inspired and driven my thesis. Little did I know then that I would be so fortunate to have her as my thesis advisor years later.

Special acknowledgements go to the community of Sault Ste. Marie, the former workers of the mill, city historians, local professionals and city developers. My story would not have been complete without their voices and opinions.

Finally, this thesis is dedicated to my family, for their support and love. To my parents who have been through this with me since the first day I decided to stray from home to continue my education. The distance from home never impeded their encouragement. I am blessed to have them in my life. My thesis is also to inspire and encourage my younger sister in continuing her education; I wish her the best of luck in her endeavors. 
Prologue: Avant Propos

Industrial sites are often historic icons, bearing witness to different periods of growth and decline in the history of the city. As the industrial landscape changes, it leaves behind imprints of daily life and culture. These lived and conceived spaces provide us with means of reading the tightly woven threads of cultural, social and historical depictions that shape the city and its advancements. It is only in the failure of such legacies that communities question the viability of industrial sites in the city's fabric and ongoing history. In their former glory, industrial landscapes promote the pride of industrial heritage and of perseverance that contributes to a strong economy and growth. The unsettling nature of failure and sentiments of loss among the community often inhibit continuity and regeneration of these spaces. Abandoned industrial sites are deemed no man's land; their ruins are seen as scars among a shaken economy.

Post-industrial sites often appear to be detached with the progressive developments within the city. In their state of decay, they cease to resonate with daily life. The urban industrial landscape is commonly stereotyped as an image of towering chimneys and billowing smoke within the city's core. The postindustrial site is associated with the social impacts of industrial abandonment for residents, that includes not only job losses, but also serious health problems associated with living and working near contaminated sites. The premise of this thesis is to dismantle this image, and question how these landscapes can be adapted and reintegrated into the city in a way which contributes to both future progression and the unveiling of the past.

Prologue: Avant-Propos 
Centers of industrial production are consequential parts of capitalist industrialization. However, it is what has remained of these industries, once they have been abandoned, that is of interest for this thesis. Post-industrial sites are commonly transformed through neglect and gentrification by new investments that impose entirely new functions rather than awakening the past through an architectural dialogue (Crinson, 49). When seeking to activate networks that reside within the urban landscape, one must not peel away the representation, but be aware of its history and relationship with the surrounding fabric.

The following thesis has been influenced by my observations of the degradation within my hometown of Sault Ste. Marie, as I have encountered and understand the hardships of living alongside industrial ruins and in the midst of a failing industry. Similar sentiments have been questioned over the recent and past decades, notably in the work of Aldo Rossi, Tim Endensor, Alice Mah, Paul Virillio, and among others.

The thesis assess the current situation and state of de-industrialization to determine a foundation for its revival. This will be explored with respect to the ruin as an embodiment of its fluidity amongst the social and physical networks, with respect to time. The dichotomy between the ruin, as a manifestation of the past and the present, continues to shape the surrounding community and will be emphasized in this thesis. The project aims to build a general narrative that will begin to delineate both the process of growth and the morphology the ruin will take as a response to a continuation of this dialogue with the city. The significance of the ruin in contemporary space will be developed by utilizing the following methodology of approach to inaugurate the revival and re-generation of the former St. Mary's Paper Mill.

The thesis is divided into two parallel architectural designs: one will address the 
void left by de-industrialization while the other will consolidate the physical presence of the ruin. As part of the thesis, a separate booklet with diagrams, designs and historical context images will be attached as an appendix to this text. This booklet will review the site's history and help orient the reader regarding decisions made in the design portion of the thesis. This thesis, in conjunction with the appendix, is intended to not only satisfy my yearning to understand the history of this site and its potential, but also to provide a document accessible for the community to ponder the larger scope of postindustrial practices and projects in Sault Ste. Marie. 
Figure 1.1.1: View of the Foundry and rail yard, St. Mary's Paper Mill. 1920.

The concept of legacies poses a certain tension when re-adapting abandoned industrial sites. Legacies of industrial ruination and urban decline refer to its initial creation and enduring features, both social and material. Their decline involves the inheritance and historical traces of past environmental impacts, followed by job losses and economic downturns, which negatively influences people and places. (Mah, 25) The inauguration and initial inspiration for the project emerged when studying the mill's recent past and extended history. As a native of Sault Ste. Marie, it was surprising and enlightening to learn that this industrial landscape had such an influence on the city's early development and contemporary structures. The thesis commenced by studying its extensive history in order to uncover strategies of how to immerse the project into the ongoing story of our industrial heritage that will not be impeded by tales of decline. 
The St. Mary's Paper Mill has been around for over a century, whereby the site has a rich history as the foundation of city growth. Prior to 1895 the site was used as a trading post, and in 1901 the construction of the mill had begun to take fruition. During this time, Francis $\mathrm{H}$. Clergue stood out as a crucial figure in the mill's history. His ambitions and plans are still visible in the present story of the city's fabric. Clergue was truly a pioneer and had constantly pushed Canada's pulp and paper industry to the forefront. Through his vision, the mill's industrial buildings were quite unique and experimental, becoming the first of its kind in North America. He developed new processes and machines that eventually became common practice among North American paper industries, and by the mid-twentieth century had risen to be the leading pulp and paper mill in Canada. (Real Estate Carrick Limited)

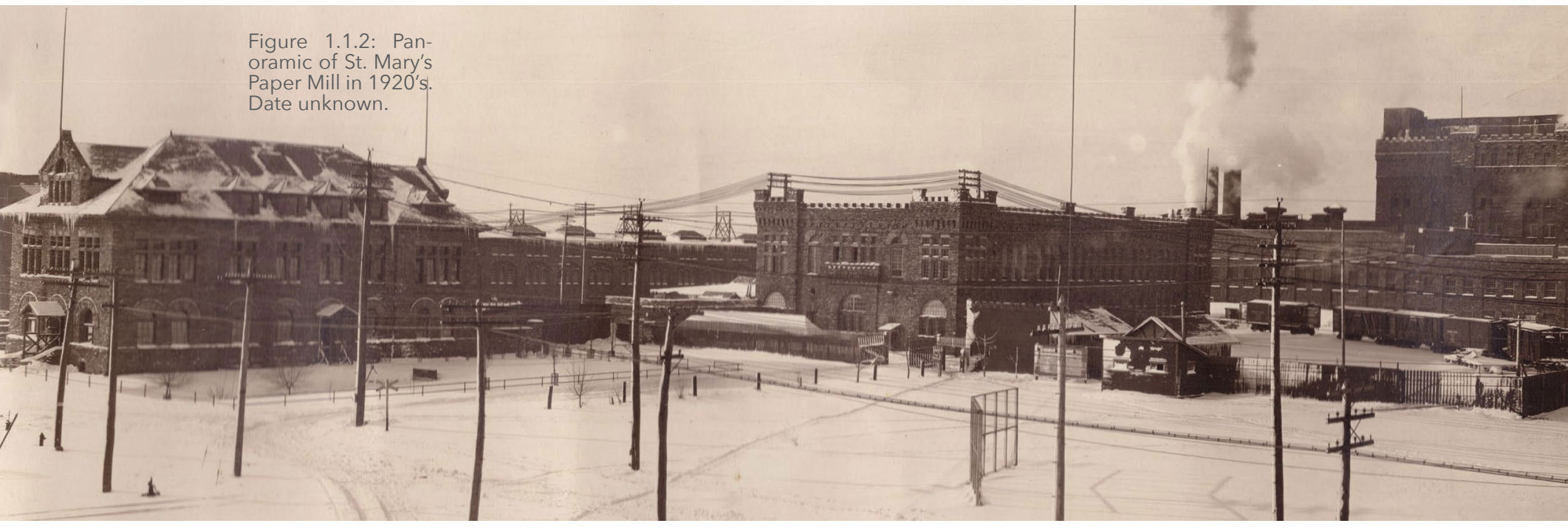

Clergue was quite a cunning businessman. His enthusiasm and drive for prosperous economic development in Sault Ste. Marie can be read in the present industrial landscape of the region. His mission to create a successful industry in the North did not end with paper production, although many supplementary businesses arose as means to support the pulp and paper mill. At the time Clergue was instated as manager, logs were transported through a series of watersheds leading to the mill. Production had diminished as the 
logs arrived too wet for production and soon after Clergue, along with several engineers, devised ways of drying the waterlogged resource with sulphite. This invention necessitated the creation of pulp towers as a crucial procedure and infrastructure for the production of pulp in North America. Sulphite deposits are uncommon in the Sault Ste. Marie region; the resource is readily available in the neighboring city of Sudbury. In light of this discovery, Clergue then devised strategies for transporting sulphite between Sudbury and Sault Ste. Marie. Clergue, already proving to be a prosperous entrepreneur had convinced the city council of Sault Ste. Marie to construct a steel plant (Algoma Steel) ${ }^{1}$ in order to facilitate the creation of rail systems between the city and Sudbury. For many, the manner in which industry settled itself in the city is not well known to the population at large. Ultimately, this string of industries had come from the early developments of Clergue's pulp and paper mill. All these connections to the various industries, existing infrastructure and sources of revenue can be traced and are visible in the mill's original plans.

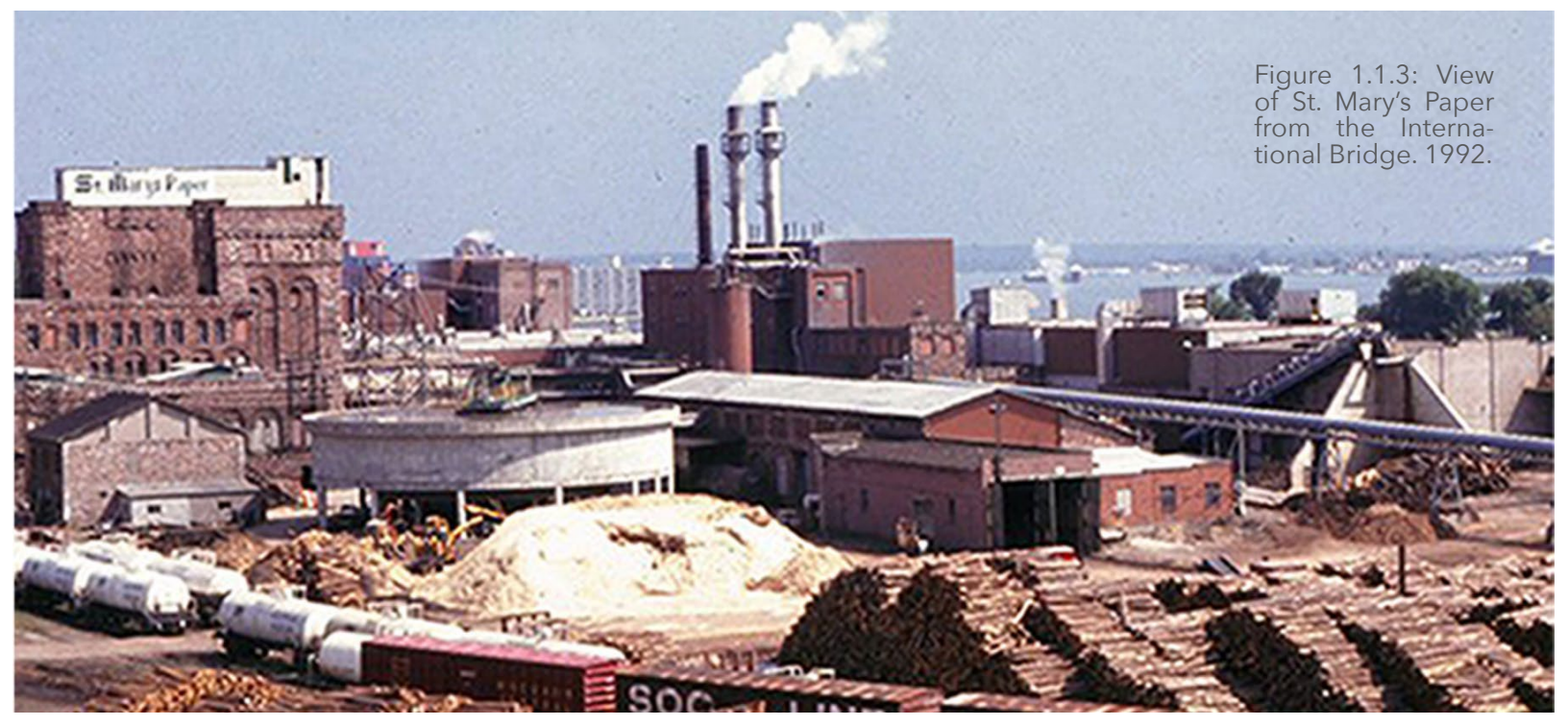

Clergue's legacy saw many successes throughout its history, however there were times when production suffered substantially. This brought about strikes and

1 The steel plant is now under the ownership of Essar Steel, it remains the largest source of employment in the city until present. 
even closures, although production remained intact and the life of the industry was sustained. It wasn't until the 1980's that the mill began to see the effects of lower demands in the paper industry. This period was really the beginning of the process of ruination that has effected the present landscape and image of the mill. While many efforts were targeted at sustaining capital investments for the company, production began to look promising a few years after the most recent deficit in 2003. Shortly after, the needs and demand for paper production decreased so rapidly that the mill was forced to close permanently in 2011. The mill was then bought out by the Riversedge Development Inc. in March of 2012 and the site was then slated for demolition, as its industrial use as a paper mill could no longer be viable for the continuation of the site's development. The collection of industrial structures were carefully removed from the site to reveal the historic sandstone buildings of the Clergue era that had been swallowed by layers of building additions.

The sequence of historical moments and developments make up a large portion the city's heritage. However, these periods of history are masked by the recent economic struggles with the industry since the early 1980's, where most citizens are not aware of the mill's extended rich history, as they have become only fixated by the troubles and demise the industry has brought in the most recent past. Interestingly, an article was written about the mill in July of 1920, entitled "The Soo"- Visit of the Canadian Pulp and Paper Association, the text discusses the issue of memory loss and disconnect from the past. The quote from the article states "The early days of Sault St. Marie are rich in lore of a past that is slipping from us far too quickly." (CPPA) This thesis in a way re-addresses this concern, reviving this topic of the site's history, loss and disconnect from the city's current fabric and landscape.

Chapter 1: Clergue's Legacy 


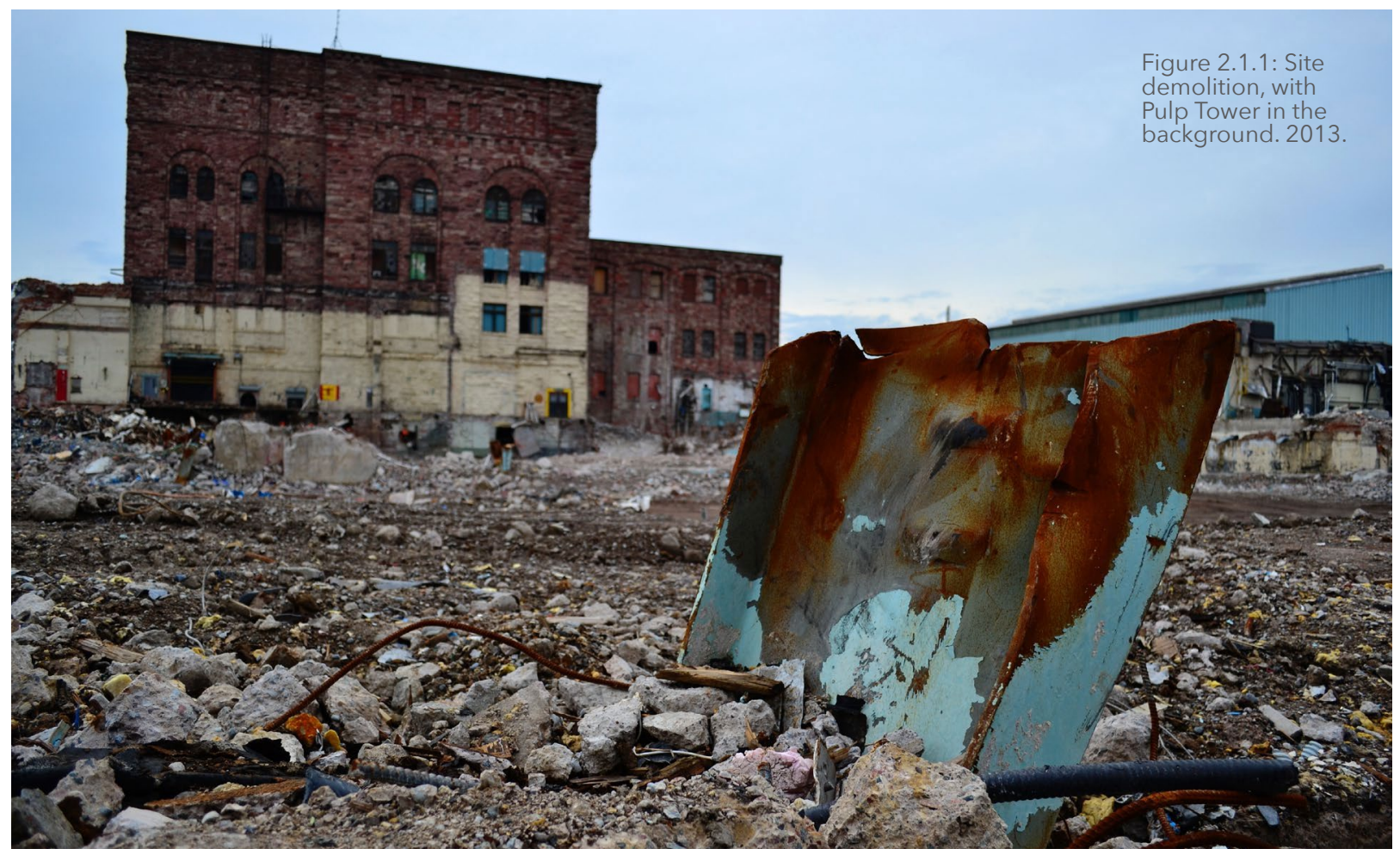

The Industrial Accident and Invention

Post-industrial sites are ambiguous historical records of inhabitation, as I had experience myself before formally researching the site's history. Abandoned industrial sites allow one to experience the ruin and to employ tactics of both simultaneously remembering and forgetting past integers. The anthropological experience that it evokes depends in some way on its condition as a historical ruin. The conditions by which they are often found are unkempt, while at the same time ethereal. What we are left with often resembles the skeletons of the site; the skeleton, being a common analogy used by Aldo Rossi in Architecture of the City. Recent developments concerning abandoned industrial sites have seen constant tension between the interests of heritage and those of regeneration. The humanist conception attempts to integrate the subject and object, whereas the modernist ideology attempts to separate the past from 
the present. With respect to modern architecture today, post-industrial sites are seen as contaminates, since they are elements that engage history and typology. (Rossi, 5)

For Rossi and many others, the modernist critique of history is a hindrance to invention and fails to see the importance of history and typology as a generator for transformation that is unforeseeable (Rossi, 5). Rossi's notion of the skeleton provides us with an analogy for understanding historic sites. "For it is at once a structure and a ruin, a record of events and a record of time and in this sense a statement of facts and not causes." (Rossi, 5) Past vestiges provide the architect and architectural user with a living medium for the biography of the postindustrial site, but it is memory that provides the materials for autobiography. Rossi argues that when memory begins, history ends and ergo encompasses both future and past time. It is to be noted that the images of ruins activate this unconscious memory by linking the discarded and the fragmentary with a newly erected architectural space by bringing the ruin into dialogue with the issues of our time. The iconic imagery of the skeleton, of death and abandonment become

Figure 2.1.2: Clutter from abandoned foundry building, 2013. an active contribution to the process of transformation of post-industrial sites; it is with death and the ruin that a new beginning emerges. (Rossi, 11)

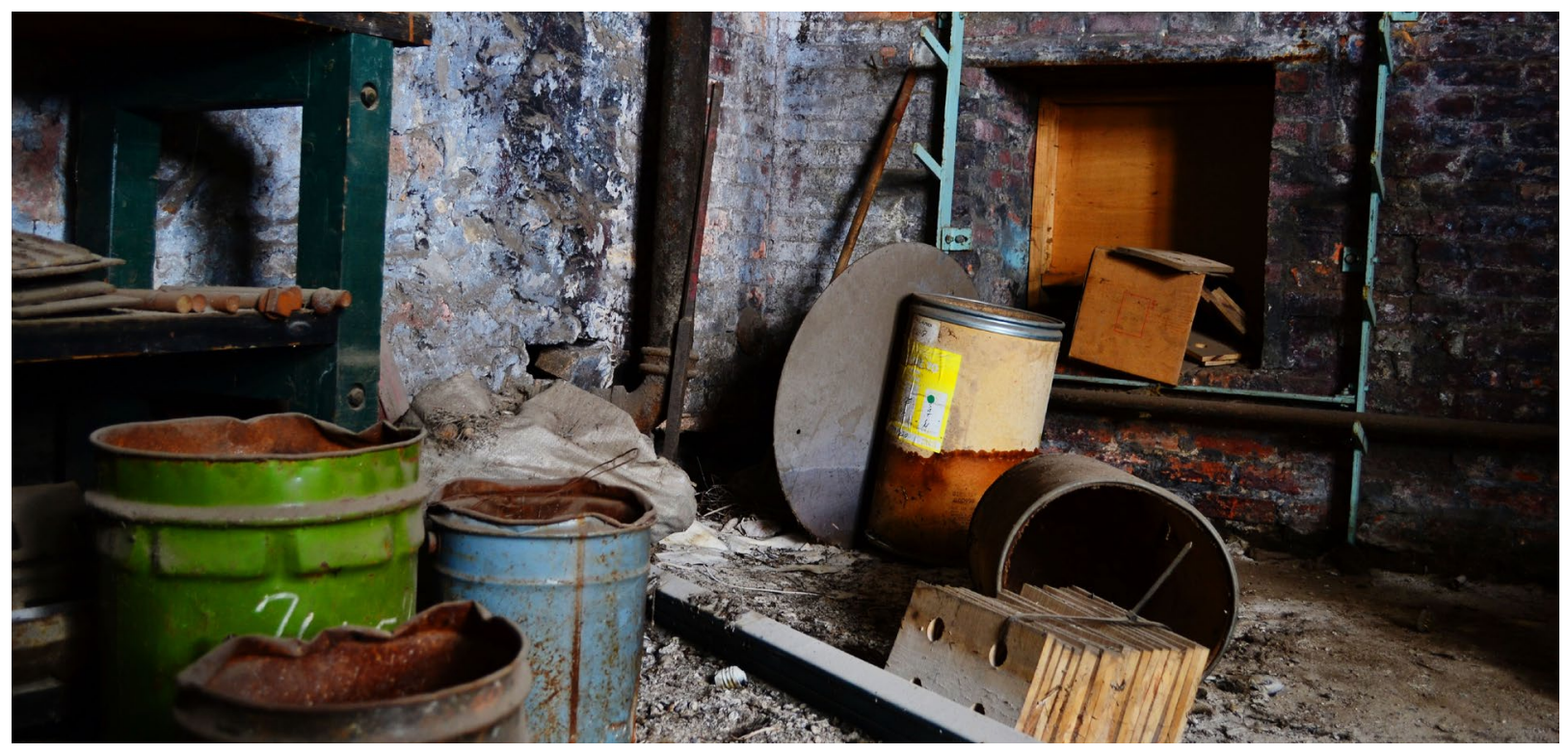


In The Original Accident, Paul Virilio insists that the uncertainty of the industrial accident proposes that ruination is "the fruit of progress and the labor of mankind". (Virilio) This hypothesis provides access to approaching the postindustrial site in new light by examining the existing parameters and networks found within and at the periphery of this space. Both Virilio and Rossi understand the need to uncover what is hidden, but also what is waiting to happen with regards to evolution and history. It is through the tragedy of industrial demise that the substance of progress and invention is revealed. These concepts become a point of focus when reading the former St. Mary's Paper Mill site that relate to the community's conception of the industrial heritage.

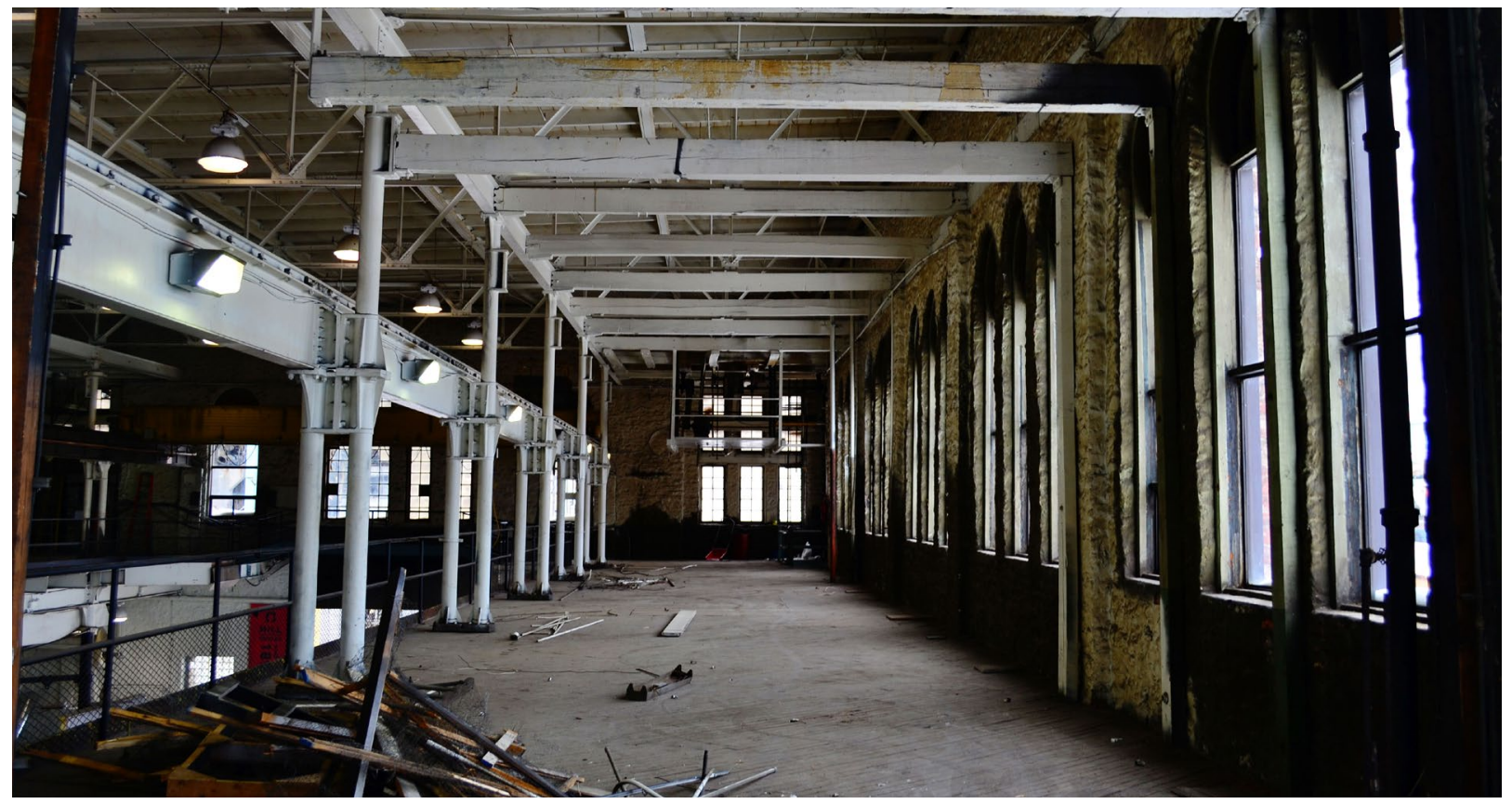

Figure 2.1.3: Machine These sites provide a gateway for a community to be able to witness the shop interior, St. Mary's Paper Site. 2013. way a built environment manifests time as both receding and approaching simultaneously with different tempos. Within this contorted perspective the past is never over while the future rests on the horizon. The industrial site is therefore a palimpsest; much like the city- it is a field of inscription that fades, is re-written and is a delicate matter of layered traces. This architectural and social stratum creates the thickness of the past, one that requires attention and 
conservation. There are distinct figures that link the city to the postindustrial site; these memorials in themselves generate means of mapping out the significance of a community and how it may be redeveloped. 
"Memory survives, if it survives at all, in the form of traces or residues, fetishes of the past or bureaucratic ordering of certain venerated phenomena." (Crinson, 51)

While visiting the site in the midst of demolition, I had the privilege of walking around the old paper mill site with a pair of former workers. These men had been engineers, working amongst the loud machinery of the mill in the 1940's. It was a time of great prosperity for the industry and these men were truly pioneers of this industrial process. Even in their old age, they could remember the processes, activities and buildings on the demolished and empty site. The men both talked vividly of the mill's past forms and spaces, bringing to life a detailed and evocative memory of the St. Mary's Paper Mill. Only the foundations and rubble remained of the former buildings. We found ourselves at the machine shop, in a dark and disheveled room filled with a barrage of litter and old machines. The one man chimed up and told us that this place was once his office. The room had since been readapted as an extension to the machine hall, and was being used as additional storage during demolition. He could recall where his desk once sat, where he transmitted messages to workers across the large site and even the place where workers would punch in during the early mornings and late evenings. Many reminiscent conversations with the community have occured after this encounter, and I believe that the post-industrial site is a powerful symbol for the citizens of Sault Ste. Marie. The physical presence of the ruin demonstrates it is both sensitive towards the cultures and histories, strengthening the sociological networks that surround it. 


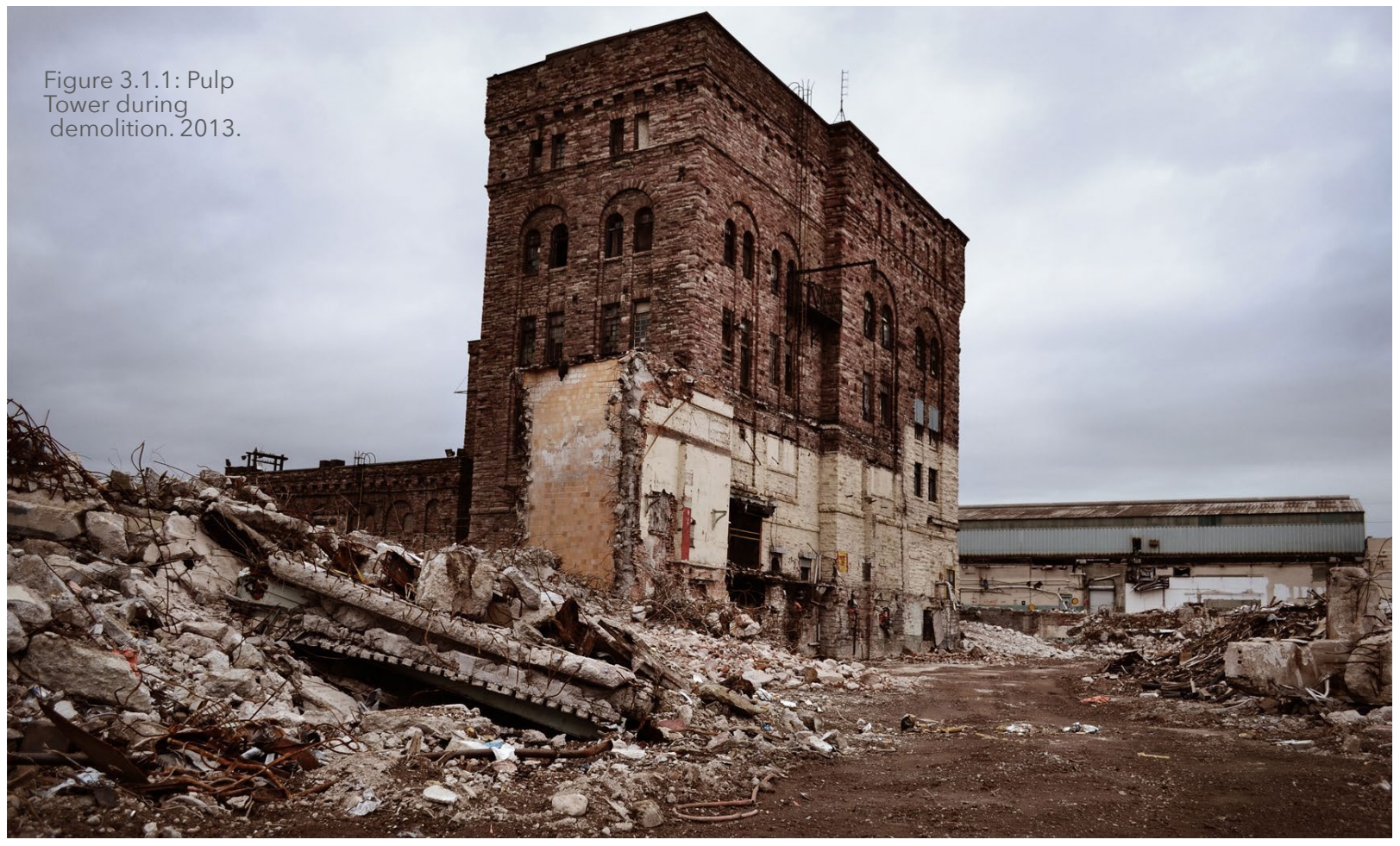

An industrial ruin is often characterized by its unstable state within the city's network. On the face of it, it would appear the ruin is no longer situated within the dense assemblage of local connections. Since the ruin stands outside the habituated organization of time, space and materiality, the position of these networks subsequently begin to slowly unravel. (Endensor, 64) With the detachment from enduring sets of associations, it would seem that the purpose and meaning of the site is lost. While networks of production and capital of the former paper mill are suddenly dropped from the local environment, they remain partially in place as a result of memories connecting workers and the community with the former life of the industrial ruin. The livelihood of the industrial image is maintained by collective memories that keep the networks of the past connected with the present state of post-industrial sites. (Endensor, 70) This was made evident upon meeting with the two former engineers. 
Memory appeals to us because it creates an immediacy that has been lost by history. Memories allow us to engage with a variety of historical discourses and is able to breathe life into the stories of important predecessors in our current projects. We have a tendency to conjoin industrial and post-industrial uses of memory that offers us a guide to synthesize traditional connotations with contemporary developments that appeal to our postmodern language. (Klein, 134) There is a narrative found within memory that converges the archaic and the contemporary that is expressed through the union of material objects and the sanctified presence of postindustrial sites. Through these projects we are able to understand the depths and morale of a community with relation to the shifting developments within the surrounding city. "Memory is not a property

Figure 4.1.2: St. Mary's Paper workers celebrating. Date unknown. of individual minds, but a diverse and shifting collection of material artifacts and social practices." (Klein, 130)

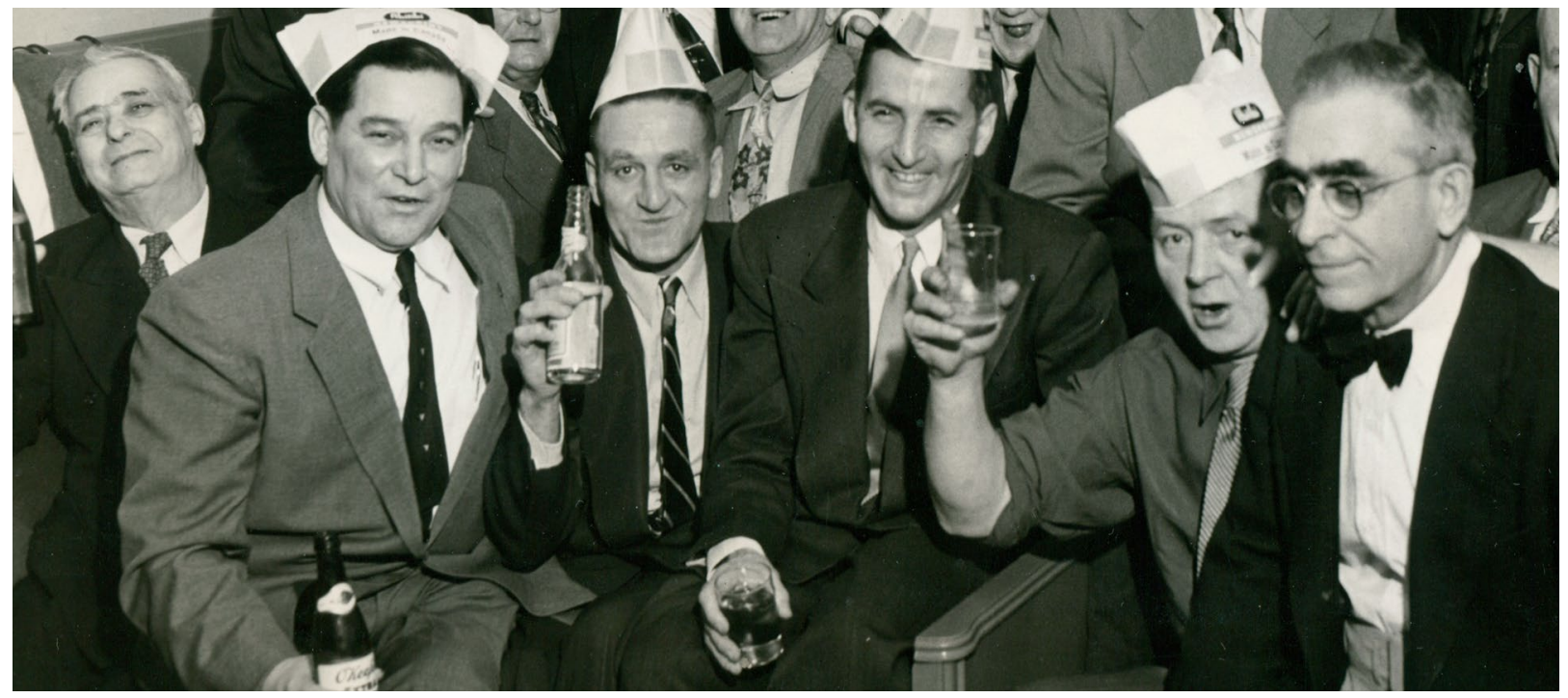

Upon grasping the potential that memories place towards redeveloping the St. Mary's Paper Mill, the thesis then explored ideas and studies performed in the text, Industrial Ruination, Community and Place by Alice Mah. In the study, Mah investigates changes in the past few decades with relation to jobs, education and social services of post-industrial cities across North America and Europe. 
Her studies provide a useful insight and cover a large spectrum of sentiments and memories associated with post-industrial sites that is achieved through interviews with communities in proximity to industrial ruination, individuals who worked at the mills, and those living in these industrial cities. These interviews and insights into life amongst the industrial ruin revealed two distinct sentiments and memories. Primarily, both nostalgic and traumatic memories arose when remembering accounts of the processes of industrial ruination. These reactions drew parallels towards the discussion I encountered with my own community.

Mah's study uncovers the underlying issues associated with memory discourse, namely the fixation on only specific characteristics of industrial decline that often determine the outcome of furthering industrial heritage and renewed development. In the case of the post-industrial site, individuals tend to only remember significant shifts, either of the triumphs of production or its decline. The duality of nostalgic and traumatic memories allow for a better understanding of how past experience is negotiated. (Mah, 55) Thus, obsession with a limited framework of sociological and historical characteristics of the industrial city can obscure a series of important artifacts, which enrich the urban fabric and landscape. We therefore could question the integrity of such a limited analyses and keep in mind the larger framework of the permanent and universal forces that play in the redevelopment of these sites (Rossi, 24). There must be an active acknowledgement of both the extrinsic and radical changes that have occurred in order to understand this avowal and disavowal of memory and physical space. 
The Phantom and Its Mirror Form

My first impressions upon meeting with the former engineers drew parallels to the notion of the phantom limb phenomenon. The prerogative of this analogy is to associate the post-industrial site with a body that has been severed from a vital set of networks. Essentially, a phantom limb is the brain continuing to detect the presence of an amputated limb, although it is no longer attached to the body. (Ramachandran) In essence, the analogy emphasizes the notion that connections with the industrial ruin have been severed from the city, while the effects are continuing to be felt by the community at large. To achieve this manifestation in architectural space, I propose to begin the design process with identifying the phantom body as the foundation upon which to construct the theory of newly integrated space.

Individuals who experience the phantom limb, may encounter one of two separate feelings associated with the loss of the limb. On the one side, some patients experience the feeling of normal bodily functions while others only experience the trauma and the pain associated with loosing the limb. (Ramachandran) These mixed sentiments are analogous to the individuals being interviewed in Industrial Ruination: Community and Place, where they associated the site with either nostalgia or trauma. The patient who identifies the phantom limb with trauma is faced with a clenching and painful feeling. The body's response to trauma creates tension that is articulated by refusing a continuous narrative with memory, and therefore is not able to remember the past functions of the lost limb. (Ramachandran) This traumatic image, in the 
post-industrial setting, stands to potentially undermine and damage any new potential for the discarded landscape.

Similar to phantom limb patients who associate trauma with loss, society seeks relief from the gripping memories of death and abandonment. This obsession with certain attributions of loss that inhibit a dialogue between user and space must be surprised or shocked by an uncanny experience that appears both strange and deeply familiar. This can be achieved through the use of a mirror event. ${ }^{2}$ Such an event triggers the forgotten feeling of the phantom limb, giving access to the fragment of lost time and consolidates by filling the void through perceived physicality and tactility. Here, the ruin is being explored as a vessel of experience that dwells on both the conscious and unconscious levels of extrinsic and radical perception. It didactically stimulates the moral sentiments of the architectural user and viewer by evoking remembered interrelations. The mirroring of phantom networks therefore can play a critical role in unlearning the lasting traumatic memory of the phantom limb through visual recognition and movement. In lieu of uncovering the phantom in the industrial context, this implies tracing over the flow of former processes of social and industrial orders. The methodology and approach of this thesis lies in the resurrection of the ruin through the re-framing of psychological and physical qualities, which begin to construct and inform the phantom's reformulation. This revival through a mimetic act allows for the industrial image of perseverance to become embodied once again on site. The function and use of the demolished site can be renounced by experiencing and mapping the former environment and applied to enrich the architectural space.

2 In medical practice, the solution for relieving phantom limb pain is quite simple. Surprisingly enough, it takes only a mirror. While using this in practice, Dr. Ramachandran had asked for the patient to move their still functioning arm and look at the reflection. The result: the patient was relieved of the phantom limb pain. His theory in using the mirror shows the critical role of visual input, movement and feeling to unlearn the patient's lasting memory of the phantom limb. (Ramachandran, 33) 


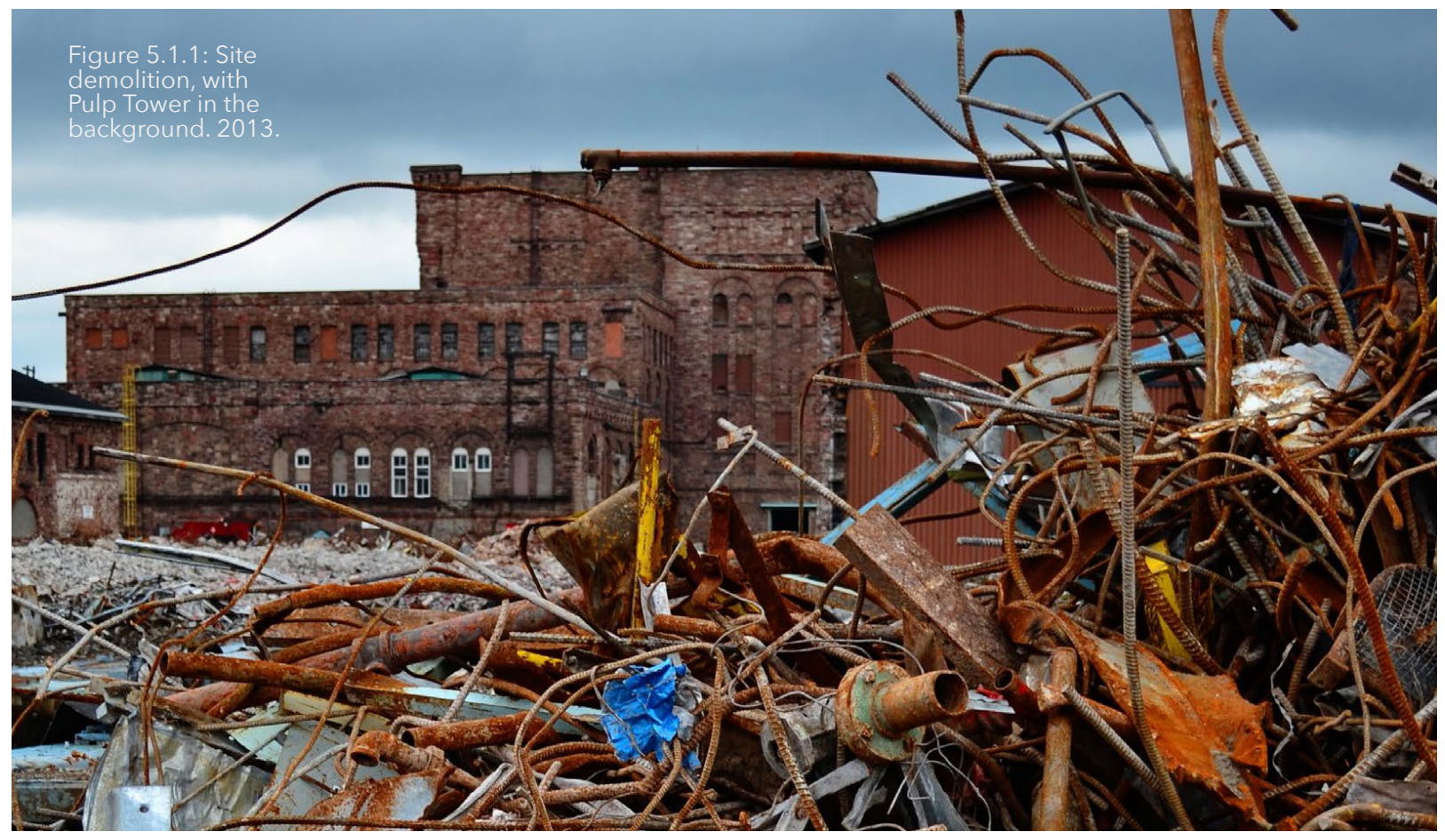

5.1 Phantom Forms and Site Context

A primary criterion for selecting the former St. Mary's Paper site was that it had to have already experienced de-industrialization, but not a complete post-industrial transformation. In this sense, the site resembles the body and the phantom limb. The essence of this thesis relies on the sublime encounter with the physical evidence and underlying networks of industrial ruination. The exposure of such a phantom framework reveals the tectonic relationships between the inward and outward flow, which inform the progression of the site's configuration.

As they began demolishing the industrial structures of the St. Mary's Paper Mill, the old sandstone buildings of the Clergue era had emerged once again. Many changes occurred throughout the mill's operation. However, the original sandstone architecture that Clergue developed at the end of the 1800's and 
early 1900's have been preserved and their use remained constant for several decades. These buildings still exist presently on the site, and are the source of recognition for nostalgic memory. The value of these historic buildings is undeniable; their re-adaption has been steadfast, as they are presently being used for a variety of social programming that extends towards the community. This segment of the thesis focuses on the faintest signs of ruins and the spaces brought about through careful demolition and voiding of industrial infrastructures. For this reason, the research called attention to the mill's past plans; speaking with former workers enabled the story of place to be uncovered in its physical state, while also bringing to light the social fabric amongst machines and laborers.

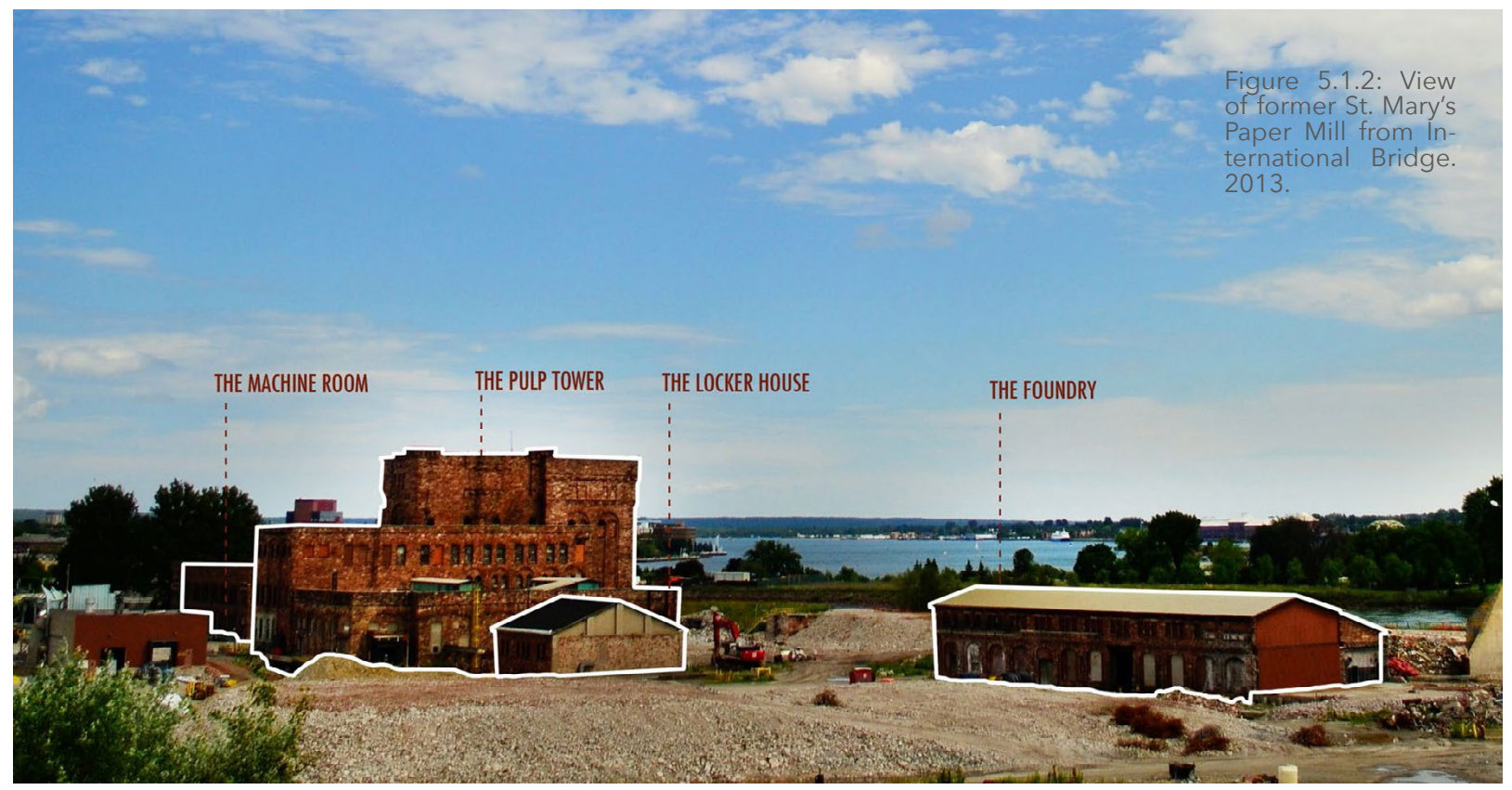

In order for the spectator to understand the constant play between the surface and deep forms they must read across the different layers and strata of the site as unified fragments of remembrance and forgetting. (Boyer, 21) It is then that we start to build a passage between the surface and the depths of the earth in order to reestablish a linkage between historic objects, the city and memory. The remnants of industrial buildings are built records of local life. To disturb 
the tradition and erase history indicates a detachment from the space itself and attempts to conceal the convoluted structure of the traditions that make it. (Wigley, 71)

Abandoned and underutilized industrial sites commonly occupy a substantially large area within the city's core, where there seems to be a growing concern for municipalities to develop this valued land. Careful consideration is placed on what types of site programming will promote sustainability and generate further developments within the surrounding city fabric. This research includes specific knowledge about the types and areas of growth that are projected for the city of Sault Ste. Marie. This required reviewing feasibility studies for the surrounding neighborhood of the mill, most notably the Gateway project. (PKF) The Gateway proposal is similar in scale to the St. Mary's Paper site development and focuses on many key themes the city and community wish to develop on both sites. The Gateway project has been an ongoing debate for the past 40 years and the project's light is fading. However, after realizing the potential of the underlying fabric of the St. Mary's Paper site, I began to form an appropriate and sustainable re-authorship of the mill. These sites therefore generate an important interest for furthering heritage by combining selective endorsement of details of the existing historic fabric, while taking advantage of new developments and growth.

The manner by which a city is able to retain industry is reflected in the policies that affect the outcome of its industrial artifact. The emotional acknowledgement that an industry is not likely to return is a critical development for deteriorating industrial sites, whether for economic, social or physical reasons. Society is still left with the hope that this void can be filled by a prevailing industry, alluding to the desire that the new development will generate the possibility of replacing the lost function. (Berens, 3)

Chapter 4: The Phantom and Its Mirror Form 


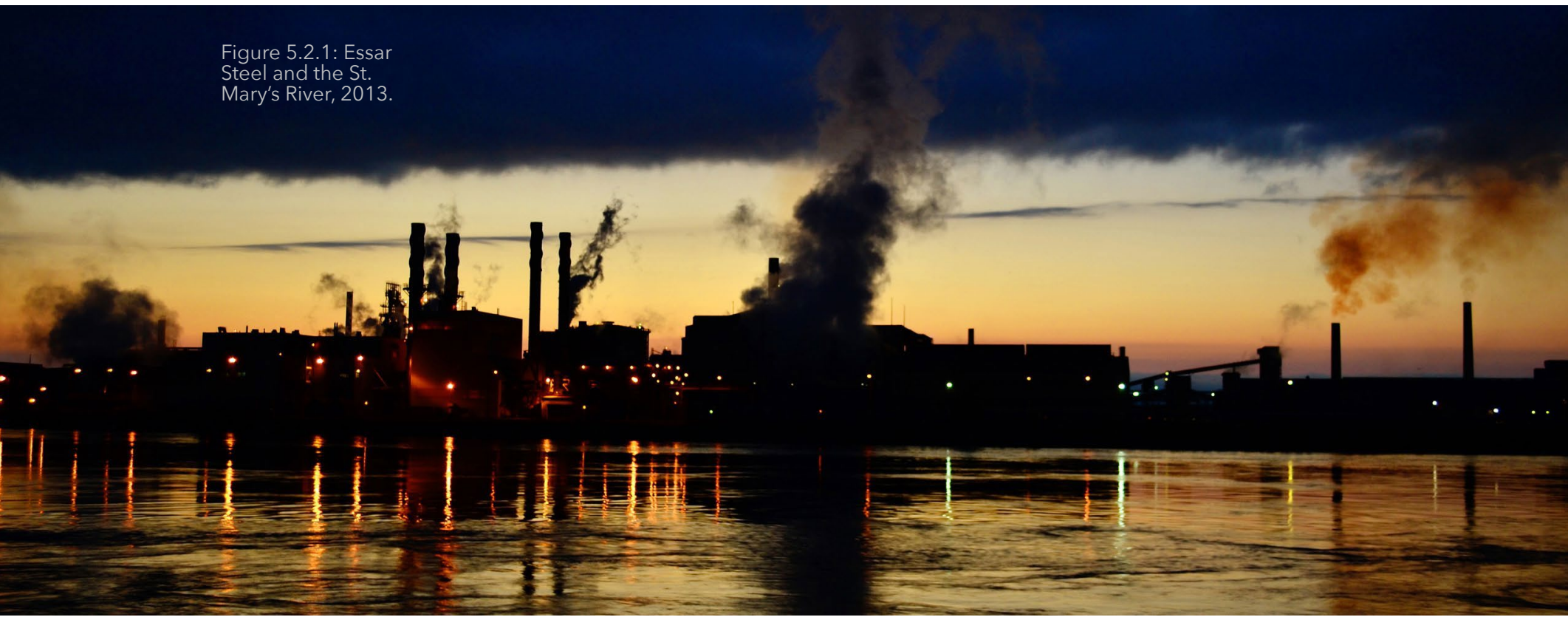

\subsection{Site Programming}

Recently, the city's primary source of growth is a result of the flourishing renewable energy industry. The city of Sault Ste. Marie is becoming the capital of renewable energy in North America. Our landscapes house some of the largest solar and wind farms in Canada. This growing industry has attracted a great number of interests towards the educational sector and Sault College, including the expansion of its Institute of Energy and Environmental Studies. To date, it is the fastest growing program and brings in the highest percentage of out-of-town students. (Common, 3) The city is also looking to take advantage of our forestry industries, and natural resources in partnership with solar and wind energy providers to create a start-up biomass plant that they have proposed to be housed on the former St. Mary's paper site. (Common, 4) We are however plagued by the toxicity of former and present industries; the city has therefore called for solutions towards a healthier lifestyle for the surrounding community. 
As part of this development, an inner-city hub trail was created to promote the flow of pedestrian traffic to our downtown core (denoted in dark red on Figure 5.22) and is being proposed to extend through the post-industrial site. ${ }^{3}$ This aspect of the program is reinforced by the sites direct access to a pathway for pedestrians and cyclists, which extends east and west along the St. Mary's River.
The desire for green spaces and de-contamination of the brown-field sites along the riverfront lends itself to be developed as a unified aspect of the program green landscapes are coupled with a biomass facility, which aspire to create a sustainable cycle and use.

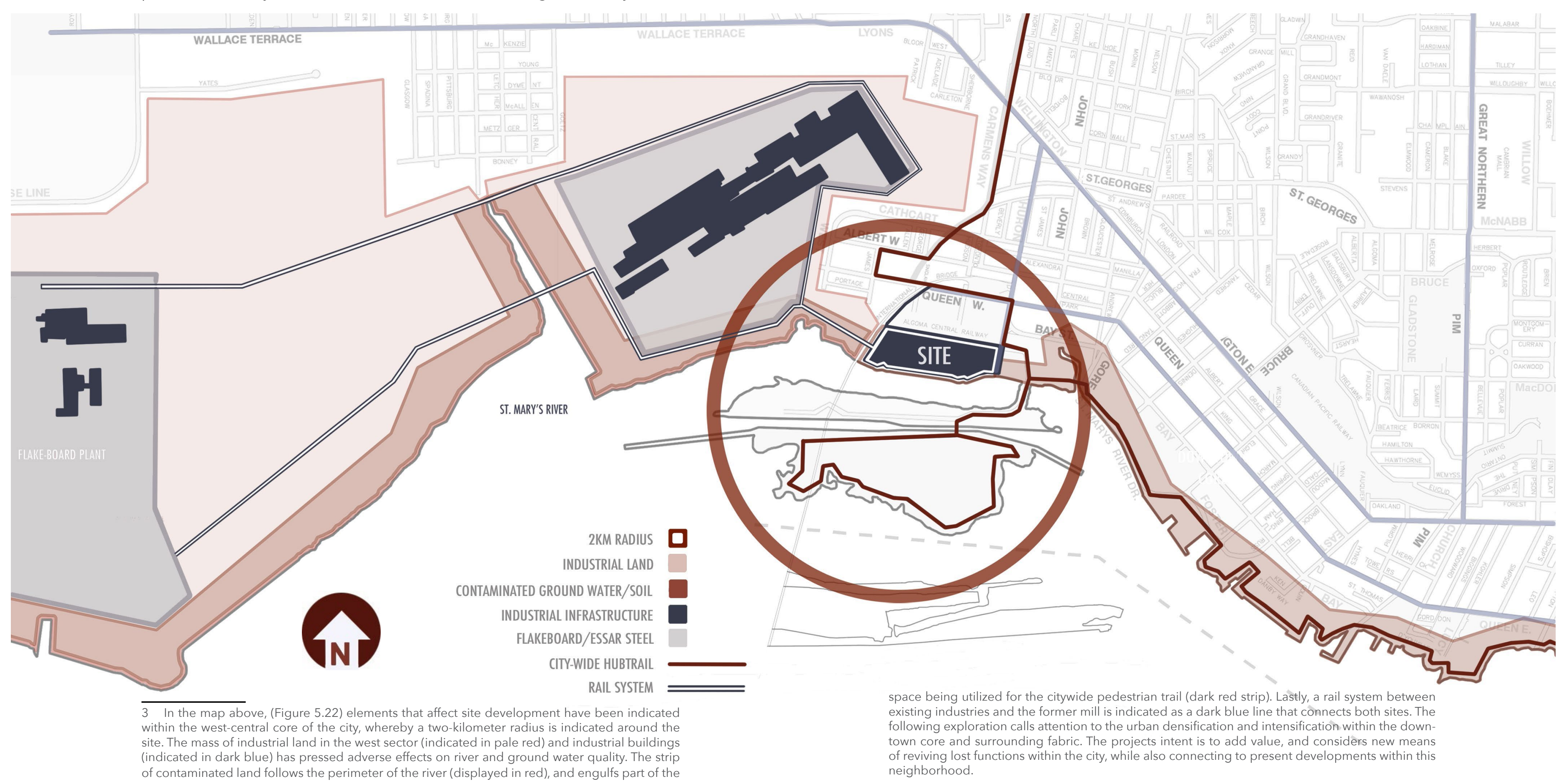


This aspect of the program meanwhile extends into the development of the Institute of Energy and Environmental Studies, in conjunction with the local

farmers market. Therefore the functional program of this design proposal consists of three elements: biomass facility, phytoremediation park, and the off-campus headquarters for the Institute of Energy and Environmental Studies. All of these will encompass a sustainable program by intertwining with the socia and communal fabric, which is essential for maintaining the site's ongoing story and connections.

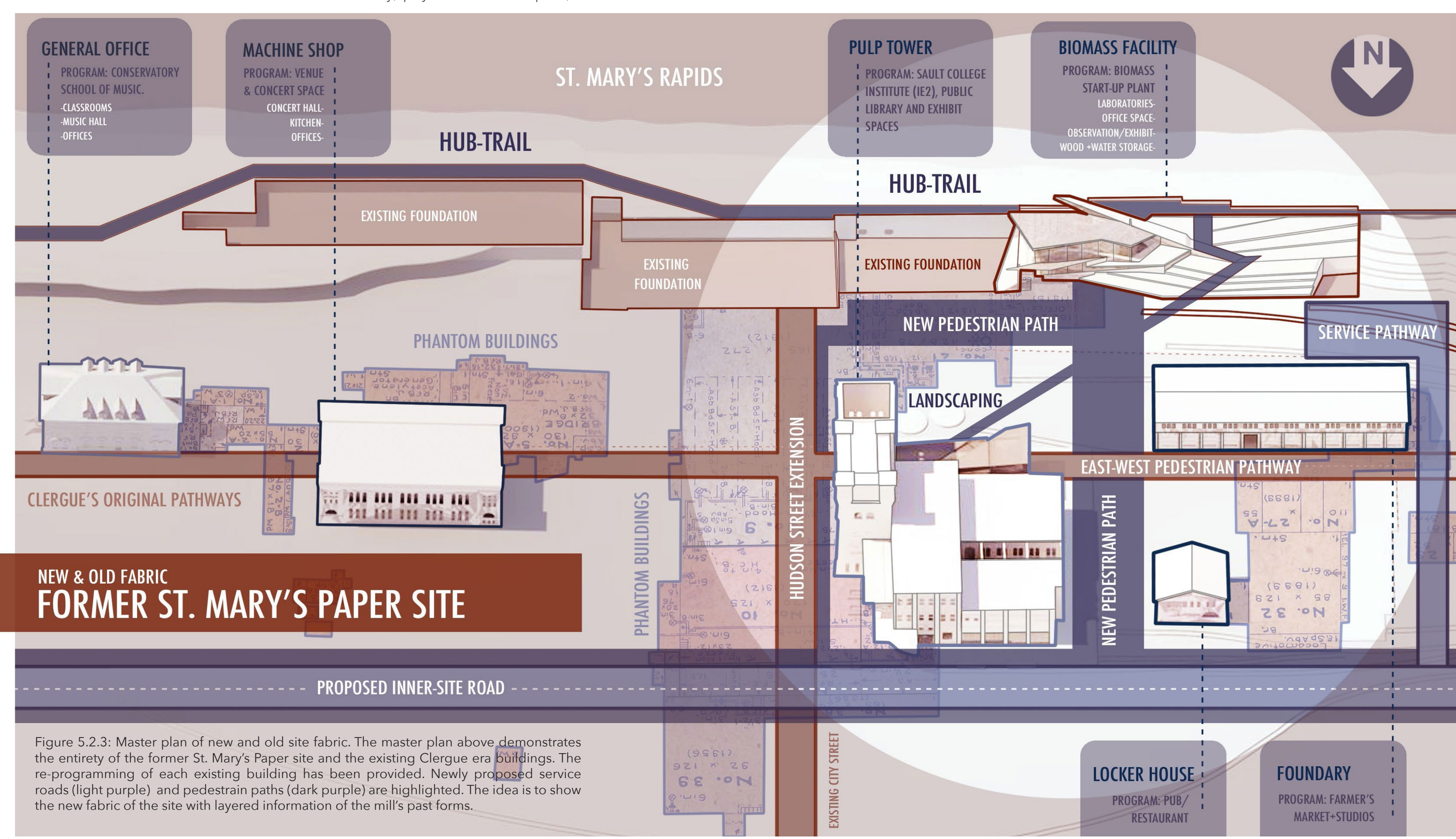


The denouement of the first factories and distribution of goods inevitably produced imprints on the physical layout and social structures of the city. The story of how industry has impacted and established the surrounding fabric can be read from their remains today. The methodology of this thesis is to revisit these networks created by industry into the context of contemporary life that are being motivated by the inherent and underlying qualities of the post-industrial ruin. Its influence is greatly marked by urban population concentrations, formation of neighborhoods and patterns of transportation and service networks; industry's monopolization of the city's progressive formation is what has shaped and often created cities. (Berens, 78) The thesis therefore analyzes the site and city at large in order to create an informed re-authorship of the spaces and networks. 
Figure 6.1.1: Past plan of the Laird and Henderson Mill Site (St. Mary's Paper Mill) 1938.

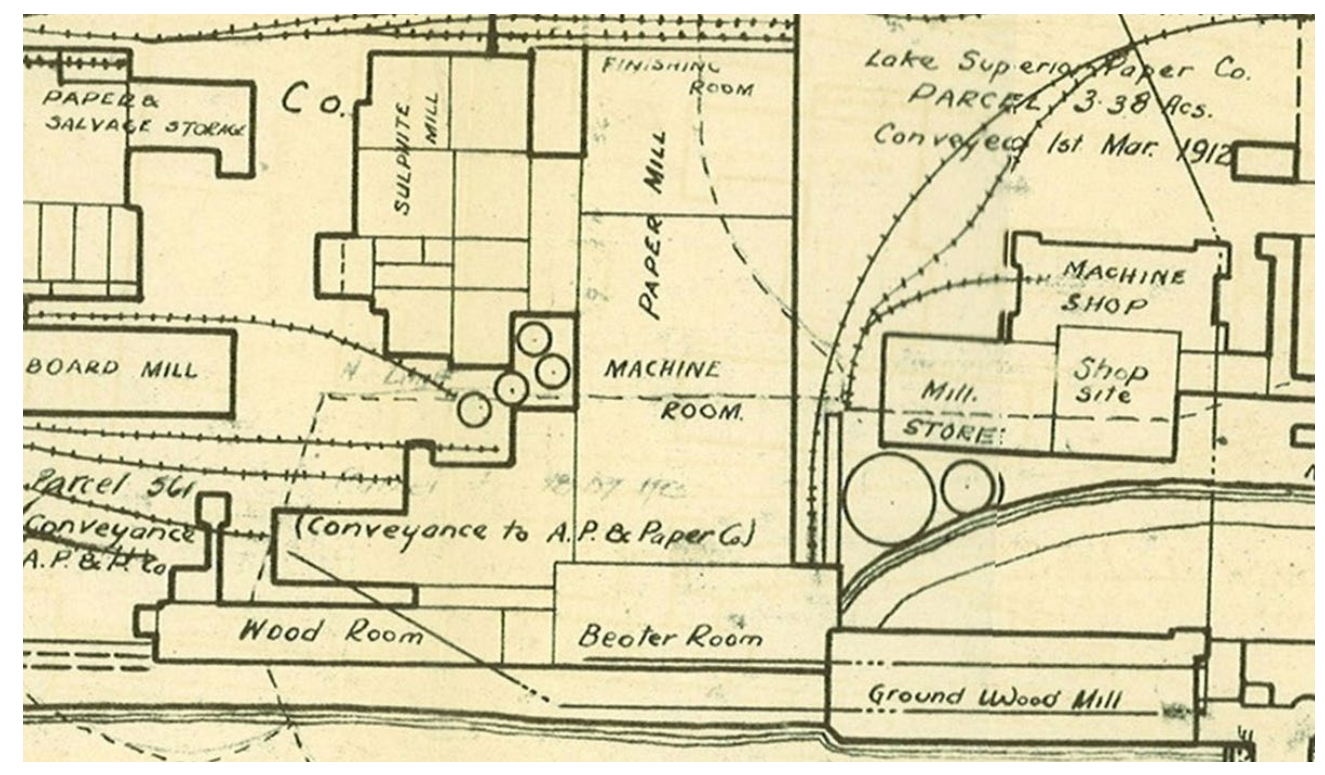

Reviving Phantom Networks: Biomass Facility Proposal

\subsection{Site Context}

Over the past months, I visited the former St. Mary's Paper site often during its demolition phase, trying to immerse myself in the project and to take note of the activities on site. Studying the mill's past plans allowed for a greater understanding of what was lying beneath the rubble, I was beginning to understand the image so many former workers had drawn up and how the traces of these forms remained visible. Most importantly, it was the industrial processes- the flow and movement of raw materials to final product that claimed the story of how this space was conceived. Taking note of each industrial stage and process, the phantom network was emerging and uncovering how it had once seeped out into the city's fabric; demonstrating how it had once entwined in the dense assemblage of local connections, that has created the intimacy of our local economic and social fabric.

The site is located within the core of the city on the west-central banks of the St. Mary's River. The river alongside the mill once fed logs downstream from Lake 
Superior. Before the implementation of rail systems between forestry industries and the city, the river had at one point been utilized during the early stages of industrial development as a resource for power and for its importance in manufacturing paper. It would seem at first glance that this connection with the site and river had been severed. Only the foundations of former buildings along the river remain. A large wall creates a fortress-like barrier between the site and river that barricades any view of the lush landscape found on the opposite bank. The retaining wall spans several hundred meters across the length of the mill creating a significant elevation change, of approximately eighteen feet, between the river's edge and the interior of the site. The masses of infrastructure used for collecting water in the industrial process still remain in place along the river. A large gate and pipe can be seen protruding from the retaining wall. ${ }^{4}$ As well, existing service paths and rail systems remain along the foundations of discarded buildings. During the mill's operation, the rail system provided in sourcing and out sourcing of raw materials and products that were transported throughout Canada and the United States. These systems also connected with

Figure 6.1.2: Retaining wall and existing foundation along the riverside. 2013. other industries along the St. Mary's River, including an operating fiberboard mill.

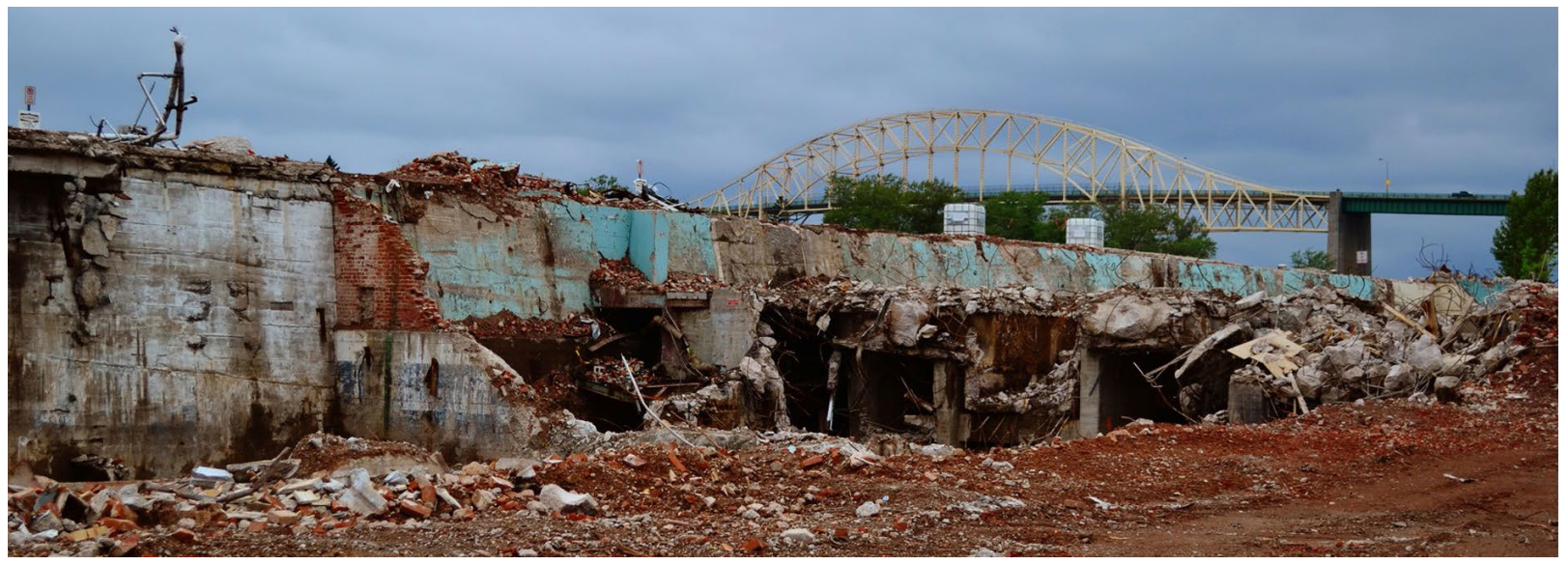

In this industrial context, the region is akin to stable arrangements of suppliers, transporters, materials, and other networks that are sewn into the infrastructure,

4 The existing retaining wall and former foundations can be seen above in Figure 6.1.2. 
which maintains local economy and development. The post industrial site is not seen as something fixed, but rather it is composed of numerous associations and entwined into various networks that stretch to the boundaries of the site. The methodology adopted will explore the social and physical remnants of the ruin that promote retention among the solidity and continuity of networks that bind urban bureaucracies, local industries and communities. ${ }^{5}$ Upon studying the site topography and networks in detail, these unique conditions pose a suitable setting for the Biomass Facility proposal. This program re-enforces the method of mimicking or mirroring the lost functions of the former buildings along the bank by taking advantage of the remaining infrastructures set in place. ${ }^{6}$

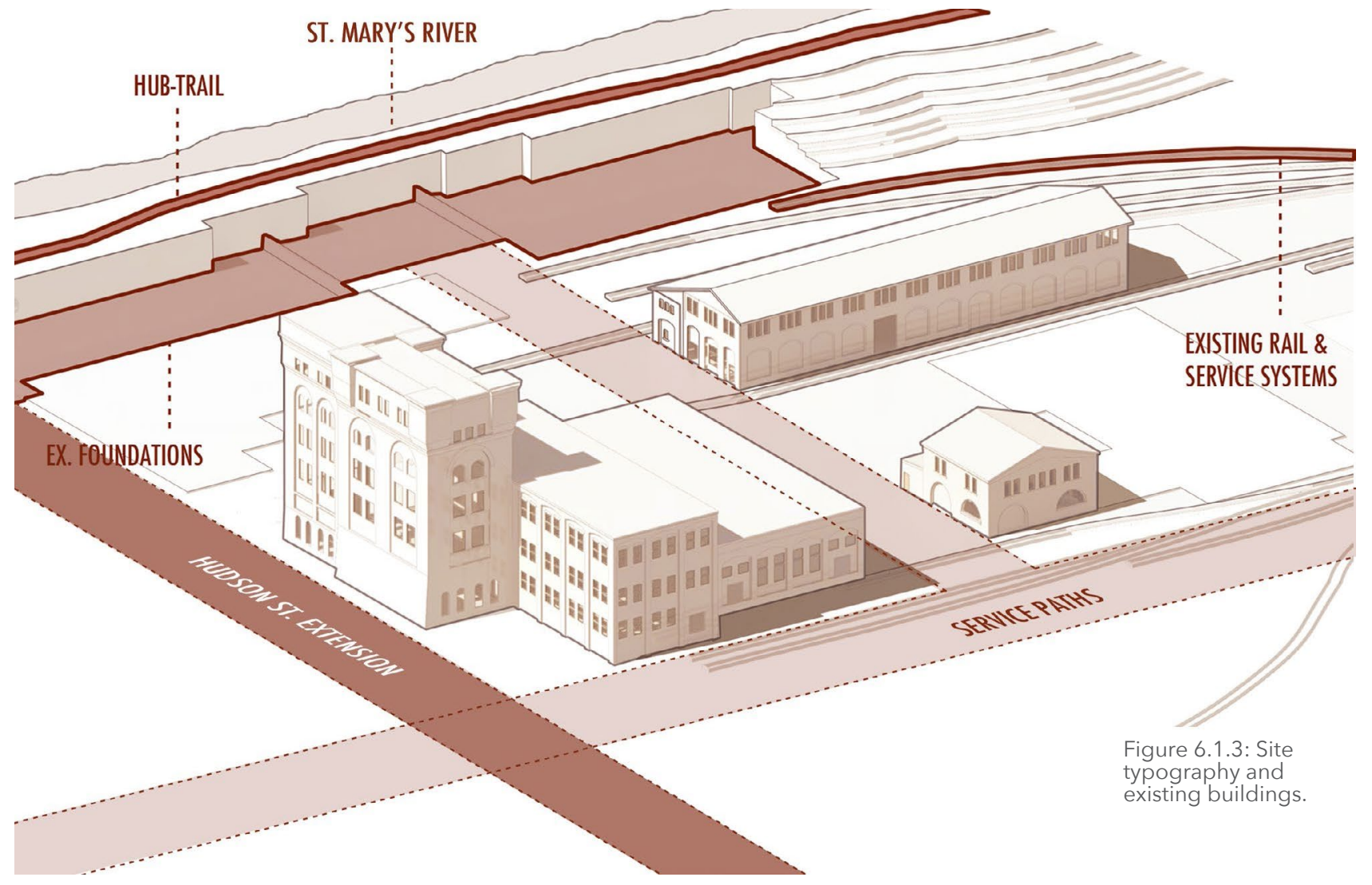

$5 \quad$ Arrangements of industrial networks along the St. Mary's River can be seen on the aforementioned map. (Figure 5.2.2.) Including Essar Steel and the existing fiberboard mill.

6 Figure 6.1.3 demonstrates the current topography of the site. The graphic indicates where former buildings have been removed, that has adversely left a retaining wall and foundation along the river. The premise is to utilize former production service pathways (including rail systems and existing water pipelines). The red line indicates the proposal of the continuation of a pedestrian pathway that creates a circuit around the city (as indicated on Figure 5.2.2).

Chapter 6: Reviving Phantom Networks: Biomass Facility 
Biomass energy production is a method of extracting energy by incinerating biomass products, which is then converted into either fuels or electricity. These products can range from compost to wood chips and agricultural byproducts, although wood remains the largest biomass energy source today. The energy created is clean and efficient, producing a substantially low emission of unfavorable toxins. Water is needed in the production of biomass energy in order to create steam that is then converted into electricity. (Quaak, 1)7

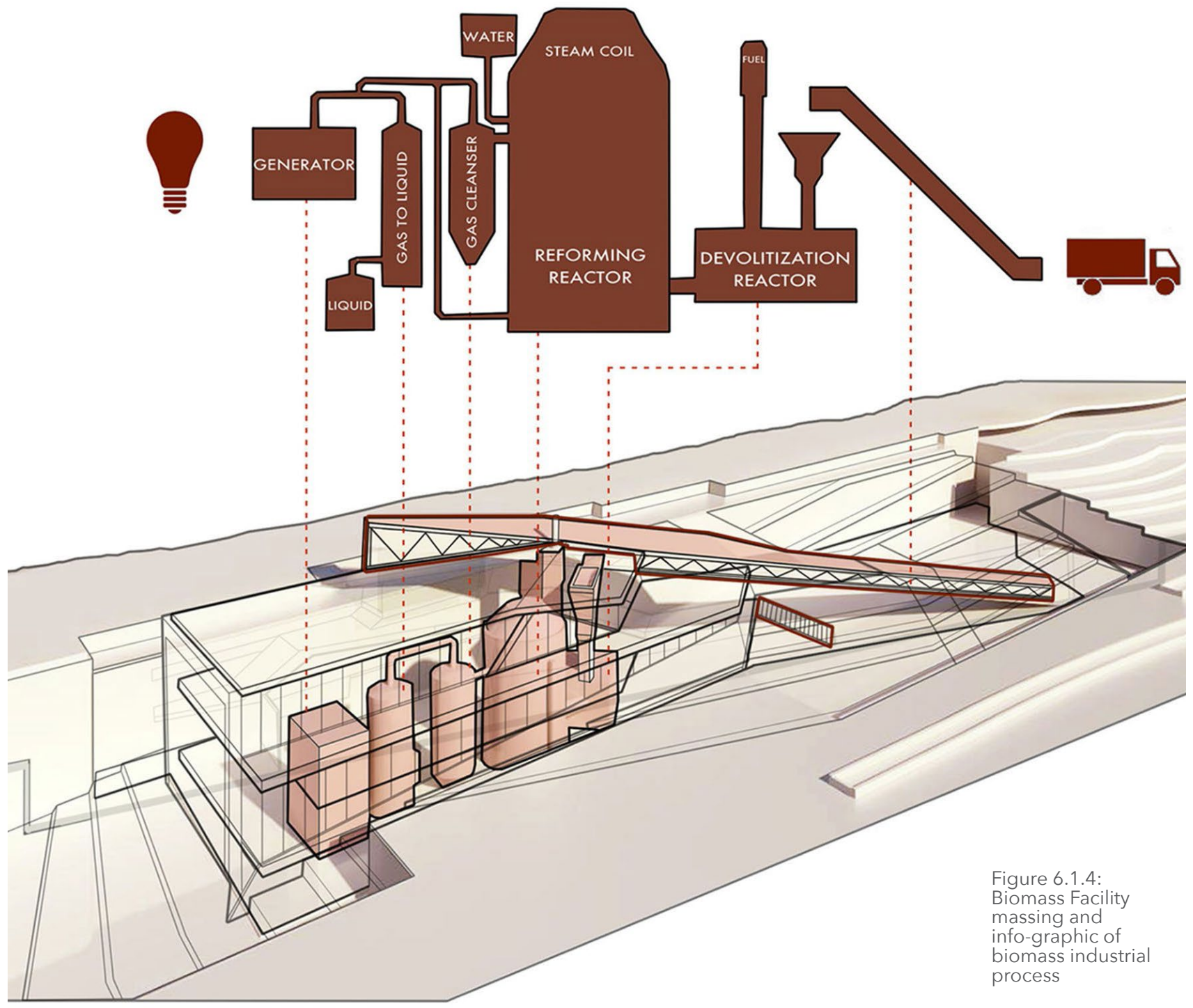

7 The industrial process is used as a mechanism for architectural design and site layout. In this sense, the idea is to determine the newly formed biomass process and how it may be viable in lieu of the discarded paper mill buildings. The movement of production becomes a force, which drive circulation and space. The following systems were drawn from the literary report: Energy from Biomass: A Review of Combustion and Gasification. (Quaak, 14) 
The proximity of a biomass plant to a watershed, therefore, is key for optimizing the use of water in production. As a result of compact technologies, biomass facilities take up a fairly small footprint and their scale is relatively insignificant compared to the mass of the former St. Mary's Paper Mill. To give an example, the Schilling Power Station in Schwendi, Germany comprises of a total area of 10,763 square feet and is capable of generating energy for a nearby hospital and up to 1450 detached houses in the surrounding neighborhood. (Archdaily)

In comparison to the relative footprint of the Schilling Power Station, the area of the existing foundations on the south bank of the St. Mary's Paper site consists of approximately 31,000 square feet. The space is therefore ideal for housing this type of industry. With this, the proposed biomass plant would generate power while lowering hyrdo-electric costs for the site, along with neighboring communities. The intent is to escape gentrification and invigorate the surrounding fabric, since this area is slow to develop due to its associated with low-income properties. The site's proximity and existing railway connections with the operating fiberboard mill, (approximately $0.5 \mathrm{~km}$ from the site) is an ideal source of raw materials for biomass production. Wood chips and other byproducts from the fiberboard mill would be transported by rail and utilized in the biomass energy production on the former St. Mary's Paper site. The biomass plant will also utilize the existing water in-take that once fed the former hydraulic grinder and beater room buildings. By refortifying existing connections and networks with the site, the livelihood of industrial heritage is therefore being maintained. These physical traces, although muted, can continue to connect past industrial uses with present state developments. 
Initially, the project's form had emerged as a result of the unique conditions set in place along the river. Since it is nearly impossible to interact with the river's edge, a strategy had to be set in place to address the voids created by the demolished buildings. Another factor, which drove the design, had been the city's desire to expand the citywide pedestrian trail. As part of the expansion, they proposed the path follow the contour of the river along the post-industrial site. However, the current topography does not allow for the safe passage of pedestrians into the centre of the site. Since the removal of the former structures creates a significant drop in elevation from the river down into the site, an artificial hill is designed as part of the Biomass Facility in order to accommodate pedestrians entering or exiting the site through the citywide hub-trail. A section of the retaining walls, meanwhile, protrude out from the level of the pathway in order to create a barrier between the trail and rapids. The land that had once been reserved for pathways and service roads along the river is considered unsafe, even during production as they encroached too closely alongside the rapids.

When restructuring the inoperative service path alongside the river, careful consideration was made for the implementation of this pedestrian connection with the site. The premise was to highlight the creation of newly formed guidelines towards the remaining Clergue buildings and post-industrial site. The design strategy for the artificial landscape and pedestrian path was heavily influenced by the axis of existing and newly created networks. The biomass plant is formed in such a way that the downward path of the artificial hill points towards the site, while the pathway of raw-materials entering the building lead 
upward towards the city. This strategy is to reinforce the balance between a space that encompasses both city recourses, raw materials and production with the flow of people and community into the site.

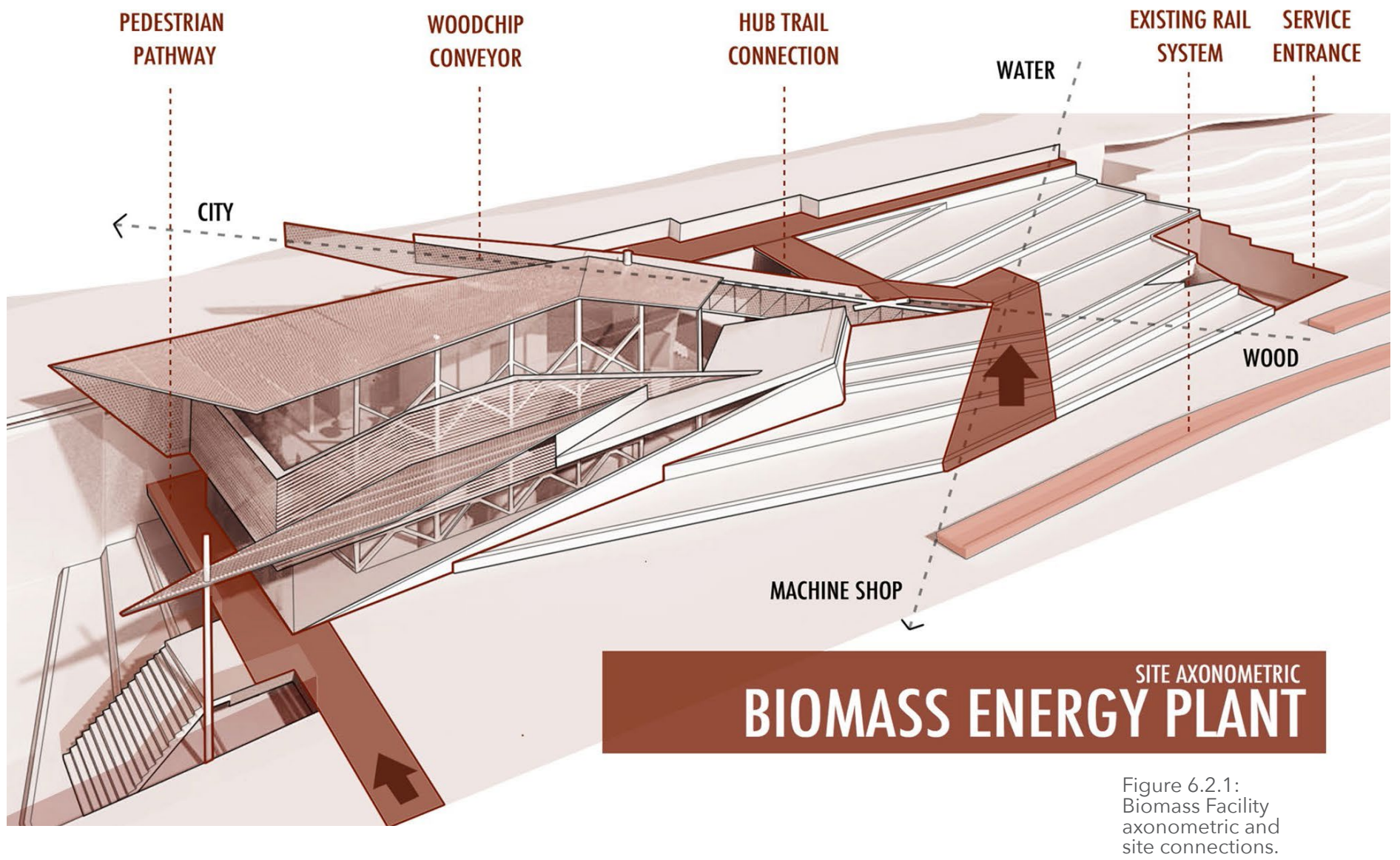

The exterior design embodies the creation of an arresting presence to beckon visitors, while simultaneously creating an awareness of how the building's pristine natural landscapes are conserved and re-adapted through biomass production. Sited between the existing foundation and neighboring wetland park, the building presents a low and subtle profile within the landscape that does not impede views towards Whitefish Island ${ }^{8}$ and the International Bridge. The 14,000 square foot structure is partially capped by a vegetated roof, which

8 Whitefish Island is situated next to the former mill and comprises of a divided land between the federal government and Batchewana First Nations. It was developed in the late $18^{\text {th }}$ century to house our city locks, today it is being used as an aboriginal park to which the public is permitted to tour these wetlands by boardwalk. Further developments on site look to connecting with the island.

Chapter 6: Reviving Phantom Networks: Biomass Facility 
is intended to blend with the surrounding landscape. The biomass plants sits quietly under the artificial hill, and protrudes upward to allow light into the interior spaces. The location beneath the landscape takes advantage of the existing foundations, and is used to create the basement level of the facility. As such, the foundation transforms into a basin and is used partially as a landscape feature, along with the basement space of the facility. The strategy is to allow light to penetrate within the basement levels, while setting a natural environment for those working within the building.

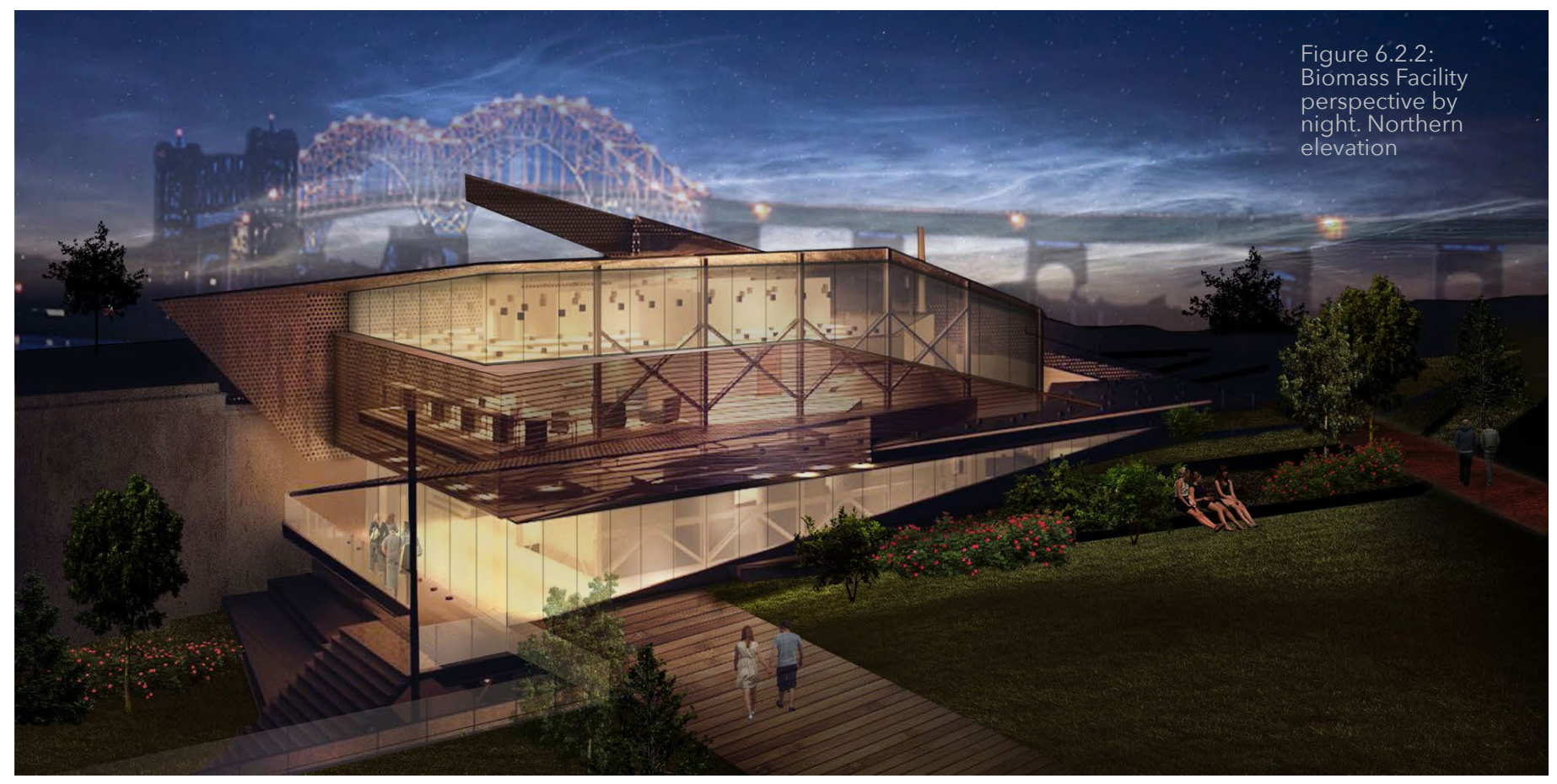

The structure and exterior facade is meant to be a veil, seemingly blending into the industrial and natural landscape, alluding to the ghostly presence of the former mill's built environment. The design is intended to integrate principles of industrial flow as well as to express the notion that this space holds strong connections to industry within architectural space. The building is structured in a way that where biomass production and machinery are held, the structure of the building is at its heaviest. Thus creating a centralized core structure, that then stretches and becomes more delicate and subtle as it expands towards 
the exterior. The interior structure, as denoted in Figure 6.2.3 is inspired by the city's vernacular steel architecture and utilized many connections wrought in steel structures and bridges found within the city. As well, there is an attempt to honor the phantom limb of the site in how the architectural language is depicted. In considering the phantom, its mimetic body and imprints left behind by the emptied industrial landscape, a poetic handling of materials will emphasize the concept of this thesis. The structure is a mixture of steel and concrete, each of these mediums is handled in such ways that emphasize the refortification of industrial heritage and allusions of nostalgic presences. A prime example would be the use of concrete, emphasis is placed on how the structure of its erection and construction is removed that then leaves imprints of its creation and application. The methodology of handling such medium is emphasized in construction as well as surface treatments that present a raw aesthetic juxtaposed by the soft imprints of wood grain marked by the concrete's formwork.

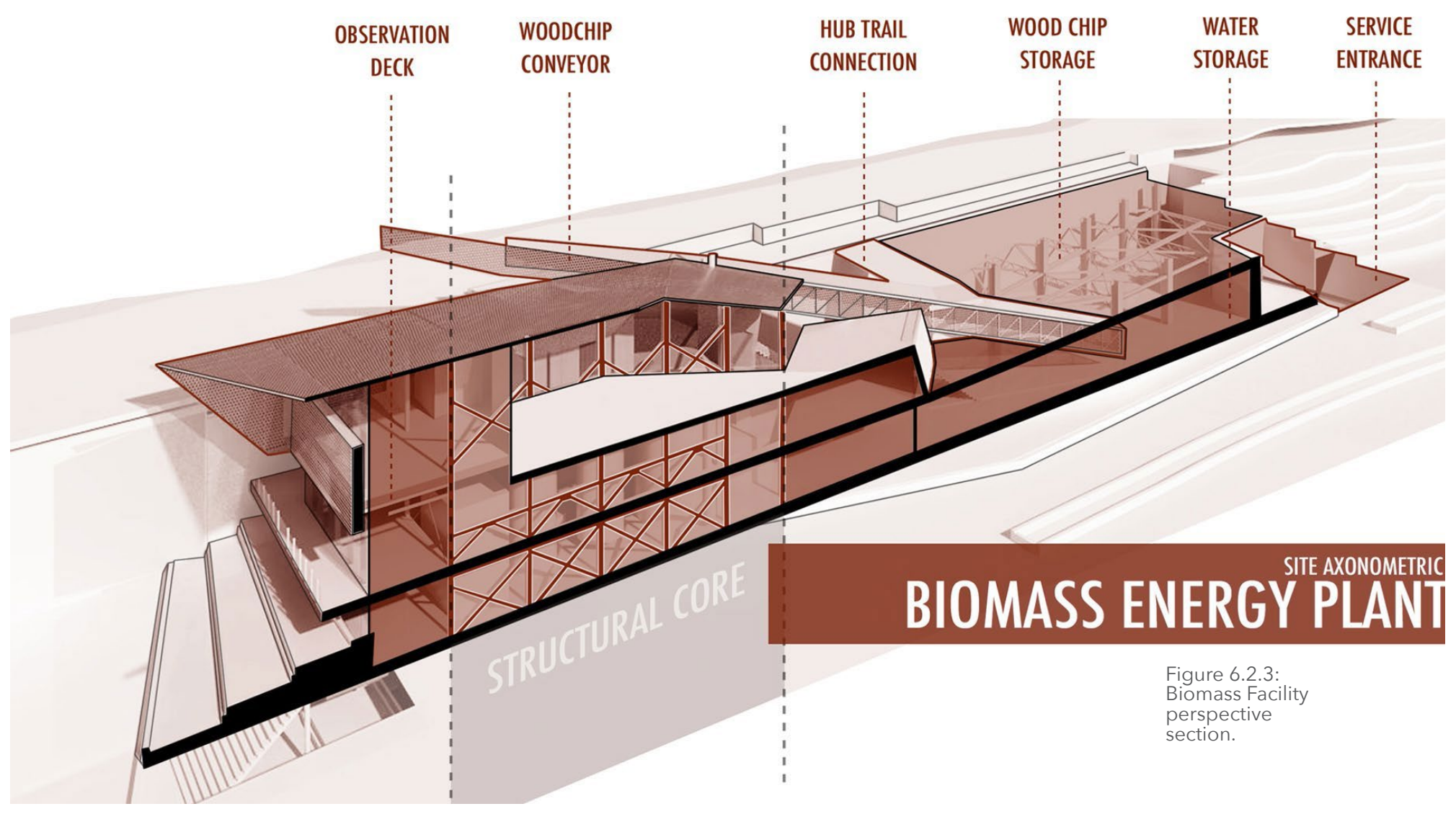

Chapter 6: Reviving Phantom Networks: Biomass Facility 


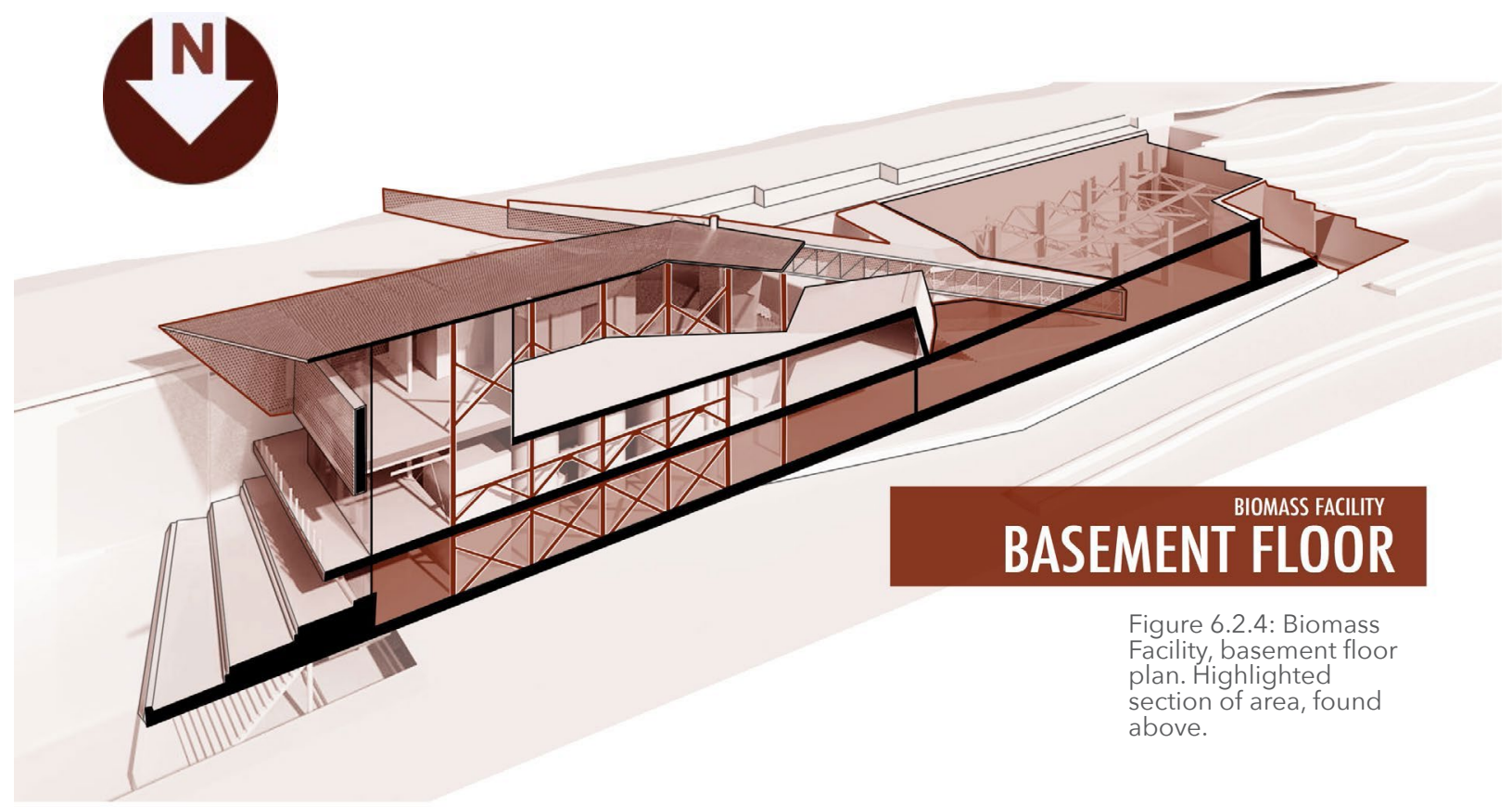

The perimeter of the former foundation was strategically utilized for the basement level of the Biomass Facility. These foundation walls provide the enclosed space; its original fabric has not been changed. A landscape feature can be seen to the far left, and allows light into

office spaces (5) and the machine room (8). Space for wood chip (1) and water storage (2) are provided in conjunction with existing service pathways. While these spaces do not require light, they are strategically placed at the rear of the building.

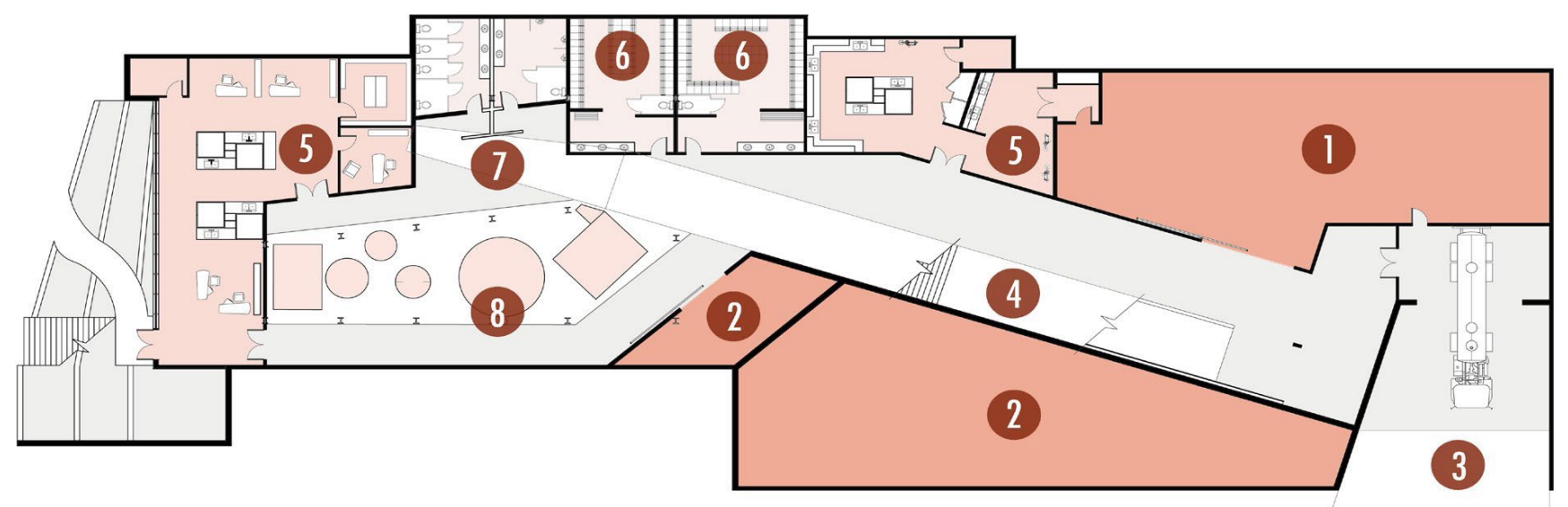

(1) Wood-Chip Storage; (2) Water Storage; (3) Service Entrance/Ramp; (4) Wood-Chip Conveyor;

(5) Laboratory; (6) Locker Rooms; (7) Washrooms; (8) Machine Room. 


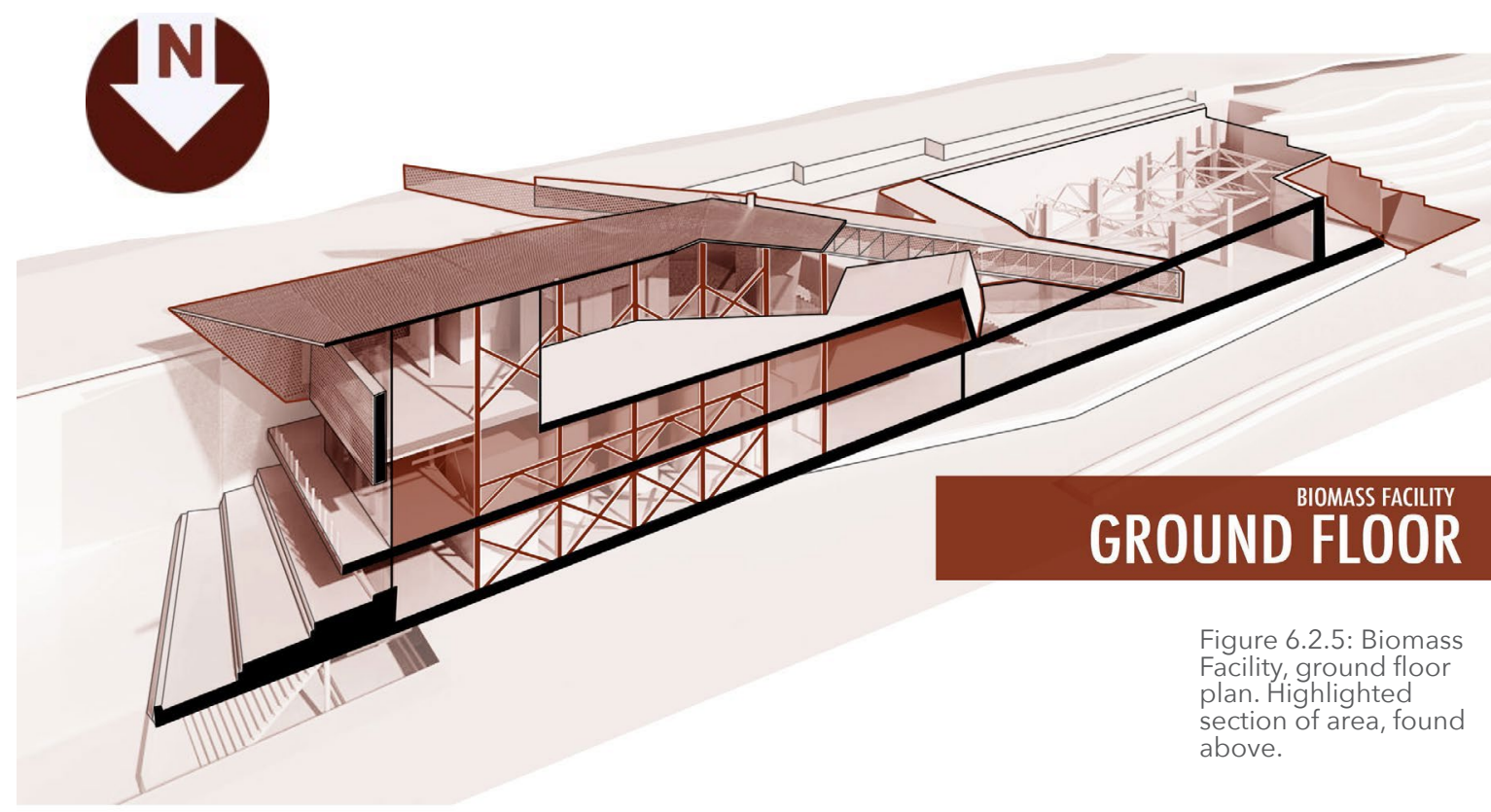

The ground level of the Biomass Facility primarily encompasses the observation deck (3), atrium for the machine room (2) and the beginning of the ascent for the remediation park hill (8) and hub-trail pathway. The existing retaining wall can be seen at the rear, whereby the laboratory (6) has direct contact with its surface and waterintake resource. From the laboratory (6) and observation deck (3), views are provided towards the conveyor element and wood chip storage. In this sense, one is able to view the entirety of this industrial process from the ground level. An exterior deck wraps (1) around the building between facility and landscape basin (12) that provides access to the southern sector of the building.

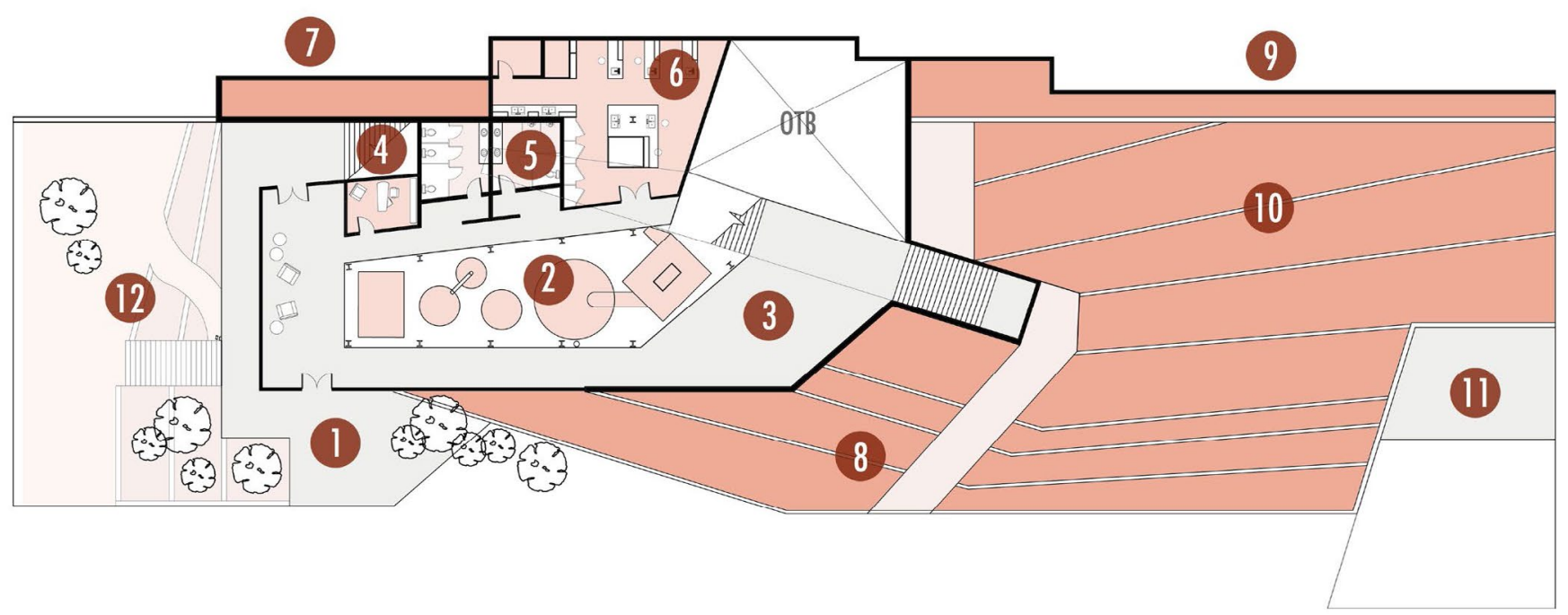

(1) Elevated Pathway; (2) Machine Room; (3) Observation Deck; (4) Office; (5) Washrooms; (6) Laboratory; (7) Duct/ Pipe Space; (8) Hub-trail Connection Pathway; (9) Retaining Wall; (10) Remediation Park; (11) Service Entrance. 


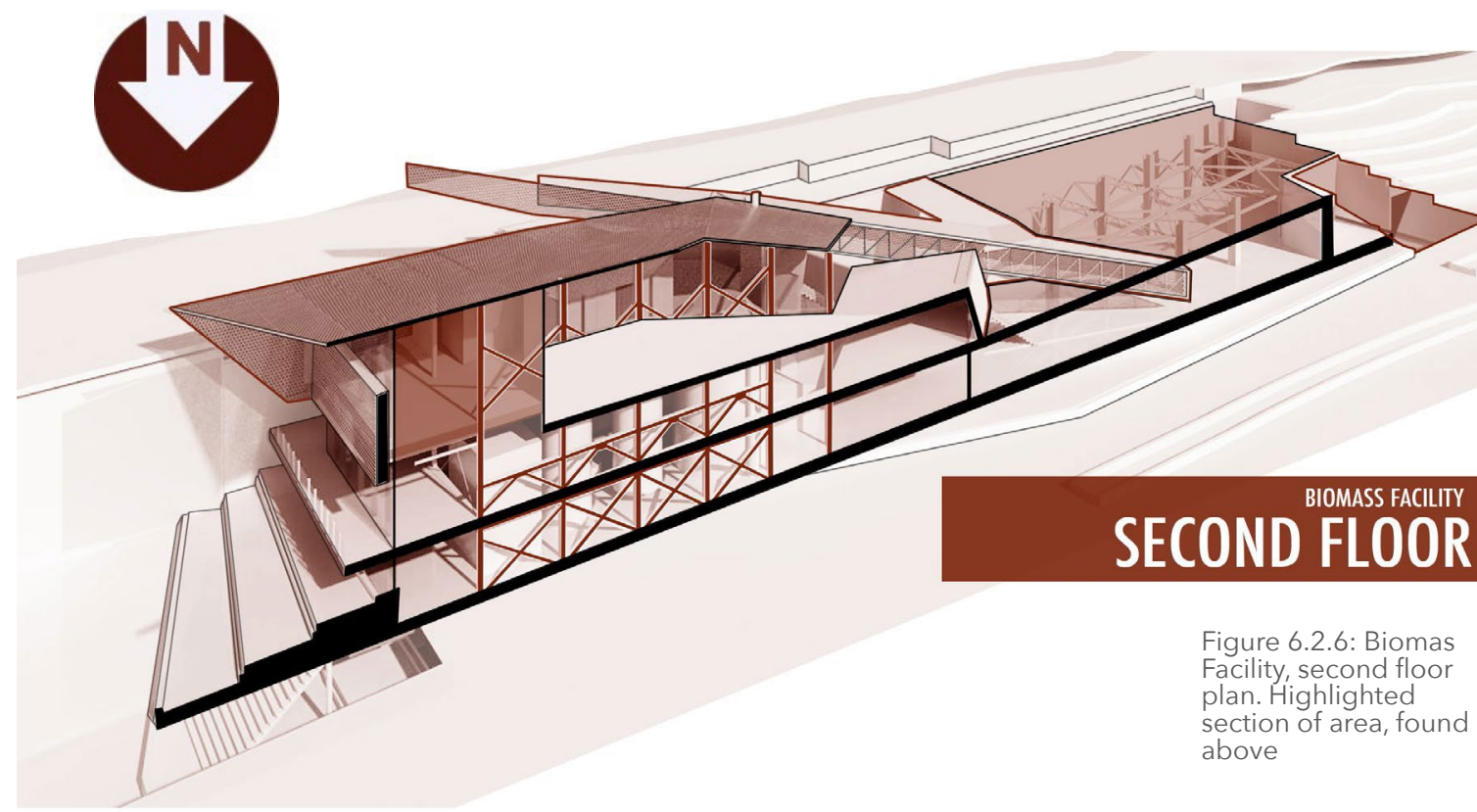

The second floor of the Biomass Facility is uniform with the level of the St Mary's River edge. The retaining wall (1) acts as a barrier between the narrow strip of lands before the rapids and the pedestrian pathway (2). The remediation park hill (12) allows for the safe passage of pedestrians from the top of the river edge to the interior of the site. At

the final level of the facility, office spaces are provided for professionals in the renewable energy sector for the city. A reception desk (3) is placed at the level of the pedestrian pathway to accommodate any individual seeking to take part in the observation deck exhibit (4) found on the ground level.

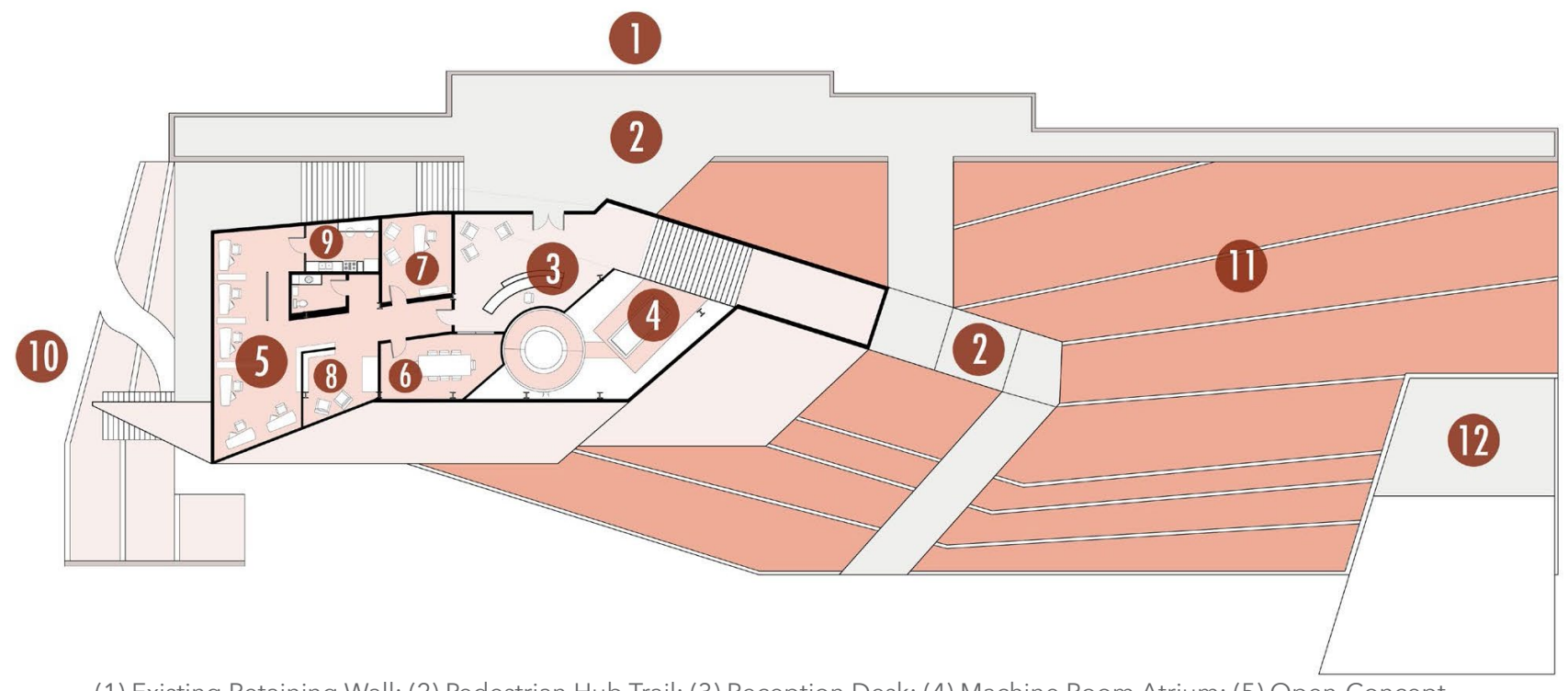

(1) Existing Retaining Wall; (2) Pedestrian Hub-Trail; (3) Reception Desk; (4) Machine Room Atrium; (5) Open-Concept Office Space; (6) Boardroom; (7) Office; (8) Office Library; (9) Kitchenette; (10) Landscape Basin; (11) Remediation Park; (12) Service Entrance. 
In terms of the industrial programming, raw materials are imported through the existing service corridors set on site. A furnace then processes these materials, once an elevated conveyor has transported them. This elevated movement and slice across the building poses a unique industrial condition. In this instance, the industrial structure is being used to elevate the architectural features of the space. The egress of people flows in line with the industrial process, as circulation spaces follow this action. The architectural gesture of this shard pierces through the spaces and becomes a focal point within the exterior and interior of the facility. Its presence is sharp, which is emphatically defined to delineate industrial perseverance and the spirit of industry on the site.

The furnace and machine room comprise a total of 2000 square feet that span two stories as a central atrium space. The mezzanine walkway, inspired by the previous mazes of steel grate walkways above the operating machinery in the former buildings, overlook the open boiler room. A shared laboratory, between the Biomass Facility and IE2 students, is placed at the rear of the building for direct views onto the observation room. As well, from within the laboratory, one can view directly into the lower portions of the buildings where wood and water storage are situated. This industrial dwelling is strategically optimized to house not only workers but create a living classroom atmosphere for students in the Institute of Energy and Environmental Studies programs. The exposure to sustainable and ecologically friendly technologies and construction materials are not limited to the students, as pedestrians are encouraged to take part in the viewing platform, to which informal displays set the stage for an exhibit. The architectural space is meant to beckon experimentation, participation and learning for the community at large.

In light of the allowance of communal accessibility on site after production, the community is encouraged to freely interact with its spaces. For this reason, the

Chapter 6: Reviving Phantom Networks: Biomass Facility 
design's intent is to blur the boundaries between the social and industrial fabric. As mentioned previously, the structure allows for thin edges to be created that propose a lighter and clairvoyant language- reinforcing and celebrating this accessibility. In lieu of creating an effervescent façade, the project borrows from a technique by artist Ned Kahn in his Articulated Cloud project, which is to create a large grid of hinged aluminum panels that interact with wind movement. (Kahn) In essence the building begins to tell the story of its environmental surroundings, the billowing of such a construction brings life into the structure and alludes to a ghostly presence. The material form is transformed in such a way to suit the context and space of this particular project. In analyzing the flow of Kahn's design, I have proposed using perforated aluminum, as it would create a more gentle resonance with the wind and would impede less of a distraction for those working within the building.

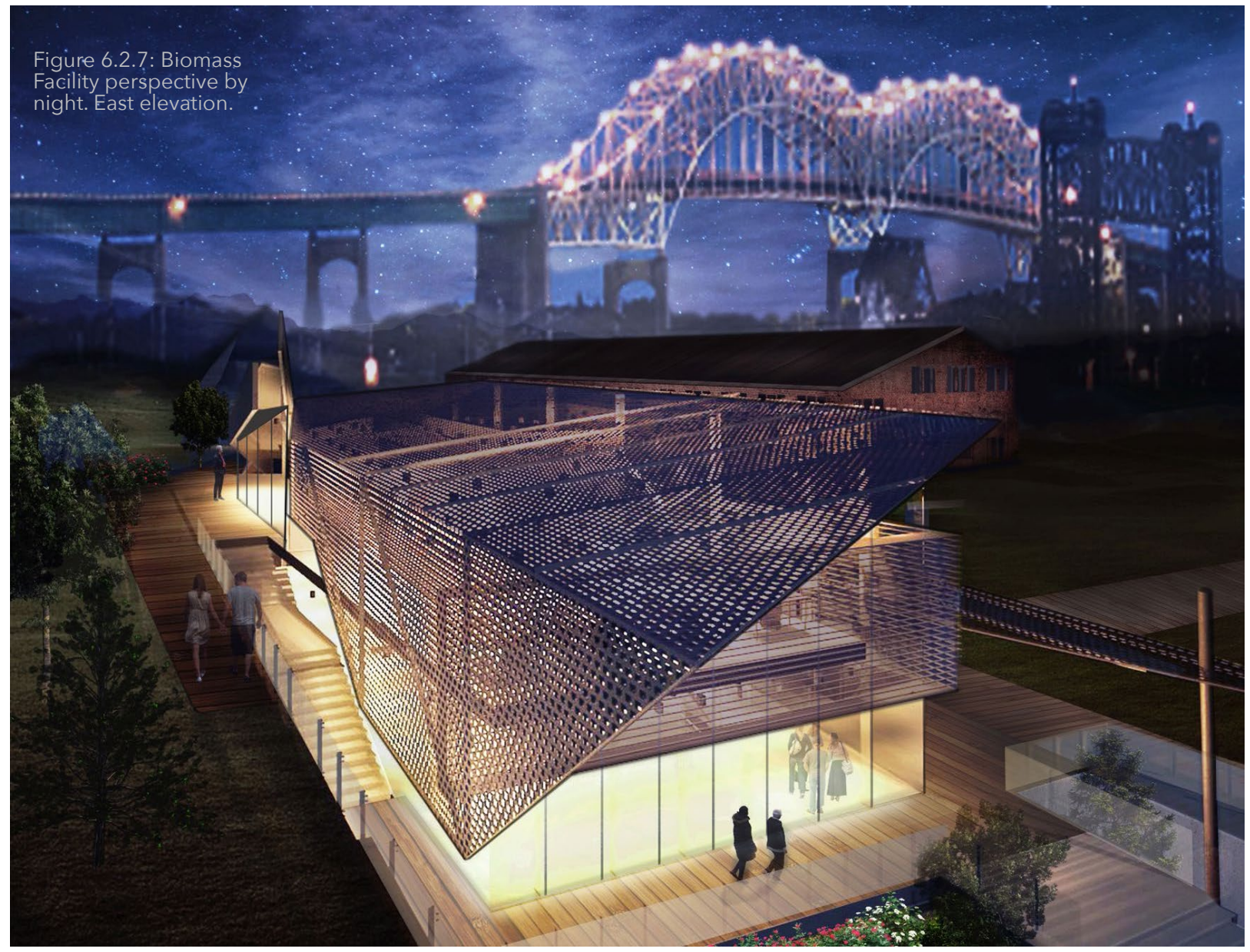


The building is strategically peeled away only slightly from the former retaining wall, as the pedestrian pathway slices through a portion of the building along the southern face. This section of pathway presents the in-between space of the old structure and new intervention, whereby the former foundations are exposed to one side and the Biomass Facility façade to the other. The movement of the perforated aluminum panels gently dances in the wind and reflects light towards the corroding former retaining wall. A spectacle of chipped paint, rust

Figure 6.2.8: Southern perspective of Biomass Facility. Façade shines onto existing foundation of previous industrial building. and crumbled sections of the wall are mixed with a mosaic of refracted light as pedestrians move past. Their presence oscillates the billowing façade, bringing life and energy to the ruin and new intervention.

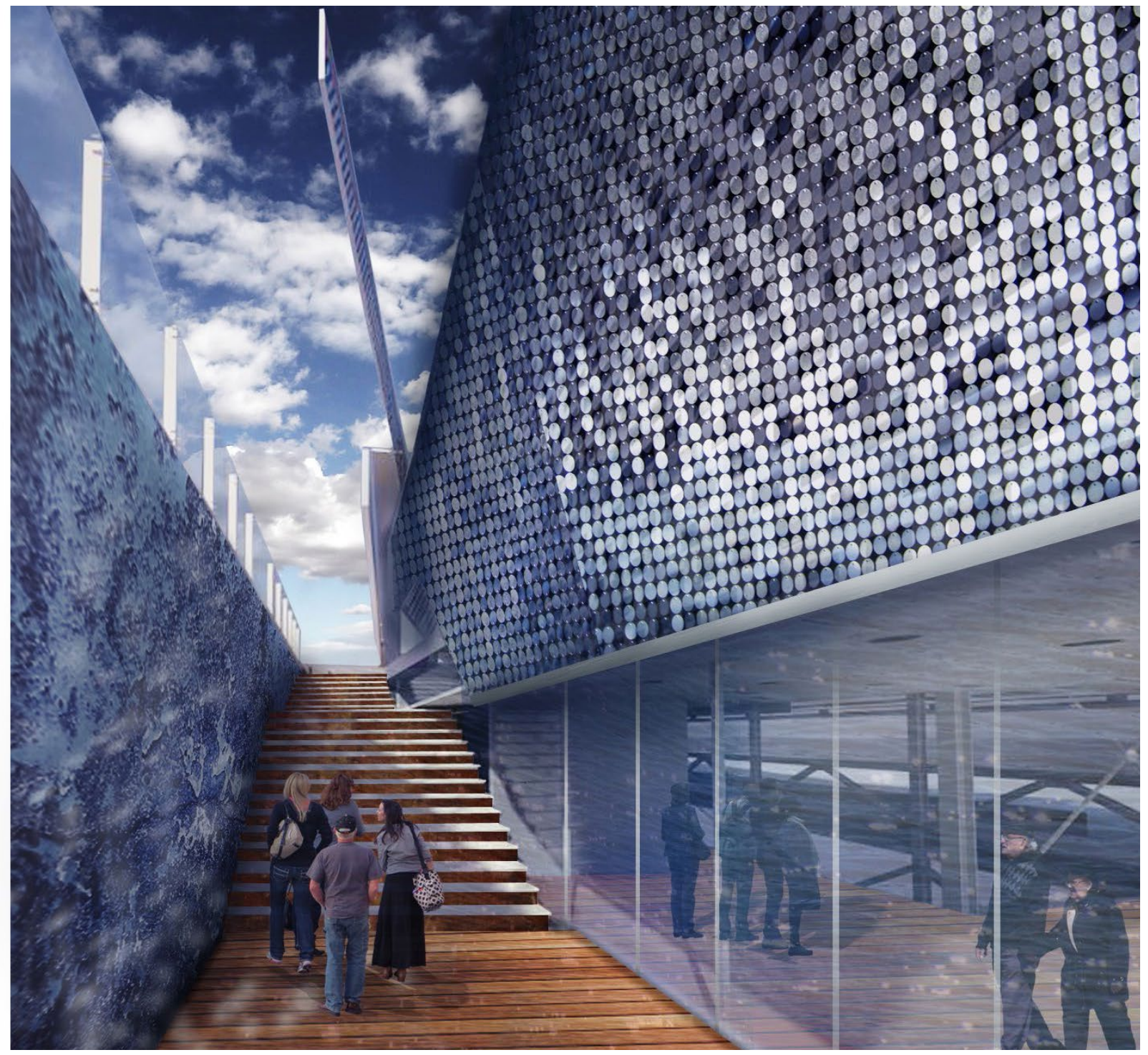

Chapter 6: Reviving Phantom Networks: Biomass Facility 
This strategy of peeling the building away is to not only to allow for pedestrian egress but also to maximize the amount of light entering the offices and industrial spaces. Landscaping next to the pathway is used to promote greener spaces along the riverfront, as well provide passive solar strategies with the use of shade from trees. Vantage points and sightlines into the interior of the facility are open for the public to view as they pass by the building and over the artificial hill. Thus emphasizing that the community' presence is one that is welcomed; accessibility is encouraged, whereby the site thrives on such social and communal companionship. 
Mediating The Toxic Image: Phytoremediation Landscape

The common nineteenth and twentieth century industrial factories painted a rather melancholy image of the surrounding fabric. These consisted of dirty neighborhoods; their districts self-proclaimed no man's land, sealed off from the progressive life of the commercial and middle to high-class residential areas. A barrier created not only by sooty smoke and noxious fumes but roads and tracks; their locations shaped the patterns and further development of many cities (Berens, 115). In large part, an alarming number of residents in post-industrial cities saw industrial and urban decline as the defining story of the city. The tale is told by those individuals who experienced the worst effects of job losses, poverty and predominantly the adverse consequences of toxic contamination. (Mah, 52) Based on a series of interviews with locals in post-industrial cities, Alice Mah begins to delineate a re-occurring story of the sentiments of the community with relation to industrial ruination and the effects of toxicity. It would seem that amid a crumbling infrastructure and land rich in toxic contamination, that the majority of residents are reluctant to leave communities embedded with memories and bonds to industrial landscapes. (Mah, 176) The thesis therefore encourages and devises strategies to impede their displacement by addressing such toxicity and environmental concerns.

The district surrounding the former St. Mary's Paper Mill and industrial sector is commonly associated with dereliction, low sociological and psychological competence and higher health risks. It is a place that has projected an image onto the city that seems to have plagued its use and morphology into the present day. Lagging zoning by-laws by the city of Sault Ste. Marie may be to 
blame, as the implementation of health and industrial acts were only set in place by the 1980's. Despite the recent implementation of municipal acts, the site does not wholly constitute or pose a significant health risk but rather a pressing local environmental issue. Although the state of health for the community is not being affected directly by the paper mill, one must still consider the longterm environmental impacts for citizens and consider the threatening image of toxic legacies towards post-industrial redevelopment. The methodology of the following section is drawn from addressing the complexities, pain and difficulties associated with the mill's toxic landscape with means of remediating contamination in a low-impact manner.

The Canadian-U.S. Great Lakes Water Quality Agreement (GLWQA) was established in 1987 as a result of the negative environmental impacts caused by heavy industry on the St. Mary's River, including bi-products of the St. Mary's Paper Mill. (SSMIC) The far stretching river, linking Lake Superior to the west and Huron to the east, is one of the primary sources of fresh water for a number of communities in the Algoma District and Greater Sudbury Area. Clergue's industrial legacies in Sault Ste. Marie- the paper mill, steel plant and other manufacturing powerhouses- had once been celebrated for harnessing the full potential of the river. At present, the St. Mary's river's exuberance has been diminished as a result of its toxicity. The adverse contamination of industries has dissimilated fish and plant ecosystems, sediment composition and the overall water quality in Sault Ste. Marie. (SSMIC) In order to protect and restore the river, the city and federal government have enacted and developed a Remedial Action Plan. The criteria for such act is to restore the river, develop sediment management strategies and monitoring plans for heavily affected areas along the St. Mary's River- notably the stretch of river along the city banks and industrial sector. The projects arising from the act have experienced lagging or even cancelation over recent and past years as a result of attaining funding for remediation, given that it is typically a 
lengthy and expensive process. For this reason many of the developments in the downtown fabric along the shoreline have experienced this issue and their properties remain vacant until the solution of funding is reached. ${ }^{9}$ Adversely, this has impacted the density and population in the downtown core. We are beginning to see the downtown fabric unravel as a result of undesired and contaminated land.
This thesis, although focused on the developments of the St. Mary's paper site, addresses the impacts of industry on the city at large. The strategies proposed in the thesis are intended to give rise and breathe life into such municipal acts. The methodology for remediation used in this thesis will assess methods to incorporate building developments on brown-field sites and pair it with cost effective manners of remediating contaminated soil.

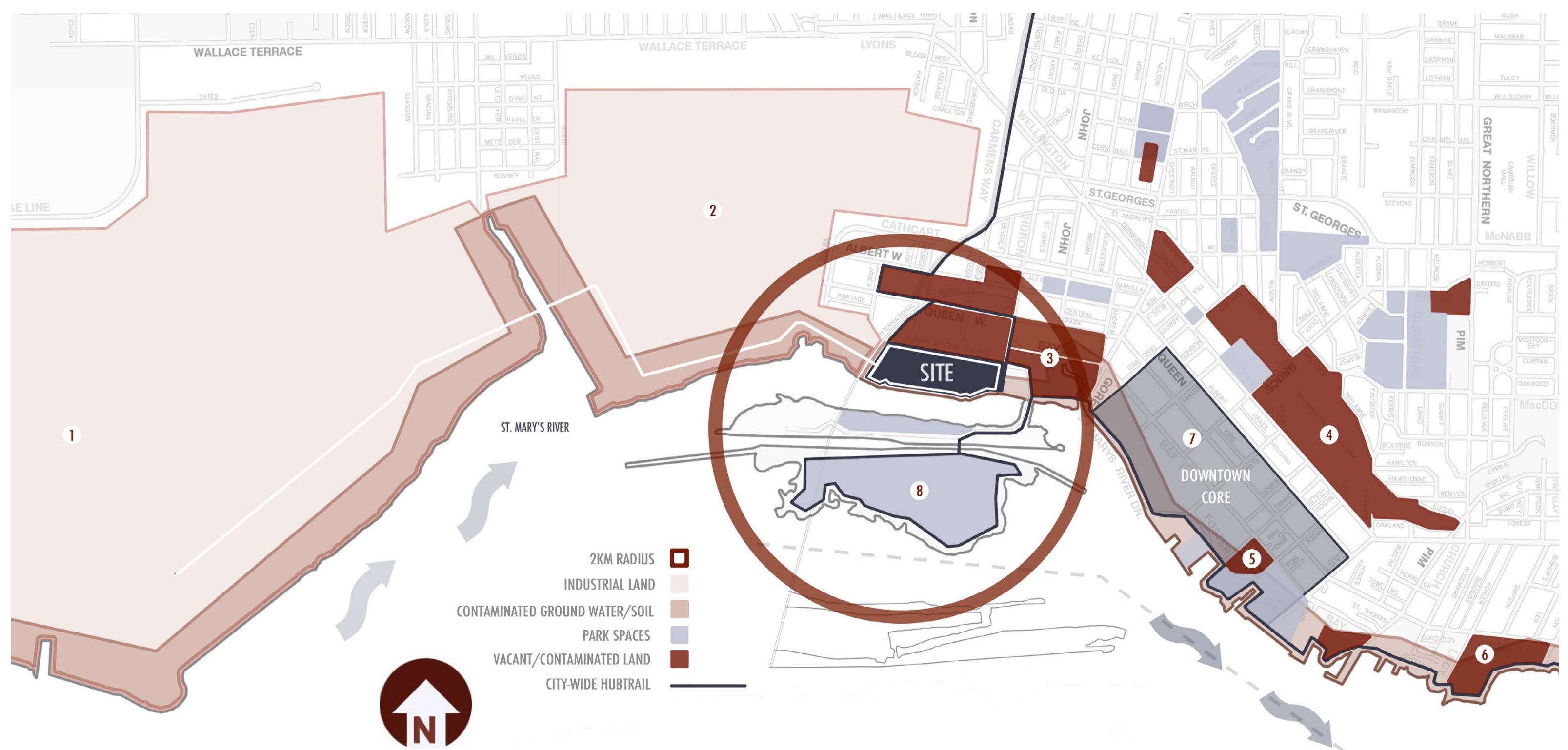

9 In the map above, (Figure 7.1.1) elements that affect site development have been indicated within the west-central core of the city, whereby a two-kilometer radius is indicated around the site. The mass of industrial and contaminated land in the west sector (indicated in pale red) has pressed adverse effects on river and ground water quality. The river flows downstream from perimeter of the river (displayed in $r$ ) and engulfs part of the space being titized for the citywide pedestrian trail (dark blue strip). As a result of contaminated land, a number of lots remain

vacant (as indicated in dark red around the city). Adversely, this has affected the diminishing fabric are indicated in light purple to give a sense of healthy land versus toxic.

(1) Flakeboard Mill; (2) Essar Steel; (3) Gateway Site; (4) Train Yards; (5) Former Brewery; (6)

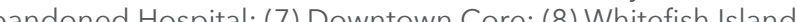


The most commonly utilized process for cleaning brown-field sites, as defined by the GLWOA, is referred to as the landfill process. Typically, contaminated soil on site is removed and transported by disposal trucks to a landfill site. The process therefore does not remediate the land, but simply displaces it. It is in essence, an "out of sight and out of mind" approach to remediation. For the city of Sault Ste. Marie, contaminated soil is transported to the Haviland Landfill. This landfill is located forty kilometers outside city limits, along Lake Superior's most treasured shorelines. For this reason, transportation costs for displacing soil are quite high and expend large amounts of energy. Thus many developers shy away from contaminated land, as it poses a large up-front cost before ground is broken for building projects. The impeding cost of such remediation is a significant factor being questioned by amendments such as the Great Lakes Water Quality Agreement and Remedial Action Plan. Proponents similar to GLWQA are eager to explore innovative ways of addressing remedial action plans, while at the same time encouraging the creation and participation of integrated social and economically sustainable communities.

In recent years, phytoremediation has emerged as a cost effective and sustainable technique for addressing land contamination. Although the properties of this process have been well known for decades in natural landscapes, it is only recently that it is being used in the context of the city. The emergence of projects, such as the Houtan Park in Shanghai, challenges brown-field site development by addressing the issues of contamination insitu. The Houtan Park consists of a constructed wetland, using the technique of phytoremediation to restore and treat polluted water from Shanghai's Huangpu River. (ASLA) The site context bares many resemblances to the St. Mary's Paper site. Shanghai is a city rich in heavy industry, in which the park reclaims 14-hectares of industrial land along the river. 
Although the project in Shanghai is significantly larger in scale, the Biomass Facility landscape in Sault Ste. Marie will employ similar phytoremediation strategies implemented in the Houtan Park. Phytoremediation employs the use of plants to cleanse toxic soils. These unique organisms allow for nutrients, while also contaminates, to be absorbed from the soil or water by the plant's metabolic and transport systems. Phytoremediation in cities involves selectively growing plants in a contaminated matrix to remove contaminants or facilitate the degradation of pollutants commonly found on industrial landscapes. Figure 7.1.2 showcases only three different manners by which plants can remediate contaminated soils, however there are numerous possibilities. For the purpose of this study, I focus primarily on hydraulic control remediation as the site boasts both soil and ground water contamination. The time in which this cleansing process elapses is dependant on which contaminants are present and which types of plant species are used. These detoxifying plants can then subsequently be harvested and safely disposed once the process has been complete. ${ }^{10}$ (Ashraf)

Figure 7.1.2:

Phytoremediation processes in nature.

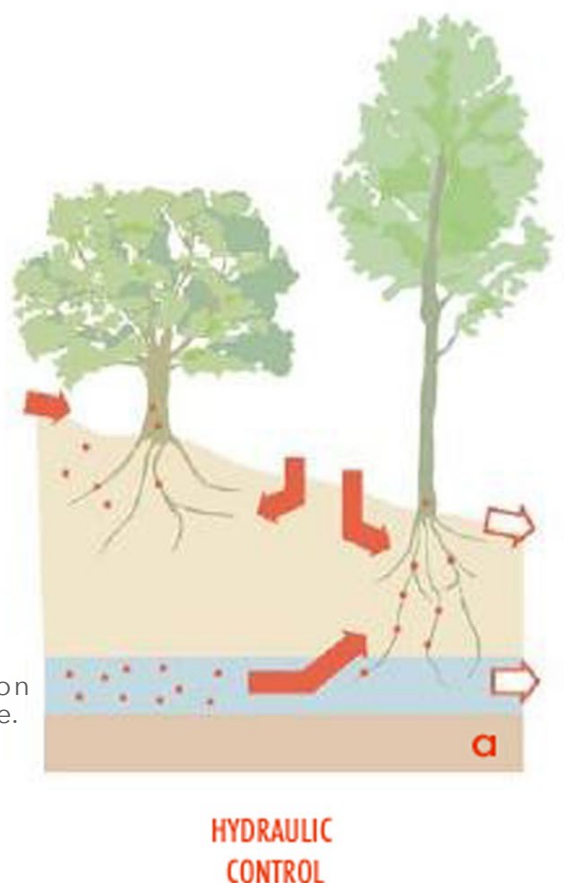

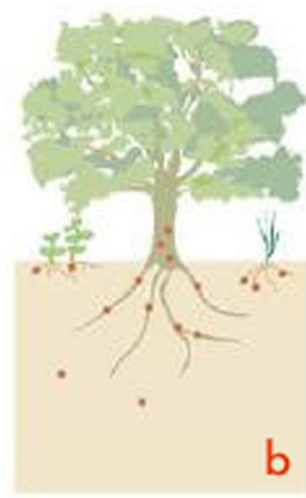

FARMIING SOIL

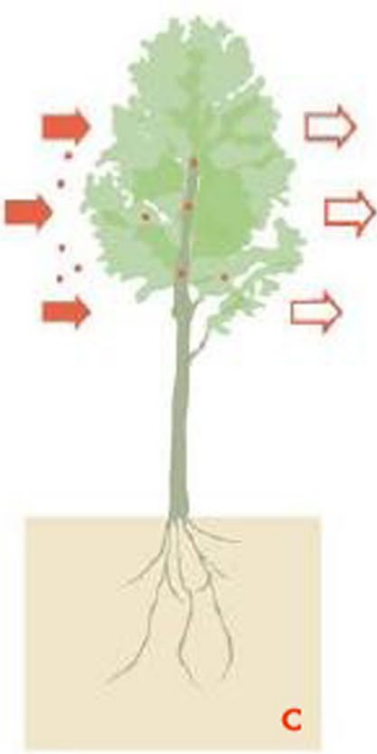

AIR FILTRATION

10 The phytoremediation process can be seen in Figure 7.1.5, whereby it is utilized in conjunction with the design roof system. Hydraulic control (a) uses the driving force a hilled scape and gravity to leach both ground and water contaminants. 
This particular method can be simply employed on site, therefore cutting transportation costs that are associated with landfill remediation techniques. Generally, the cost related with phytoremediation consists of $60-80 \%$ less than landfill processes. (Hollerung, 8) The economically feasible properties of this process are indeed persuading for investors seeking to develop prime contaminated land. The complication of such phytoremediation method is that you render valued and expensive land into parks, which typically do not generate income. Developers therefore are reluctant to use this process, unforgiving of sought-after park and landscaping spaces. ${ }^{11}$

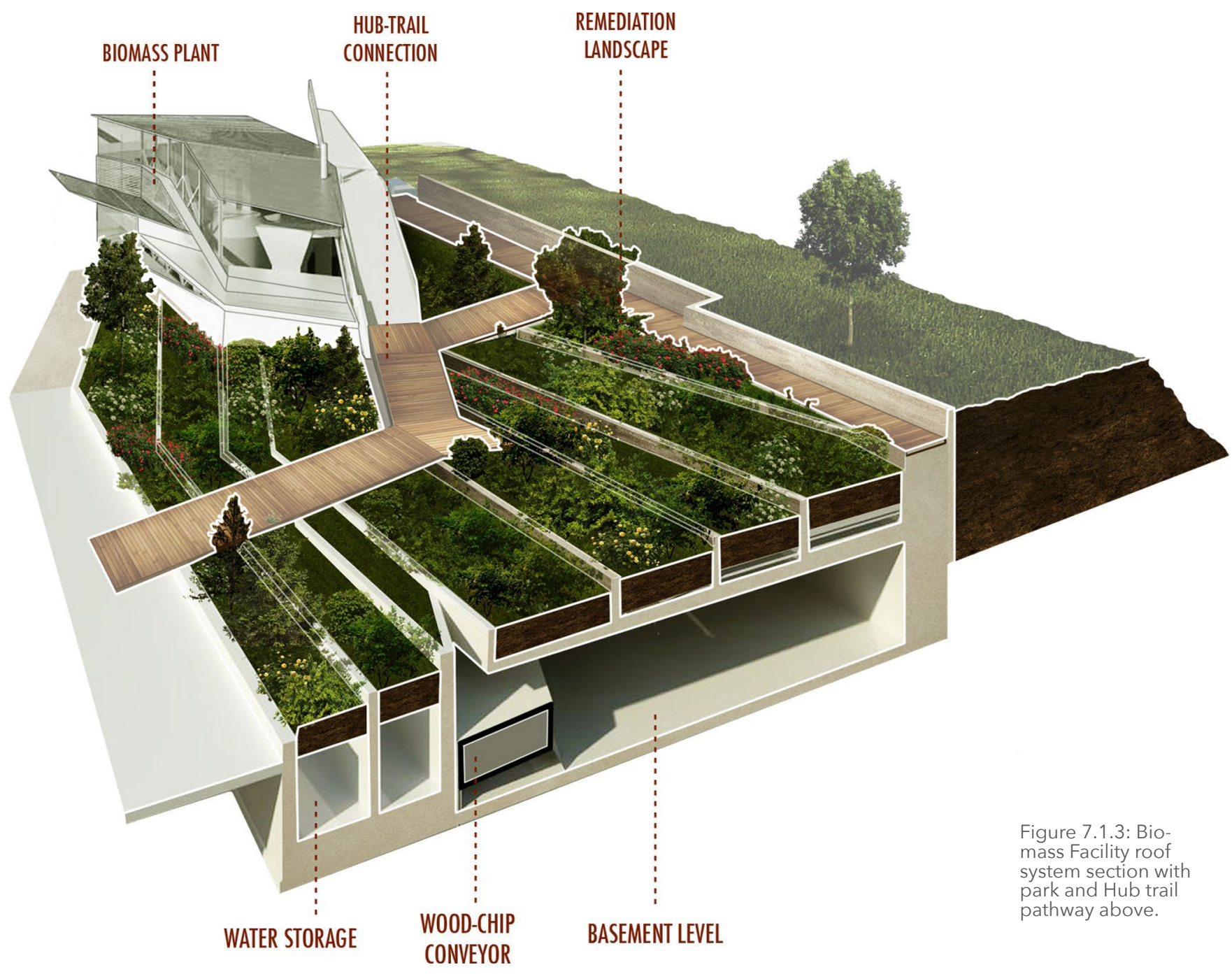

11 Figure 7.1.3 demonstrates how the constructed remediation landscape manifests the roof structure for the wood-chip and water storage below. 
The project proposes that when paired with a building development, the green roof system can therefore clean on-site contamination and eliminate the cost of landfill processes. The intent is to create a functional space that has the possibly of producing income while creating usable designed spaces. The roof system was strategically paired with the Biomass Facility, since plants that have decontaminated both soil and water can then be harvested and disposed for biomass energy production. My intention is to create a sustainable cycle between green roof and biomass production. ${ }^{12}$

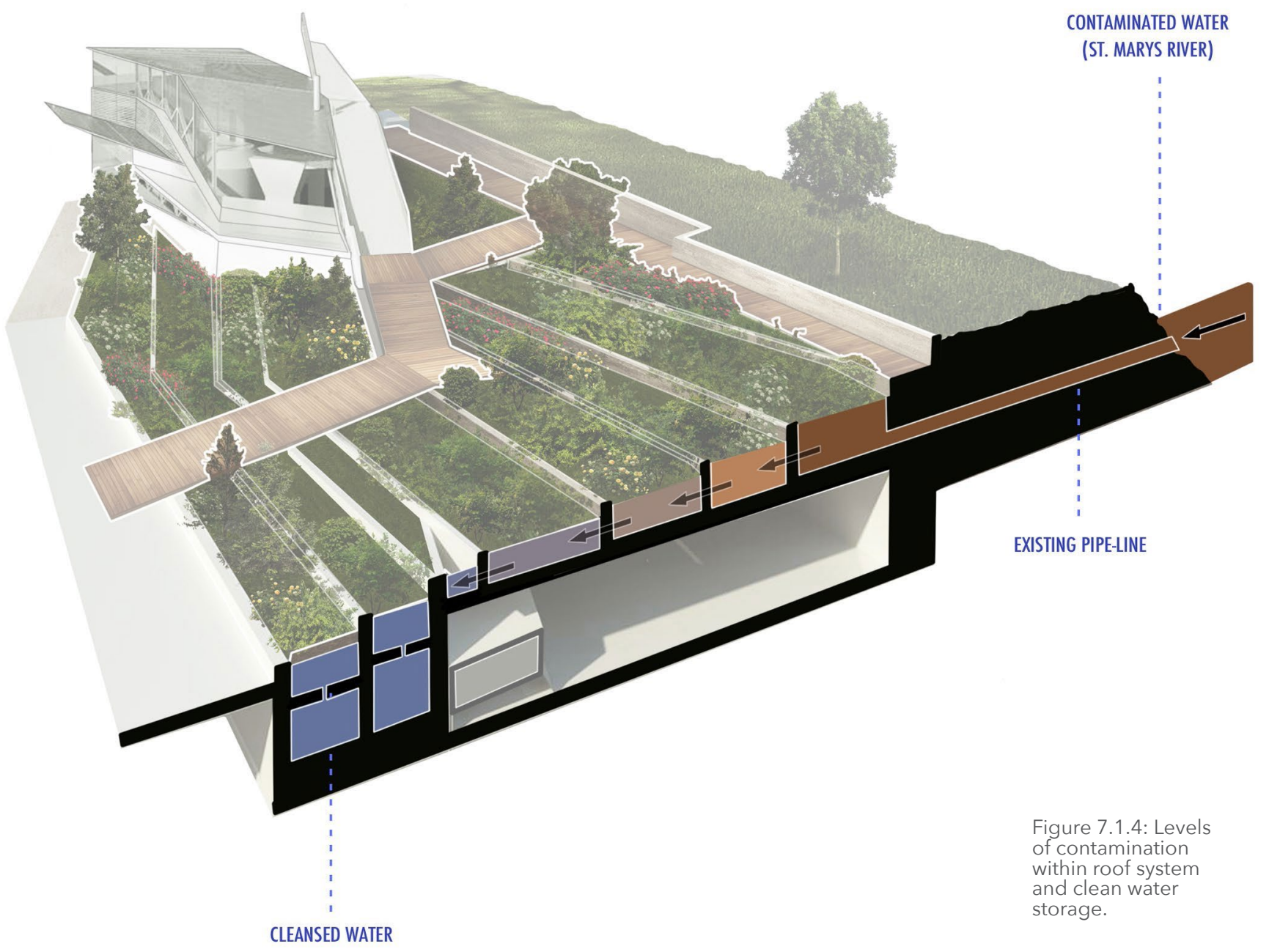

12 The diagram above (Figure 7.1.4) demonstrates the level of contamination as water is entering the remediation roof system (as indicated in the brown hue). As it percolates down the canal systems, water is cleansed and stored or used for other purposes on site (indicated in blue). 
The architectural intervention proposes a functional green roof system; it utilizes the process of hydraulic controlled phytoremediation to decontaminate soil found on the site and contaminated water from the St. Mary's River. The way that it functions is that the stepping down allows for water to be passed through a series of canal systems while the plants leach out any toxins through osmosis or photosynthesis. The diagram below (Figure 7.1.5) shows that water entering the site from the river is contaminated. Through a simulated hydraulic controlled remediation ${ }^{13}$, water travels downwards and is cleansed until it is collected into clean water storage units for the use of biomass production. This mimics the slope of a hill that would be needed to de-contaminate both ground water and soil. Lastly, a detail of the roof (Figure 7.1.6) was composed to give a sense of each layer and component. Water is carefully filtered through different layers of soil and drainage components, as shown in the section. A series of pipes were strategically designed to capture and move the water downward to reach water storage tanks, located in the basement of the Biomass Facility and subsequently used in the industrial process.

Figure 7.1.5: Detail of decontamination process in the Biomass Facility roof system.

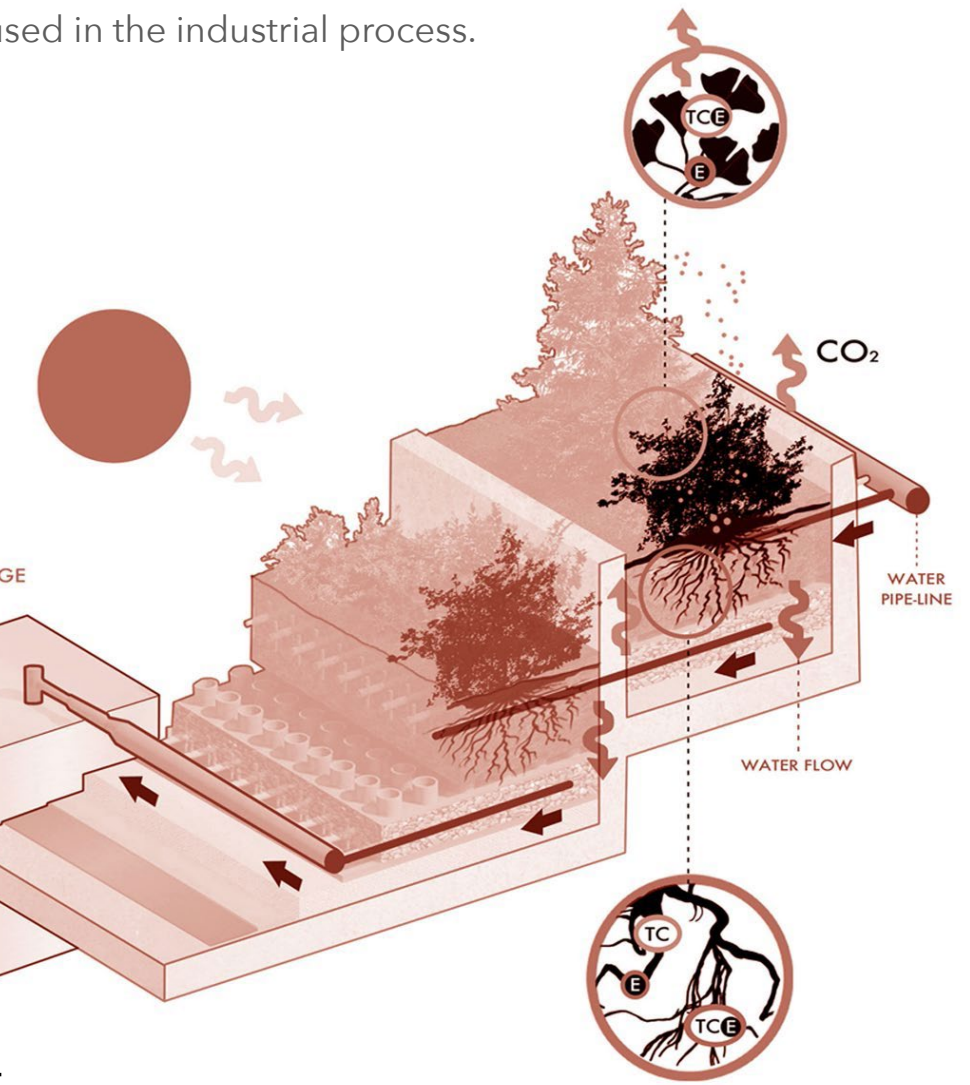

13 Refer to Figure 7.1.2 for hydraulic control diagram for reference.

Chapter 7: Mediating Toxic Landscapes: Phytoremedation Landscape 


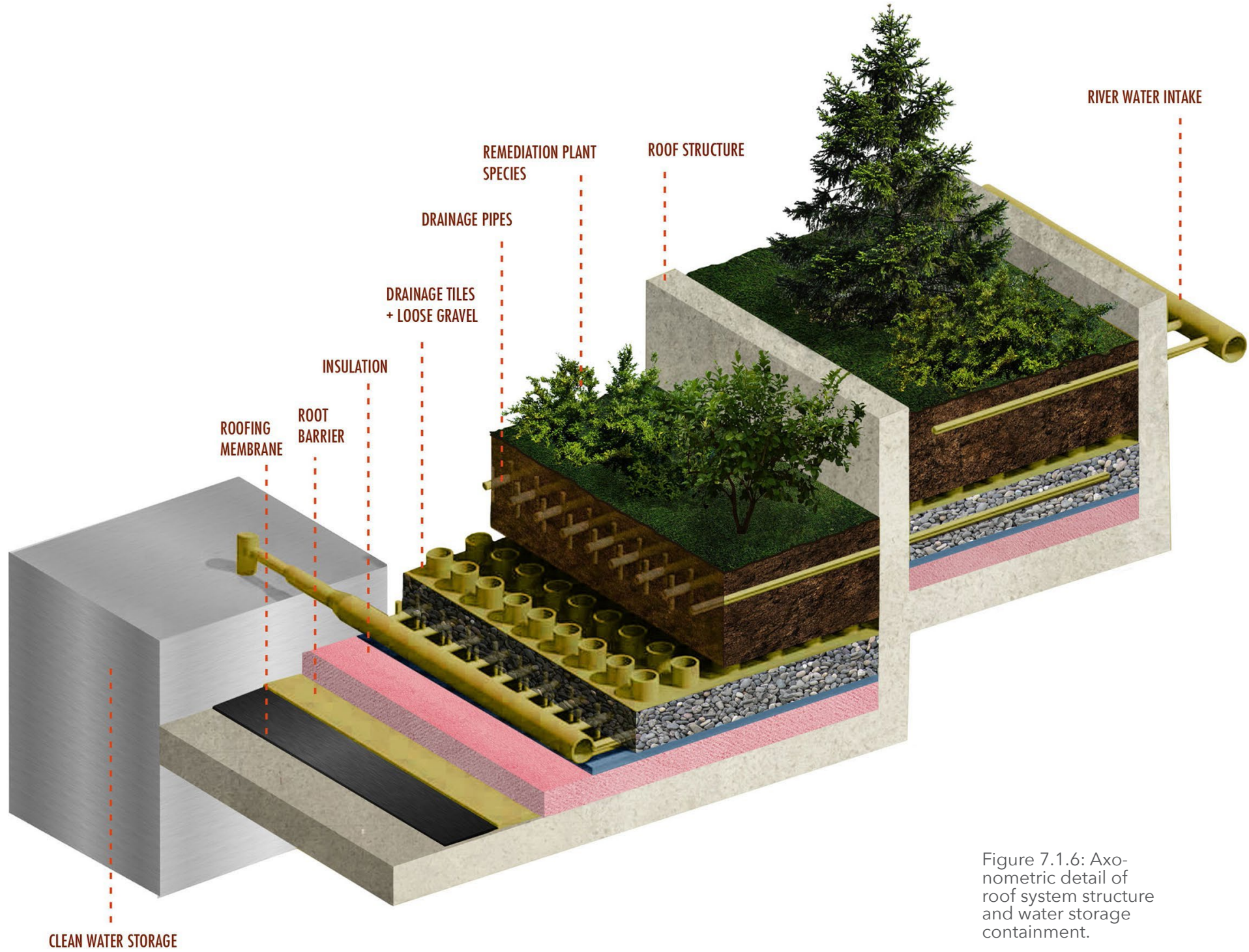

The detail above (Figure 7.1.6) illustrates the roof system infrastructure and construction materials. Water passing through the hydraulic system is filtered through different layers of soil and drainage membranes. Attention is placed on protecting the structure of the roof, as it is sealed with both root barriers and roofing membranes. Root depth poses an interesting condition for the green roof structure, as the depth of soil is strategically design to accommodate certain plant species. 
Given the site is designated as a post-industrial site and contains certain levels of contamination, the project addresses issues that are specific to remediation of paper mill sites. Since there is no available public record of a contaminated soil study performed on the former St. Mary's Paper Mill site, the research relied on other studies where the post-industrial sites were greatly similar to the paper mill found in Sault Ste. Marie. According to a study revealed in a environmental petition on the brown-field redevelopment site in St. Catharine's Ontario- previously the property of the Domtar Paper Mill, they found that the most prominent contaminants were mercury, lead, arsenic and copper (Davidoff) These particular pollutants have been the focus of precedent studies concerning the organization and utilization of particular plant species to optimize remediation. Given the phytoremediation process, defining which plant species that can chemically bind with specific contaminants is required For the purpose of this study, a table is created in conjunction with existing green roof specifications and decontamination charts. (Sarma) ${ }^{14}$
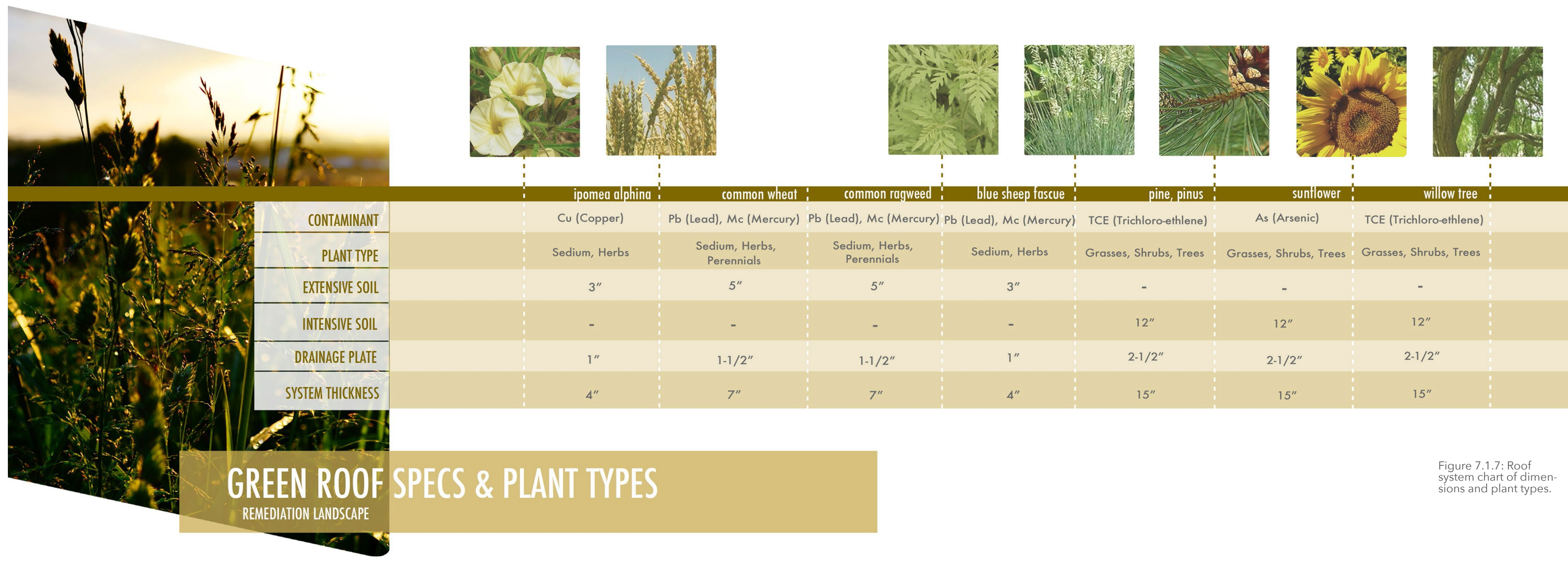

As (Arsenic)

TCE (Trichloro-ethlene)

$\begin{array}{lllll}\text { Herbs, Sedium, Herbs } & \text { Grasses, Shrubs, Trees } \\ \text { Grasses, Shrubs, Trees } & \text { Grasses, Shrubs, Trees }\end{array}$

$3^{\prime \prime}$ $2-1 / 2^{\prime \prime}$ $2-1 / 2^{\prime \prime}$

7" $\quad 4^{\prime \prime}$

$4^{\prime \prime}$
$15^{\prime \prime}$

$15^{\prime \prime}$


The limitation of use with phytoremediation in a landscape project can only optimize the process based on the plants root depth. (Hettiarachchi) The proposed green roof controls and studies the appropriate root and soil depth in each canal system, whereby the plant is able to decontaminate the full extent of the soil. This chart is particularly useful, since the depth of the biomass roof landscape varies. With this, I was able to give specifics as to which plants would be situated where and how many different species were needed in each level to address and cleanse each contaminant listed above.

Once the plants have expended their function, they may be harvested after the decontamination process and incinerated for biomass energy generation. Waste ash from the biomass production can later be used as fertilizer for the remediating landscape; while it may also be given to local farmers who partake in the neighboring farmer's market, located within the Clergue Foundry building. Throughout winter seasons, once plants have been harvested and water resources re-directed to external filtering systems, the roof then acts as an efficient thermal barrier during cold seasons. A study performed at Trent University in Nottingham, determined that temperatures under membranes of green roof systems generated heightened positive effects in winter seasons over standard roofs. (EFB) The remediation landscape is comparable to many green roof systems. However, this particular landscape is unique in the sense that it holds contaminate leaching plants and cleanses both water and soil, while possessing many of the benefits and properties of green roof systems. This includes not only thermal value, but also serves as a sound barrier for those working in spaces underneath the high traffic hub connection.

The green spaces created on the roof are meant to revive the natural setting of the mill. The project intends to create a pleasant environment for individuals working in the artist studios and farmers market in the neighboring Foundry 
building. While also, providing a setting that can inspire and educate the community. The proposed model can be directly manipulated and used on a variety of different contaminated sites and locations. While specific to the former St. Mary's Paper Mill redevelopment, it is my hope that this approach may be applied to other projects in Sault Ste. Marie as well as similar enclaves dealing with contamination. Where affordable remediation is concerned, this approach to planning has been seen to contribute to the means of facilitating developments of dereliction and dismantle the resistance of the community with regards to the industrial toxic image. 


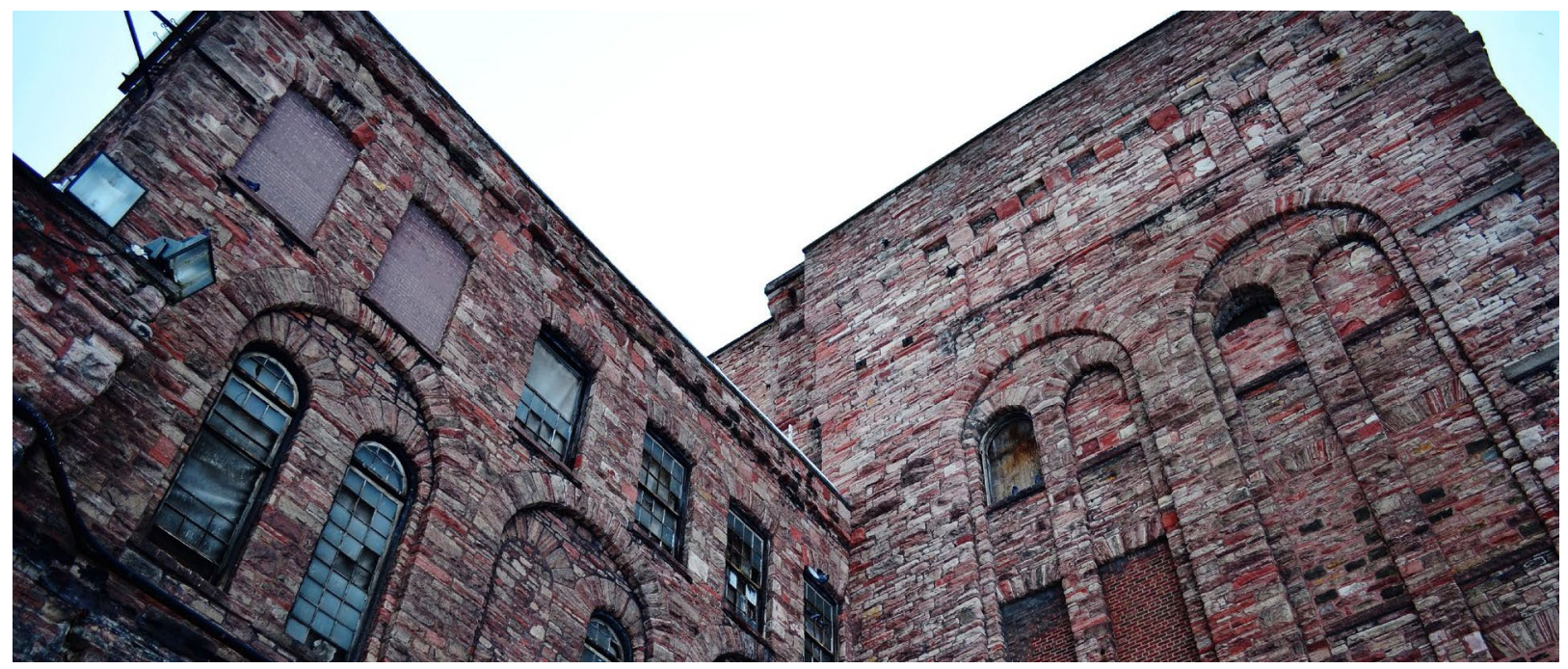

Figure 8.1.1: West façade of Pulp Tower, St. Mary's Paper Mill. 2013.

Consolidating The Void: Institute of Energy and the Environment

The methodology of this section focuses on the re-framing of contemporary space towards the motivation of the neighboring city fabric in union with the visceral qualities inherent in the ruin. The techniques and design strategy of this section will utilize the existing elements on site, as well as the calculated demolition to entice the community to use the space and subsequently arouse excitement in the adjoining city fabric. While the objective is to breathe the spirit of optimism into the development by integrating the voices of the community, there is also an attempt to escape the withering of excitement, where previous developments have faltered. Since the project relies heavily on realistic proposals for the site, the functional program serves to inspire a narrative between different sectors within the community.

A study performed by the Social Services Administration Board concludes that the majority of risk for social and educational competence is primarily associated with the west-central area. (Hoffman) For this reason, the programmes must act as a catalyst for development of nearby communities and address many 
of the demographic concerns of the canal district. As prescribed by the city and community outreach, the Pulp tower will serve as a hub of mixed-use and communal programs that are not specific to any social class. This aspect of creating a space to refortify and strengthen this derelict area is reinforced by the direct access to low-income neighborhoods and the city's downtown core. The site is situated between the east and west that conjoins the sectors of middle and lower class neighborhoods. The need for community resource centers aim at educational and social growth that lends itself to the development of a unified and multi-use program. The premise of this chapter is to create a facility within the Pulp Tower that provides spaces for shared activities, and to digress from the development of privatized gentrification.

The conditions of the area act as a point of departure for the programming of space. Given the aforementioned community needs and demographic studies, one must look into exercising support systems that strengthen social and educational competence. As the site is considered a strategic area for urban development, it places a challenging matter of reflecting on the needs of the city and surrounding community. The new intervention must carefully measure

Figure 8.1.2: Soup Kitchen community event in Machine Shop. St. Mary's Paper mill, 2013. the needs of neighboring areas, that subsequently need to be recovered or reintegrated into the post-industrial urban mode.

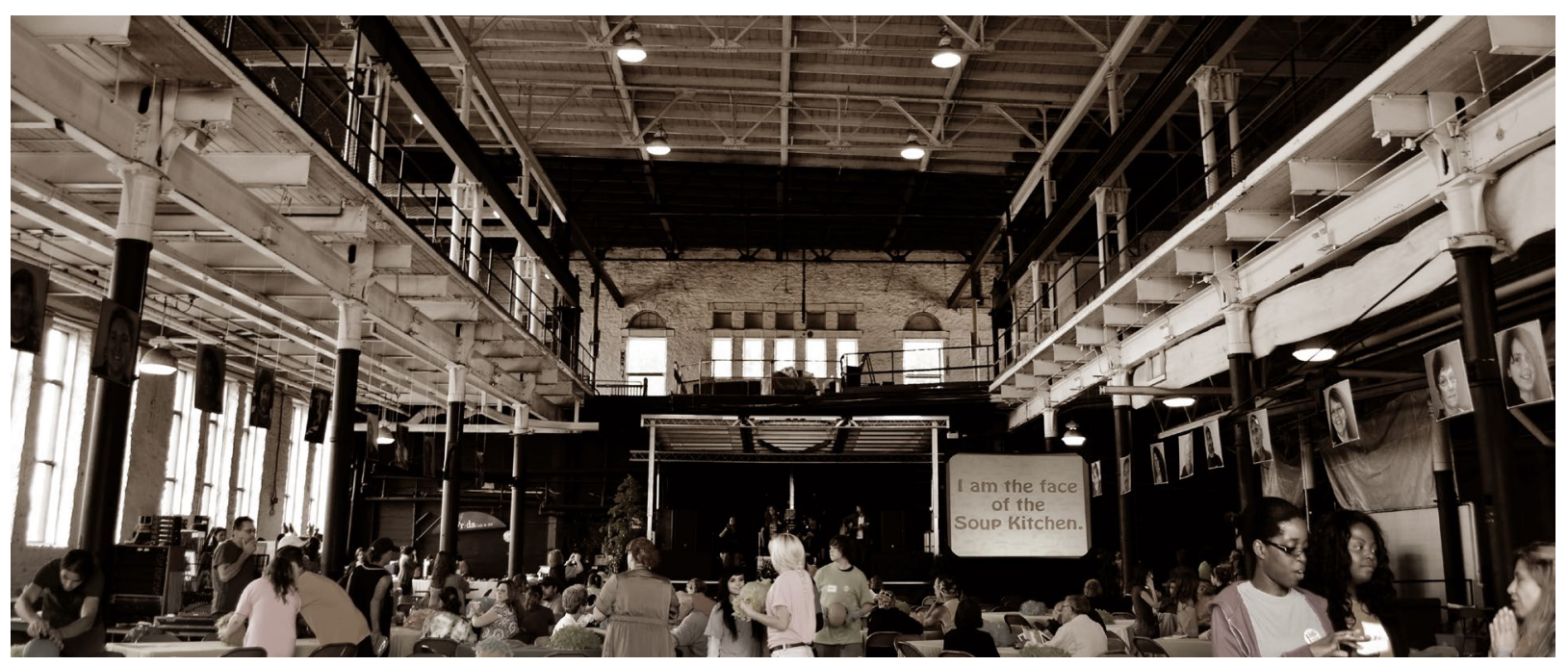


Figure 8.1.3: Social Risk Index demographic map. This in depth socioeconomic study highlights risk neighborhoods and communities that have been devised from the 2006 Census. This study has been based on percentages of lone parents, rented dwellings and government income. For the purpose of indications higher volumes of social and public gathering higher The of social and public gathering spaces. The map indicates in d gathering spaces are located in the city (including community centers, churches and youth centers), whereby the two red circles indicate the largest facilities. The proximity of spaces for social encounter and community wellness are subsequently obstructed by the neighboring steel plant. The program provides an environment that is appropriate for the demographic at risk in the site's region. This will include an internal pedestrian street spaces for youth activity and counseling that will be paired with a public library.

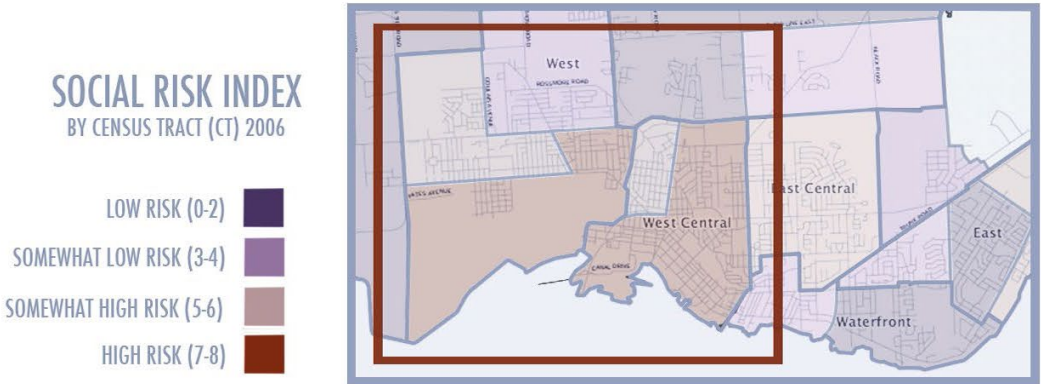

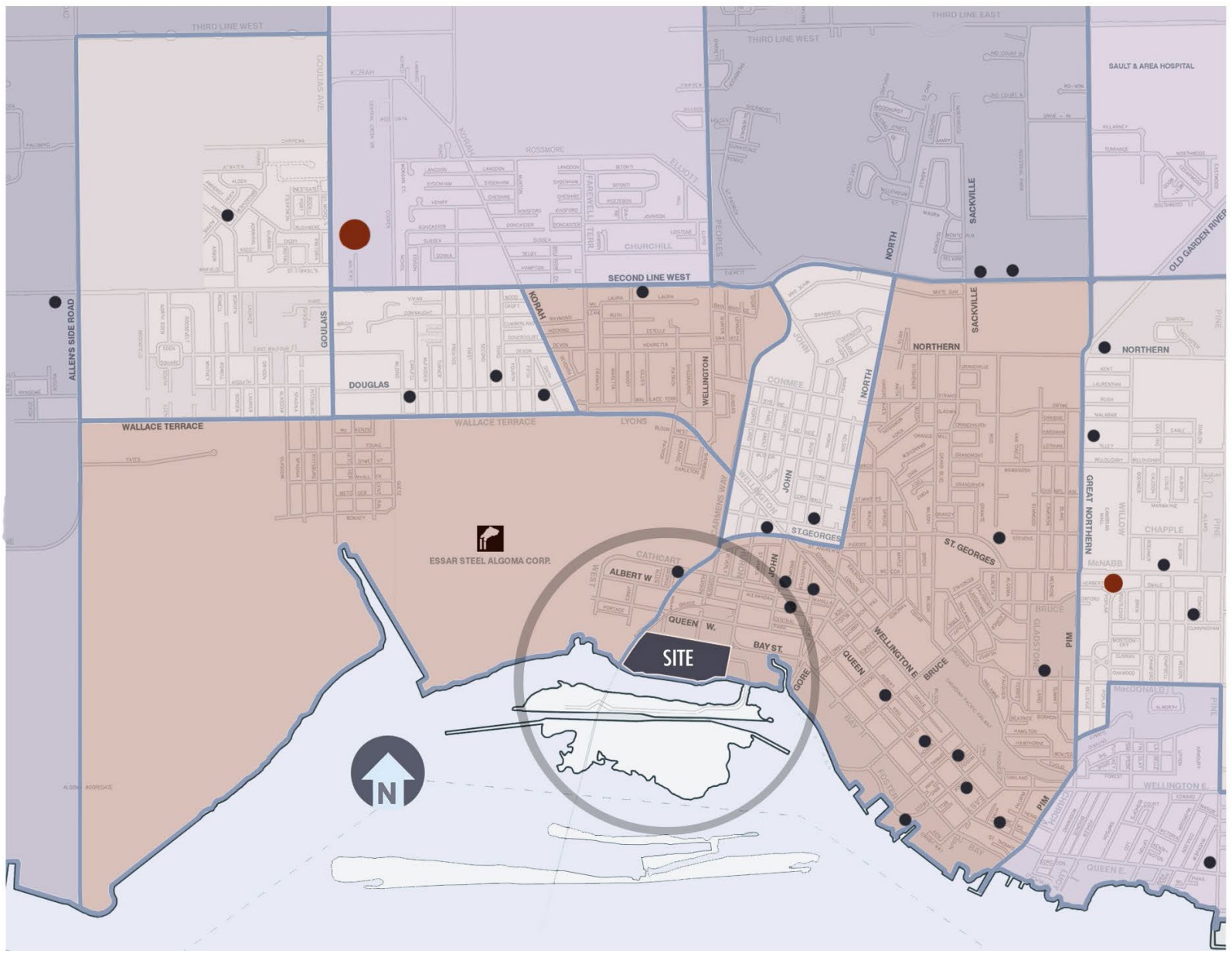

Chapter 8: Consolidating the Void: Institute of Energy and Environmental Studies 
Figure 8.1.4: Physical Health \& Well Being demographic map. This study is measured based on gross and fine motor skills, levels of energy and daily living skills of children in n. Although the study is the physical well being of children, I believe this poses a risk to not only children but also adversely family life style. In conjunction with the previous section of this thesis, the map highlights contaminated land (indicated in red) and parkland (indicated in purple) to indicate the lack of physical recreation spaces in risk areas. For this reason the city hub-trail is being extended and will add green corridors around the city. The Biomass Facility park, in particular is a sources of generation for reviving natura landscapes, while the Institute of Energy and the Environment provide educational resources on generating and maintaining healthy environments.
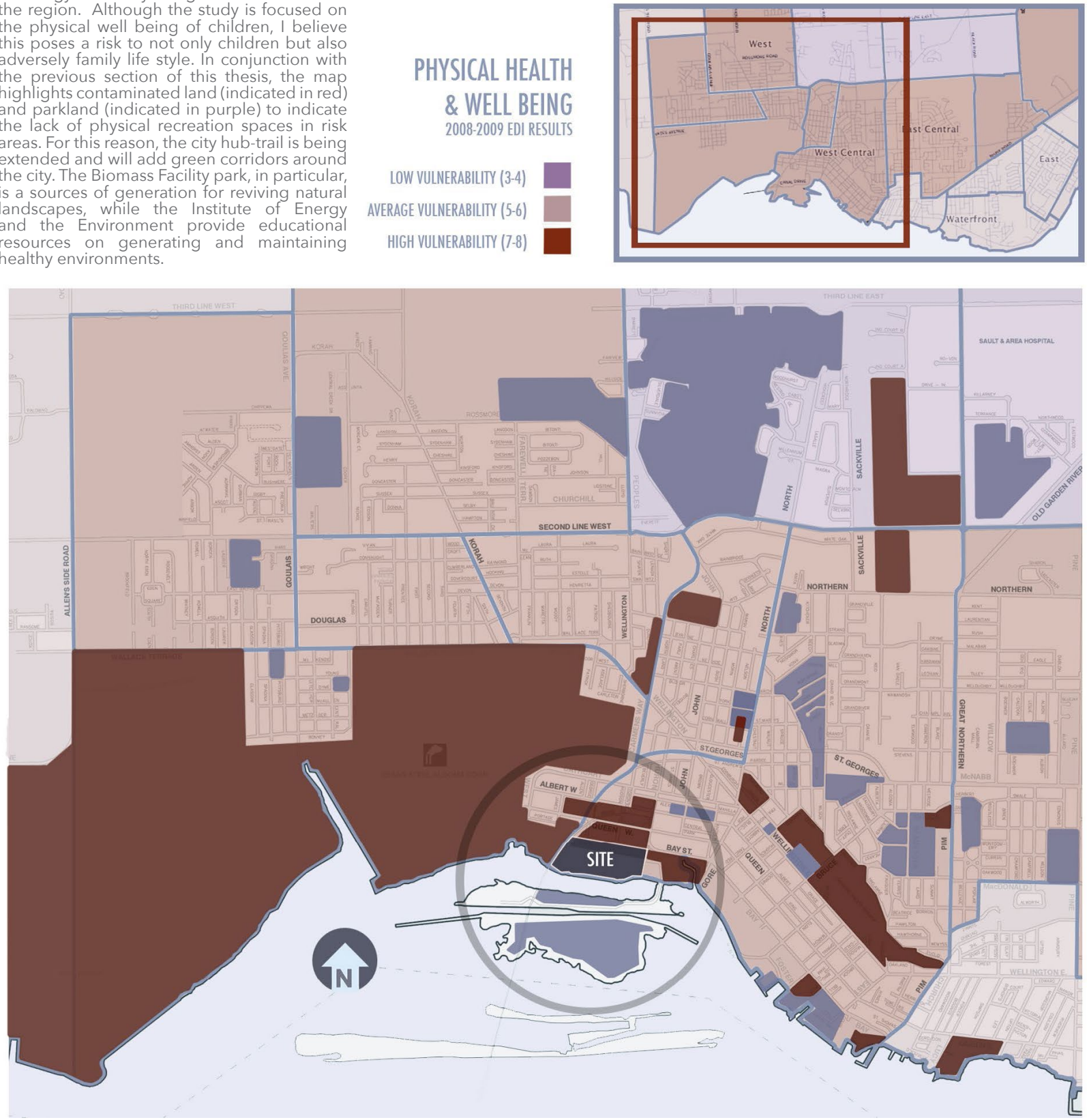
Figure 81.5: Communication \& General Knowledge demographic map. The following demographic map demonstrates that the majority of citizens within the western districts have a somewhat high volnerability for communication and general knowledge. Upon delving into geneational support ammenities for the educationa support ammenities for the within these districts have closed over the years. The program addresses this concern and intends to bring such public library amenities back to the surrounding district.
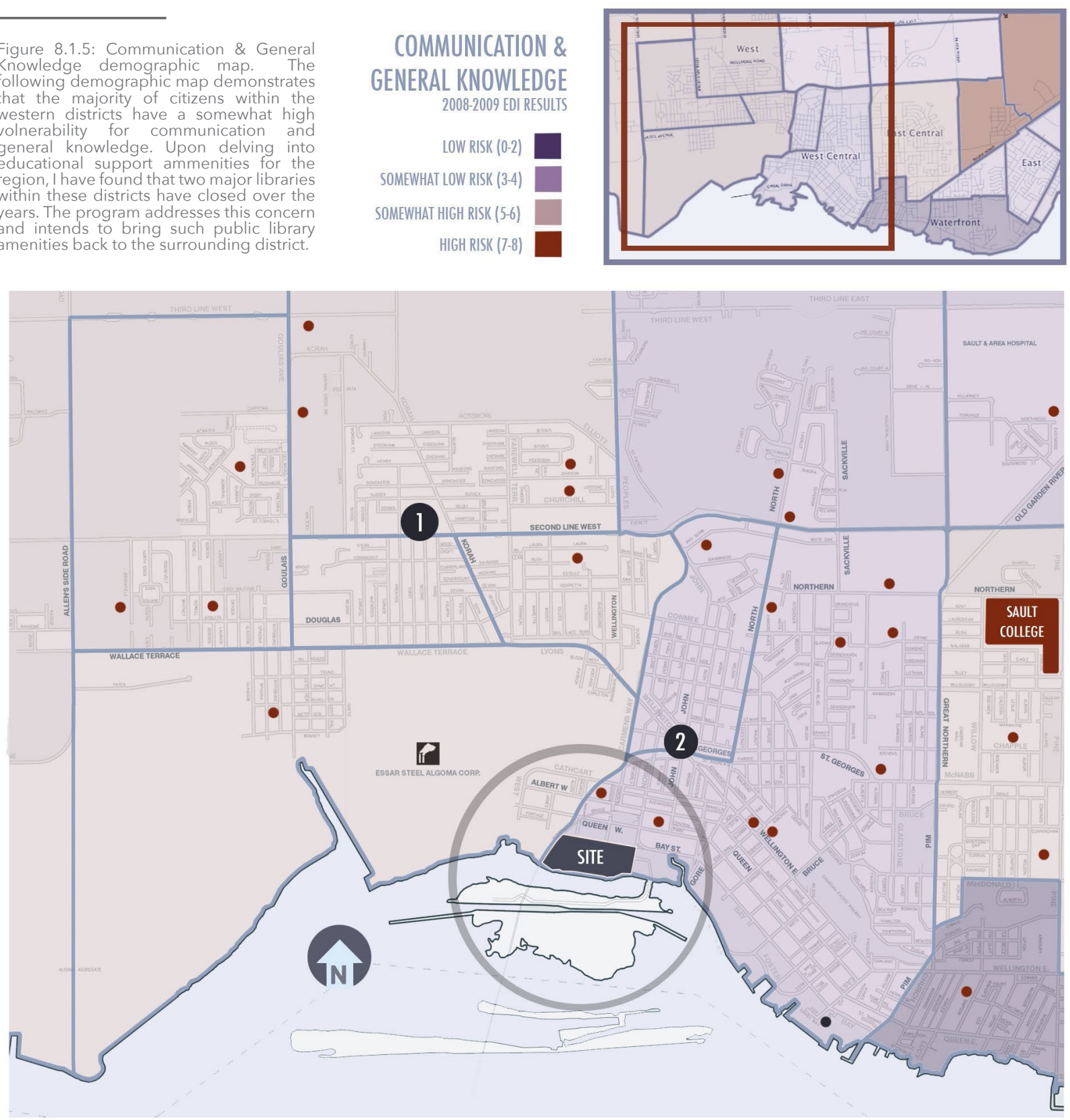

Chapter 8: Consolidating the Void: Institute of Energy and Environmental Studies 
The intervention is set to re-adapt the Pulp Tower and optimize its strength as a central landmark for the city at large. The design comprises of two approaches: the restoration and refortification of internal surfaces, along with the addition of external structures to support the IE2 program. The following new program will include: additional IE2 facilities, food amenities for the public and students, a public library and an exhibit on the history of industry in the Algoma region.

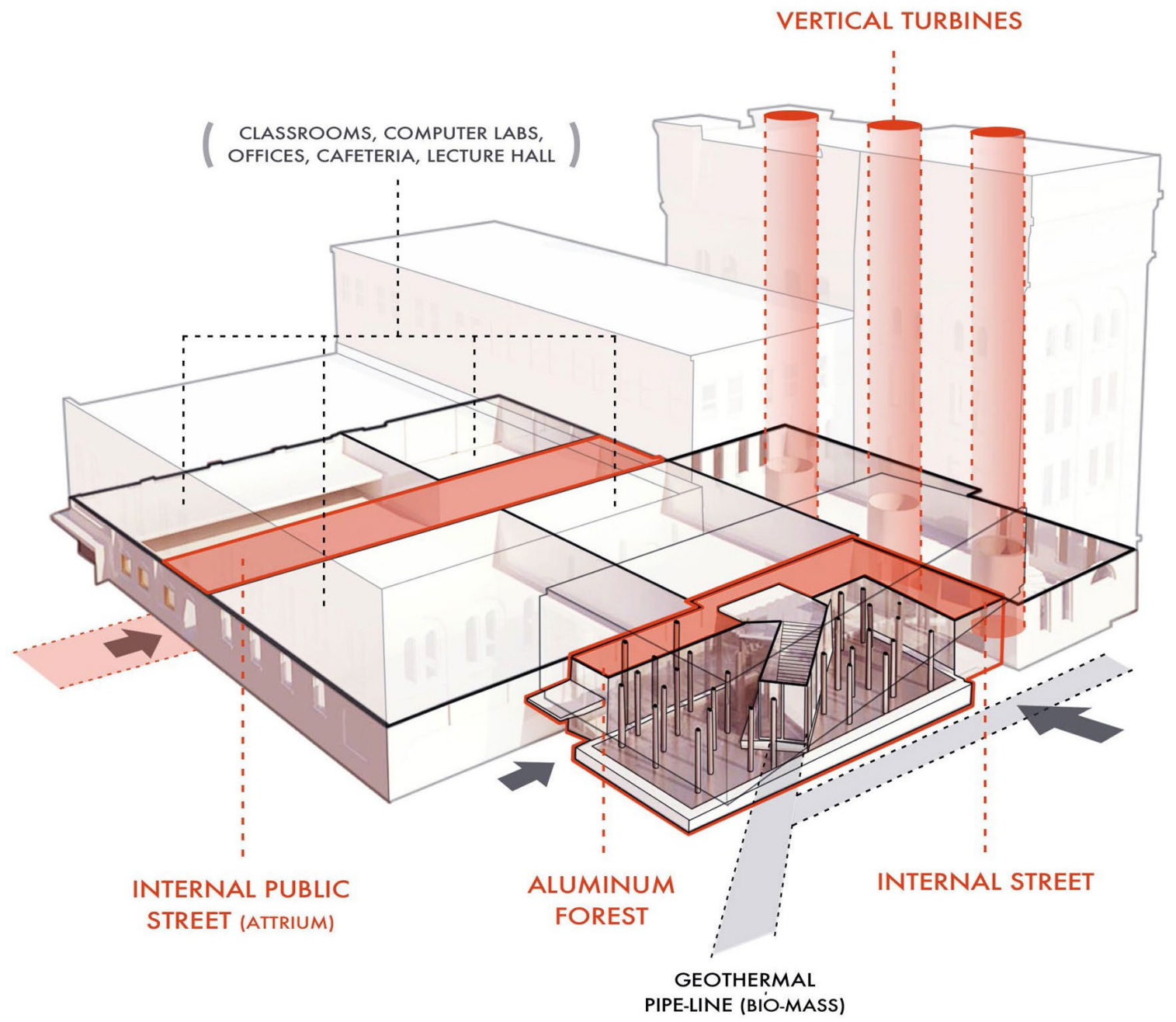

Figure 8.1.6: Pulp Tower axonometric section. The axonometric section through the building indicates where the most significant interventions will take place in the Pulp Tower. The red strip near the back indicates the interior street within the warehouse, an open corridor that exposes the old façade of the building. The second intervention addresses the void created by the removal of the digester tanks in the tower. Lastly, the building addition within the court is pulled away from the existing facades to create two internal streets and entrances into the campus building. In connection with the biomass plant, a geothermal pipeline running from the plant towards the Pulp Tower provides heat from the wood chip burning process that I wish to incorporate into heating and cooling of the building. 
8.1 Warehouse and Shops

The original Pulp Tower of the former St. Mary's Paper Mill was built in 1896, however the present form has been greatly adapted over several decades. Originally, the warehouse and shop rooms of the Pulp Tower were support areas for the storage of paper calendar machines. Along the back interior walls of the warehouse, the old façade of a past tower iteration is still present within the centre of its space. The faint signs of in-filled windows, of awkward passageways and staggered floor plates are all indications of its evolutionary construction. Prior to 1920, the tower's shop component had been added to accommodate the installation of new and larger machinery. This addition remains to date, next to the tower. The priority of the intervention within the warehouse is to restore the former street along the old façade. ${ }^{15}$

Figure 8.2.1:

Pulp Tower evolution from 1901 to 2014.

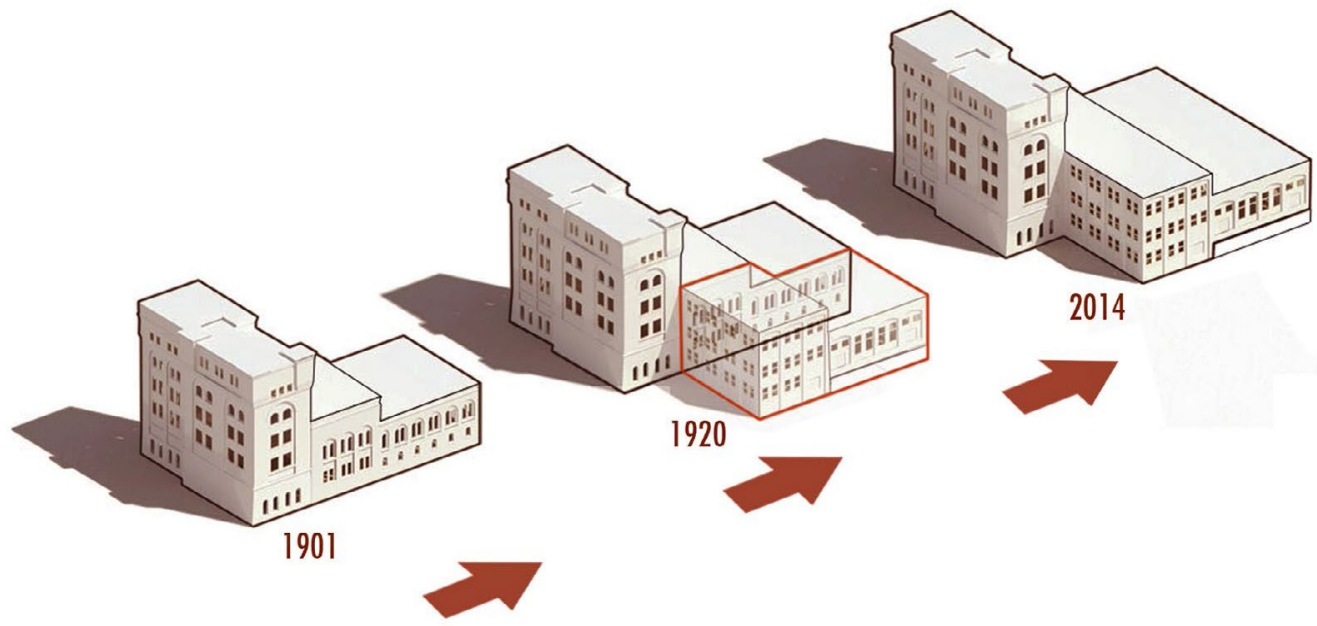

As mentioned earlier, Clergue had a straightforward vision of how the site should be organized. Prior to the tower's shop addition, a street alongside the building provided access to buildings at the rear and west sector of the mill, most notably the Locker House and Foundry. The early mill had been designed in a manner that Clergue could overlook each building on site from the office building, located at the far east end of the site. Although this strategy had once

15 An image of the tower's evolutionary lineage can be found above (Figure 8.2.1). The aforementioned axonometric section (Figure 8.1.6) indicates the existing bearing wall of the original exterior wall at its centre.

Chapter 8: Consolidating the Void: Institute of Energy and Environmental Studies 
delineated the hegemonic powers of mill owners, the notion of the watchful eye on the site becomes a way of visually connecting the buildings, as the social boundaries between workers and higher power are no longer present. The intervention is aimed in such a way to respect the validity of space, without changing the original flow dramatically. In this sense, we are alluding to the experiences that make a place feel familiar by uncovering and peeling away its history. By looking over and revealing historical traces, the project is indeed trying to evoke the underlying story of memories by attempting to form itself and create a continuous dialogue in the present. It is a process of crafting a story about local history and claiming an ongoing role in that tale.

As part of the design proposal, the industrial ruin will strategically integrate a contemporary steel structure with an aim to preserve and highlight historical materials as a fundamental fragment of the newly conceived spaces. The design process emphasizes the industrial approach and original layout of Clergue's construction, honoring the phantom forms and the site's heritage. The project has therefore been designed as a delicate balance between intervention and preservation. The enclosed space of the internal street consists of a total of 3800 square feet and has been created by pulling away a single floor plate from the load-bearing wall of the original warehouse facade. This atrium features a large glass-covered roof that floods light onto the former façade, alluding to the experience of the once open streetscape. The light filled space is meant to be a welcoming communal space at the heart of the communal facility, whereby it promotes multi-use strategies by serving as a focal egress channel to adjoining programs. The internal street can be accessed from various points of entry, while also featuring bridges and mezzanines for those passing by to admire the view from above the street. Adjacent to the sandstone façade are classrooms, offices and a section of the library. 
The purpose of public libraries serve not only the use of educational and recreational services, but in recent years have become support spaces for communities. The consensus of public libraries has shifted towards community centre spaces, and is designed to offer an extensive range of services to a broader demographic. The library's role is undergoing a transformation as a result of rapid social change and new modes of communication. Given the Social Services Administration Board study, the risk of lower levels in communication and general knowledge in the surrounding area has served as a focal point for programming; while also replacing the loss of two major library facilities in the west-central sector of the city. An important factor for the public library space is to promote the flexibility and adaptability of space, whereby it provides a setting for encounters, meetings and events. The public library is strategically inserted between the warehouse and tower components of the building, acting as a spatial container that relates to the civic square and its activities. This aspect of the program is to extend into the Institute of Energy and Environmental Studies, offices and food services that begin to inform another layered narratives between each dedicated area. The facilities have been divided into functional zones, with the aim of encouraging a mélange of services and heightened density. At the third level of the Pulp Tower, the final reach of the library cascades over the interior street and stretches out to conjoin with the exhibit and college spaces. This level of the public library features reading and study spaces for students, as it is a space that grants views towards the river and sunlight from each orientation. The reading rooms above the internal street open towards the public corridor that allows an ongoing dialogue between communal and library spaces. From within the intersection of the college and library, work zones for students are soundproofed and provide quiet nooks for reading and group work. The objective of the public library is to provide gathering spaces for a variety of users and to allow for space that can facilitate social gathering and learning.

Chapter 8: Consolidating the Void: Institute of Energy and Environmental Studies 
Figure 8.2.2: Pulp Tower basement and first floor plan.

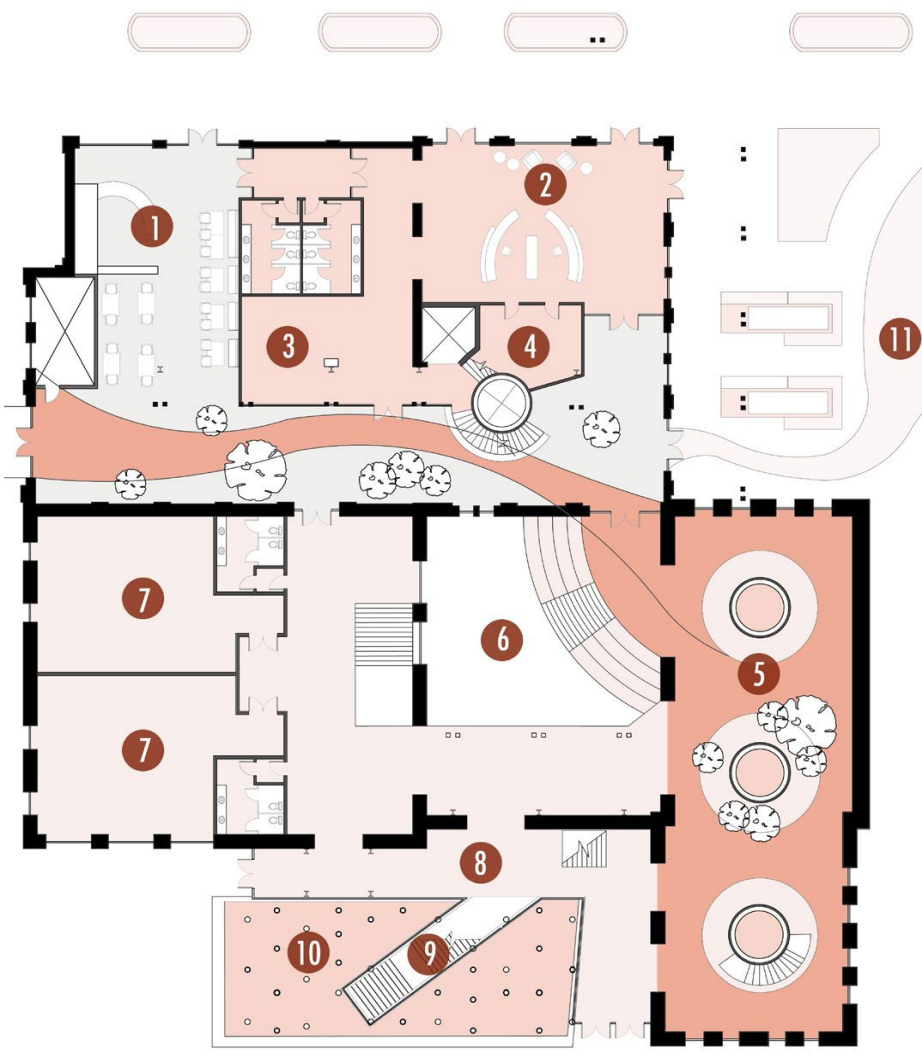

(1) Café; (2) Library Reception; (3) Library Space; (4) Reception Office; (5) Tower exhibit; (6) Sunken Theatre; (7) Classrooms; (8) Internal Street; (9) Laboratory Staircase; (10) The Forest.

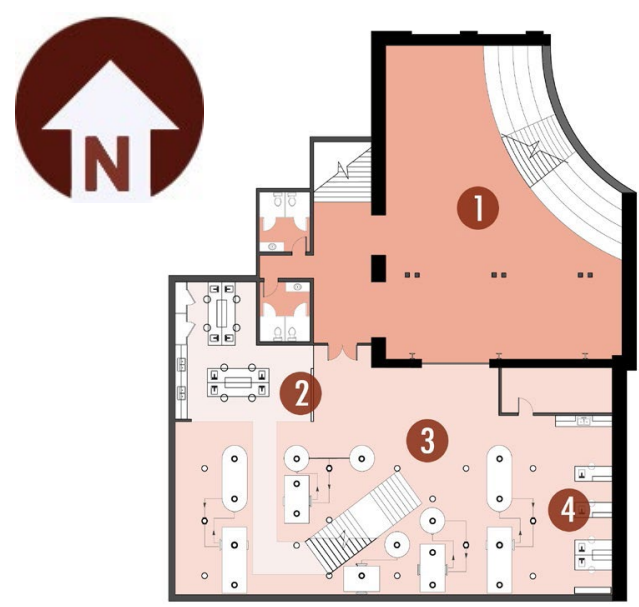

(1) Sunken Theatre; (2) Laboratory; (3) Grey Water Machine Room; (4) Laboratory.

\section{GROUND LEVEL}

As denoted in Figure 8.1.6, the Pulp tower regeneration consists of three main elements that are independent in their construction: the interior street, the tower and the student laboratory facility. Upon analyzing and studying the existing fabric of the Pulp Tower, strategies have been implemented to maintain the essence of the former industrial space. Careful attention is placed to utilize the existing structure, thus the spaces were planned in accordance with existing load bearing walls. In the first floor plan (Figure 8.2.2), the thick masonry walls have remained in place and serve as focal points to identify the placement of public egress and corridors.

The ground floor is designed to accommodate a variety of different programs, featuring an interior street that acts as a central means of egress throughout the building. The enclosed space of the street consists of 3800 squarefeet. The atrium features a large glass covered roof, whereby light penetrates onto the former façade and sets the atmosphere. In order to promote energetic flow within the ground level, commercial and public spaces make up the street front. This street front encompasses a café (1) and public library $(2,3,4)$, by which these programs are provided with directaccess and views into the interior street. A covered entrance to the east acts as a secondary street from outside the edifice, the strategy is to beckon visitors towards the internal street and draw attention to its centre (11). Given the relative footprint of the tower (5), it has been strategically designated as a circulation space that will double as an exhibit venue for the Museum of Industry and Innovation. Classrooms (7) and an open lecture theatre (6) are provided towards the southern sector of the Pulp tower. The proximity of these spaces with the tower extension begins to inform the campus boundary for the Institute of Energy and Environmental Studies (IE2).

\section{BASEMENT LEVEL}

Within the central core of the building, a sunken theatre provides space for student presentations and communal exhibits. (1) Thus alluding to the conception of a grotto that is interwoven into the tower or belvedere. Views and entrances towards the grey water machine room (2) are accessible from this level. A staircase, that can only be accessed by students, diagonally slices through the tower extension and leads towards student laboratories above. (3) The intent is to expose student activity and the internal networks of the building. 

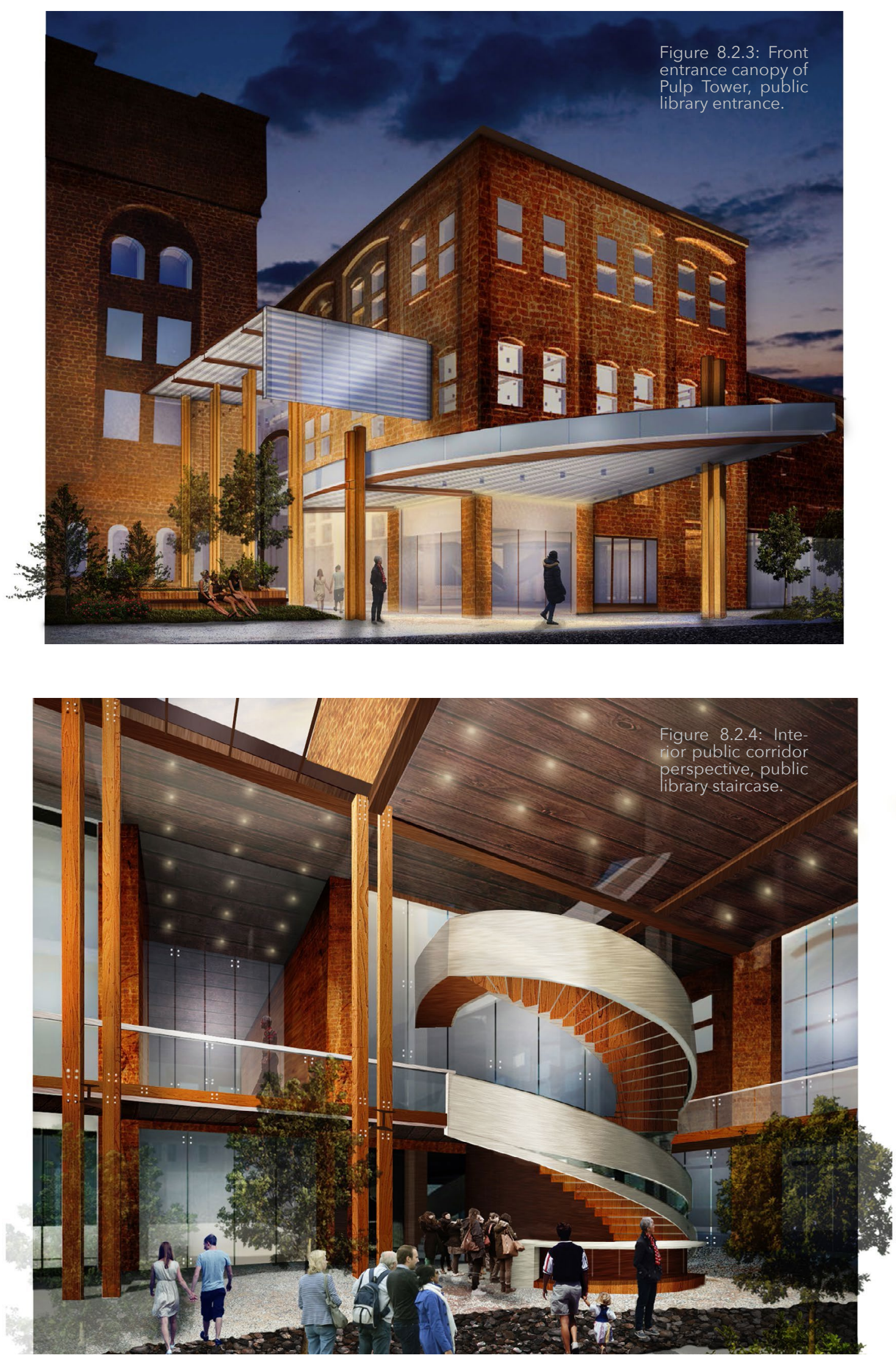

Chapter 8: Consolidating the Void: Institute of Energy and Environmental Studies 
Figure 8.2.5: Pulp Tower second floor plan.

\section{SECOND LEVEL}

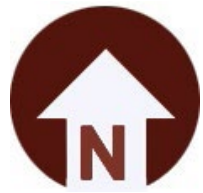

The design methodology for the second floor is to continue promoting public flow and density between each designated program, while also defining boundaries between sectors. Public egress within the building does not impede on its original fabric (bearing and existing walls are denoted as thick black walls on Figure 8.2.5). Since the library is inherently a surveyed public space, the design strategy accommodates the influx of flow in a defined space. For this reason, a helix staircase provides circulation from within the library, while also allocating access from the interior street towards other sections of the building. The second floor level features a bridge system that traverses over the street, connecting the north and south sectors. Towards the rear of the building, student laboratories can be accessed through a central corridor or tower egress. The facility is divided into student laboratory classrooms and a private laboratory.

(1) Internal Street; (2) Public Library; (3) Recreational Rooms; (4) Offices; (5) Classroom; (6) Student Computer Room; (7) Classroom; (8) Student Laboratory Classroom; (9) Private Laboratory; (10) Student Café; (11) Tower Exhibit.
Figure 8.2.6: Pulp Tower third floor plan.

\section{THIRD LEVEL}

The seven-storey Pulp Tower is strategically readapted into circulation and exhibit spaces. Since the space in the tower is limited as a result of voids created by three dismantled pulp vessels (voids are indicated within the tower), an exhibit is paired with circulation space to encourage a higher volume of public flow. The exhibit showcases the industrial history of the city and Algoma region, beginning with agricultural innovation and ending with exhibits on sustainable energy industries. The final floor of the library extends above the internal street to then connect to the tower and student spaces. Since this space provides sunlight from each orientation, reading rooms and study spaces are located on this level.

(1) Tower Exhibit; (2) Library Reception; (3) Study Rooms; (4) Reading Area; (5) Library; (6) Skylight Roof.
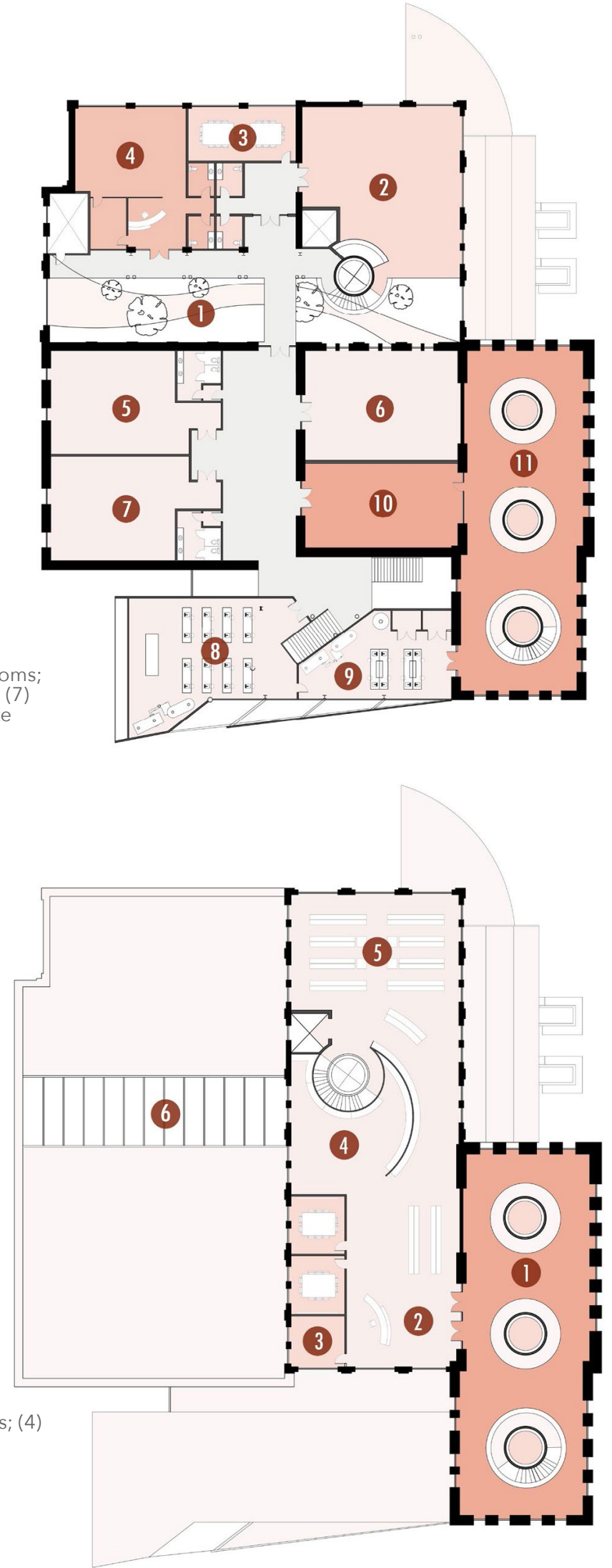
The programming of the site and re-adaption of the Pulp Tower is meant to infuse energetic life into the post-industrial landscape. At the time of the mill's operation, production never rested and the mill has been referred as space that never slept. In lieu of addressing and sustaining networks within industry, this portion of the thesis focuses on manifesting spaces to encourage the livelihood of its social activity. ${ }^{16}$

Figure 8.2.7. Multi-
use and Density use and Density
diagram for rograms within Pulp

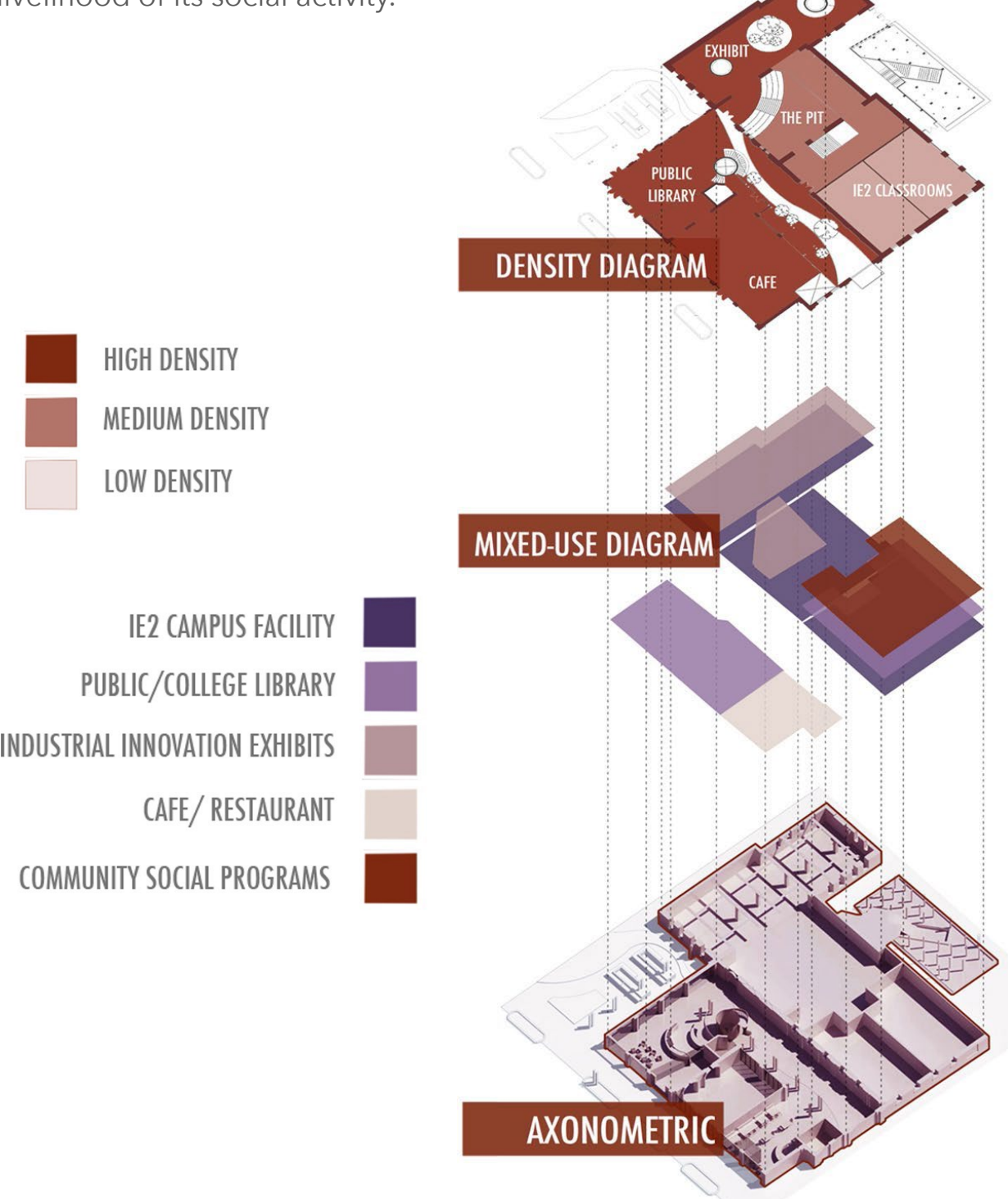

16 In Figure 8.2.7, the diagram analyzes the location of each program, its multi-use and density associated with that space. The renderings at the bottom of the diagram give a sense ofpace from the rendering and assigned a color based on its program. If the space is used for a multitude of different programs, the diagram will present itself with layered outlines that are associated with the programs colors. The intent of this visual display is to demonstrate the multi use of each a desired density The final image above demonstrates the density associated with and its occupancy as a gradation that become darker in conjunction with heightened tenancy.
The diagram bellow attempts to demonstrate and analyze various interwoven programs and the density associated with layering multi-use spaces. In order to sustain a sufficiency and thickness of occupancy in the building, certain programs mesh together with others. The premise is to design spaces that promote socia encounters among varying demographics. This opportunistic overlap allows for the density of use to be strengthened, as the space is meant to generate communal energy.

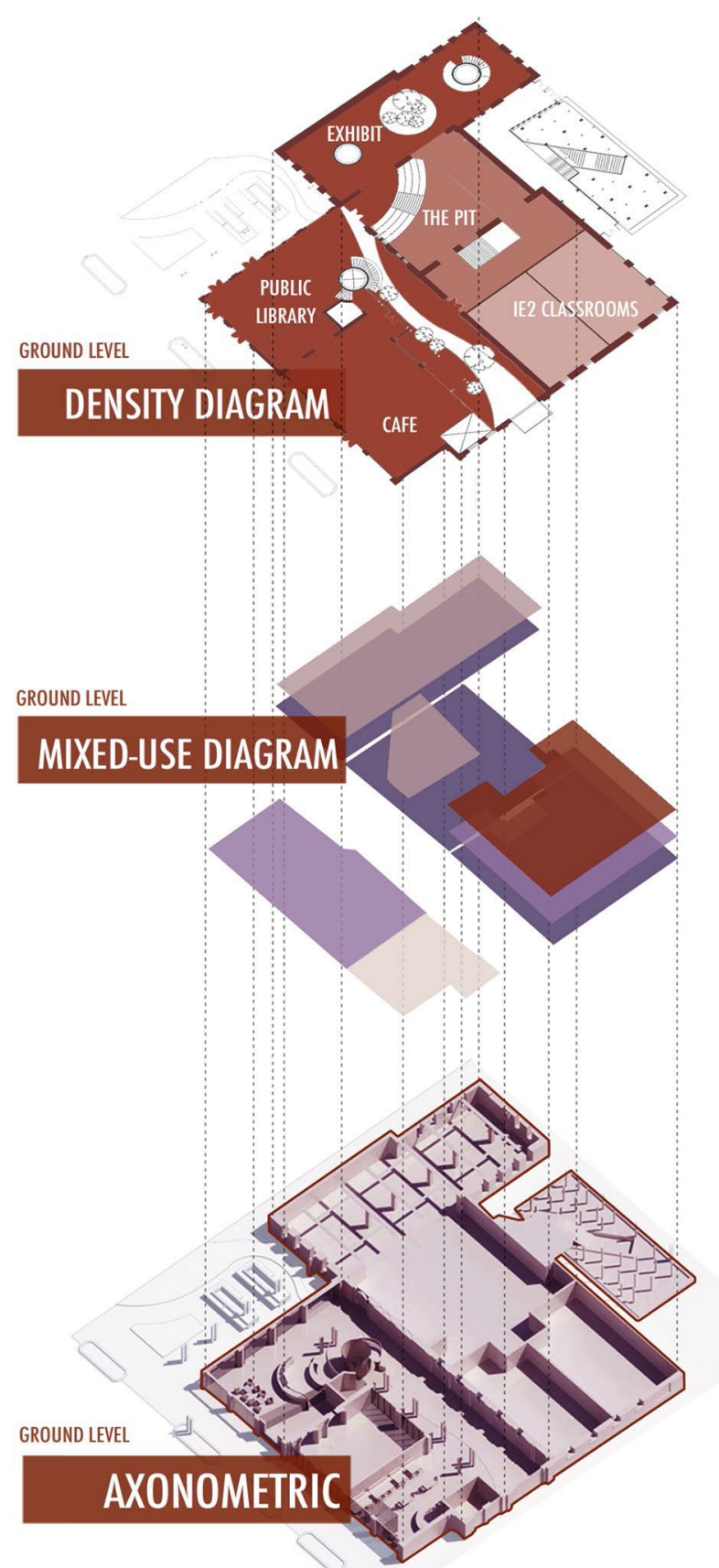

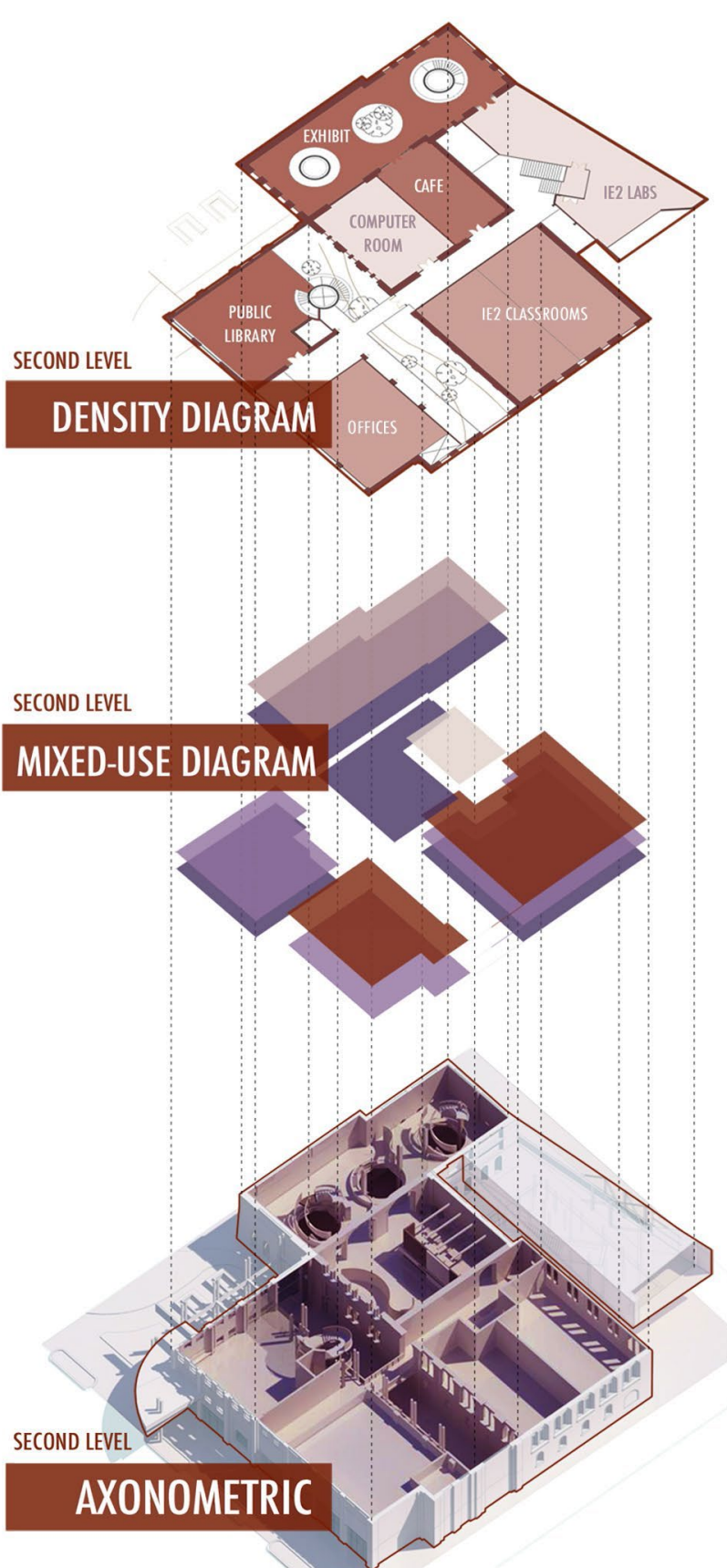


Ultimately, the Institute of Energy and Environmental Studies is the primary tenant of the Pulp Tower, the space encompasses classrooms, computer facilities, offices and laboratories. In addition to advancements in the renewable energy sector of the city, the college has proposed an expansion of regional, provincial and international partnerships between the educational and industrial facilities. (Common, 3) This will include the expansion of the Institute of Energy and Environmental Studies (IE2) and creation of its offcampus headquarters. The interventions proposed on the St. Mary's Paper Mill encourage opportunities for the fusion of a learning environment with private sector industries into a unique space. The college has proposed a team-based approach to learning environments that will promote access to industrial partners, most notably- the Biomass Facility. With this, the strategy would encompass the ideals set in place by the college and how the facility can be amalgamated with energy generation and environmental protection on site. Presently, the college is seeking capital funds to renovate an existing building on site in order to construct a campus building within the 150-acre "living laboratory" of the proposed campus located on the woodlots of the post-industrial site. The Institute of Energy and Environmental Studies is part of the third phase of campus renewal, and is estimated the building will require approximately 100, 000 square feet of space. Given the relative square footage required for campus growth, the Pulp Tower functions as an appropriately sized vessel to hold such a facility. The projected student body will consist of 450 students within the coming years; this number will set occupation and design standards for the proposed intervention.

Chapter 8: Consolidating the Void: Institute of Energy and Environmental Studies 
In the Pulp Tower edifice, the tower itself had been used in the digestion process of paper, whereby the one hundred and ten foot tower held three digester tanks. These seventy-foot tanks once housed noxious acids, which are crucial in the process of pulp production and had pierced through six stories of the tower, encompassing the majority of the tower's former footprint. Upon demolition, these vessels were stripped from this space, which has left large voids that slice through the height of the building (Figure 8.2.1). The design process approaches manners to redevelop this discarded space, with a mindful consideration of generating an atmosphere for learning and participating.

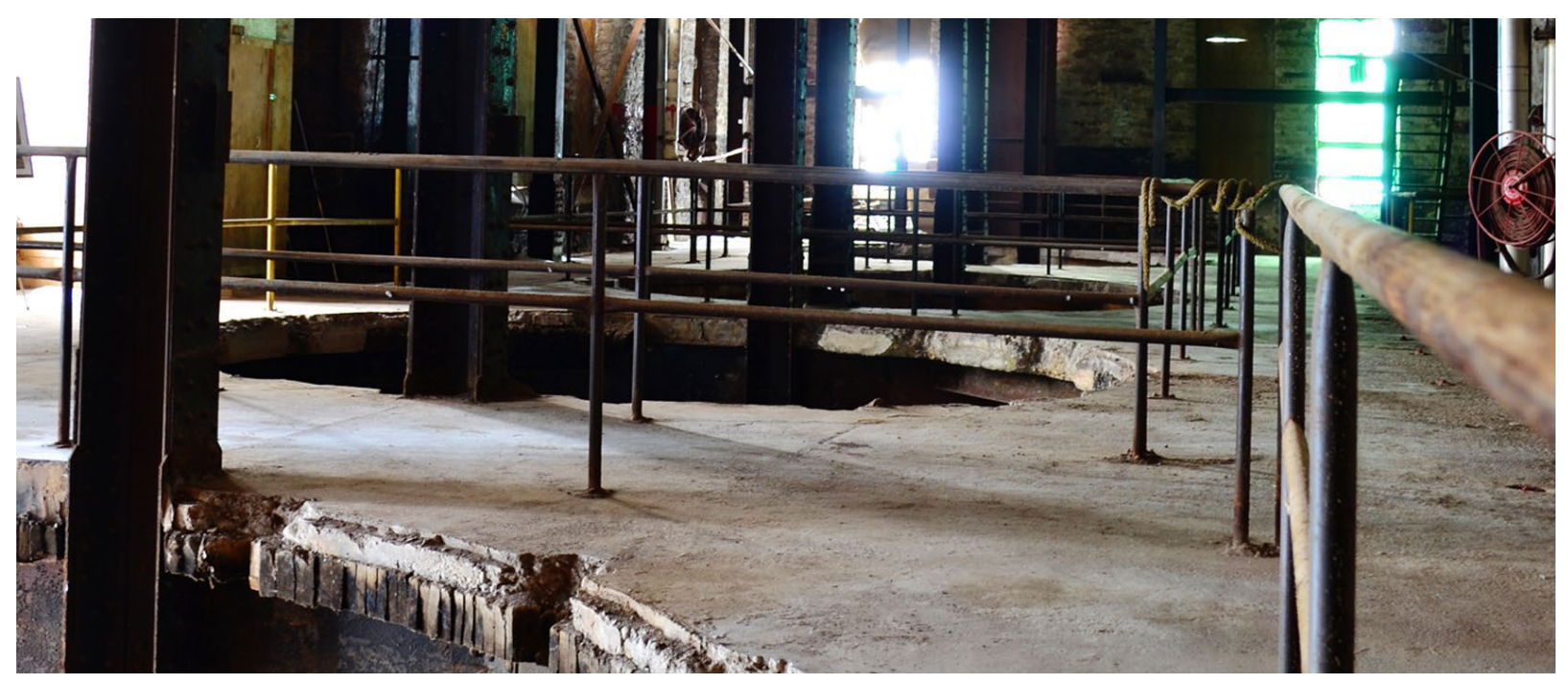

Figure 8.3.1: Voids left by digester tanks in Pulp Tow
As prescribed in the mandate for Sault College's campus growth, they have proposed that an energy-generating wind turbine be constructed on the new campus grounds. While these turbines are quite loud and require an extensive amount of space, the design encompasses the use of vertical turbines used in constructed towers. For the purpose of using such energy technologies, the proposal took precedence with studying the Council House 2 in Melbourne where the office building design features the use of vertical wind turbines (Cheung). This wind-powered technology is designed to ventilate airflow through building ducts throughout the building, meanwhile generating electricity. 
The mimetic bodies of these digester tanks are now replaced by turbines and circulation spaces, which utilize the void within this vertical shaft. These vessels not only benefit the energy sustainability of the program, but also serve as refortifying structural components for this heritage tower. As envisioned by the college, students will acquire knowledge through unique interactions with industrial processes and sustainable systems. Three vertical blades are placed at the top the roof and benefit from strong lake effects winds that the region is prone to. Since there is no danger to be in close proximity with these remarkably silent turbines, an observation deck is featured on the final level in

Figure 8.3.2: Perspective section of Pulp Tower and Student Laboratory, wind turbine function.

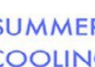

UMMER
OOLING
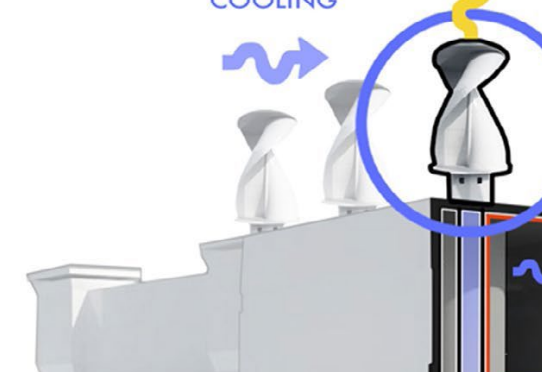
conjunction with exhibit spaces. In this sense, there is a fusion between the academic and social sectors in a unique space. The Tower exhibit spaces elevate visitors to extravagant vantages of the city and surrounding landscape as they circulate towards the top. The tower circulation serves as points of access for exhibits, library spaces and college programs. For this reason, interactive exhibits showcase and celebrate the lineage of past industrial processes from the first innovations in agriculture to sustainable technologies. Strategically, the design

Figure 8.3.3: Pulp Tower exhibit and wind turbine rendering. incorporates the sustainable and mimetic industrial process with the movement of building systems and people.

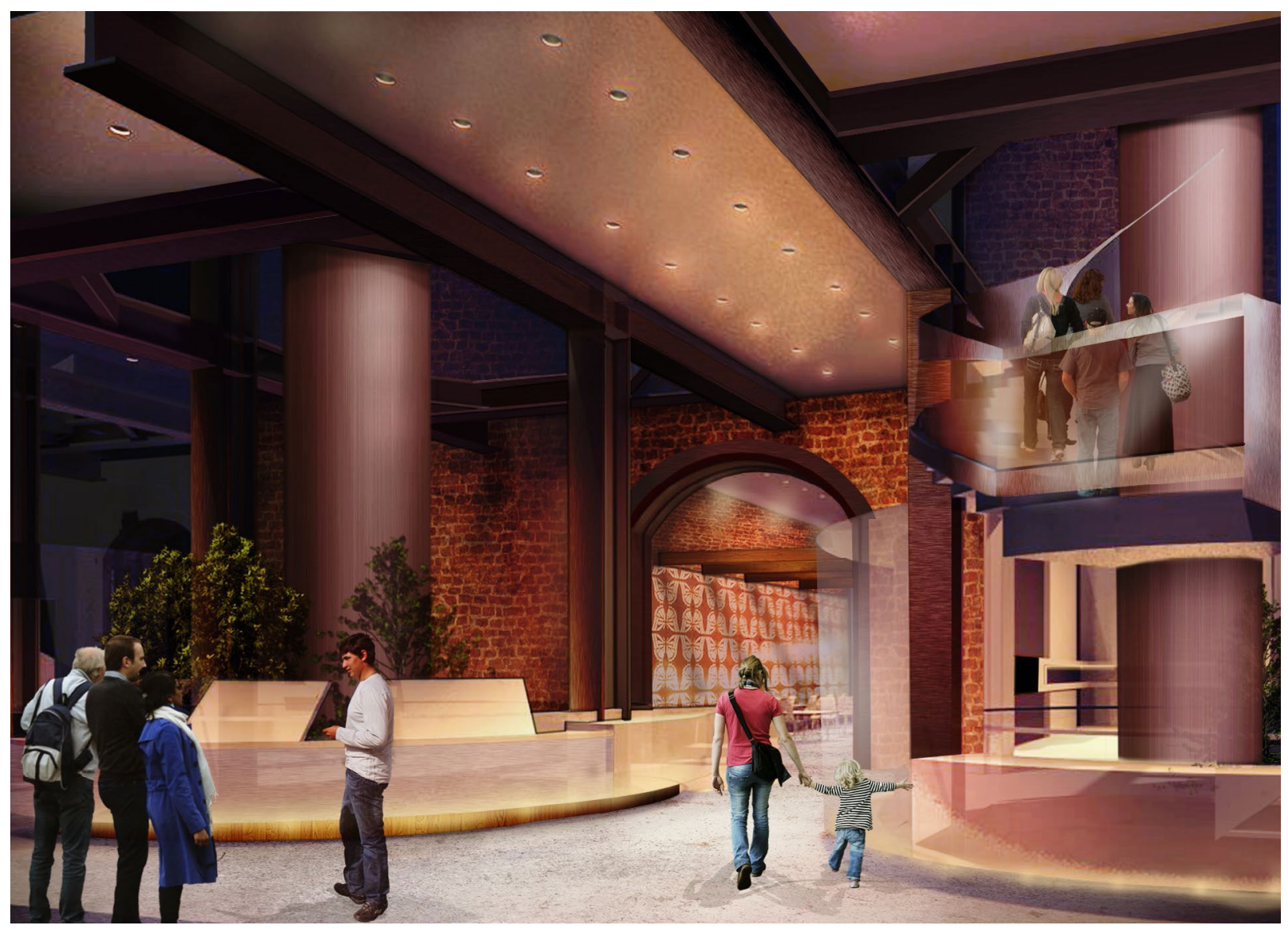

The following rendering (Figure 8.3.3) demonstrates the re-use of the tower into exhibit spaces for the Museum of Industry and Innovation. Contemporary types of construction are not imposed on this space, the existing fabric is illuminated and emphasizes the industrial language. The museum is intertwined with the circulation spaces and wind turbine rooms within the tower. This program maximizes the multi-use of the space, given the relative footprint of the tower. The exhibit is strategically designed in conjunction with the internal street, as it flows from the farmers market into the Pulp Tower. Thus, the ground level boasts exhibits on agricultural innovation that then ascend into different stages of industrial progress as viewers move up the tower. 


\subsection{Pulp Tower Extension}

The premise of the addition to the Pulp Tower is to create a campus edge as a model for future development, while also providing a focal point that presents itself as a gateway into the campus. The addition will be situated within the rear court of the Pulp Tower; strategically, the building's length will take advantage of its southern orientation. The tactic for this intervention proposes to locate a position where the addition could easily fasten itself to the Pulp Tower, without any drastic changes to its fabric. As a result of the restoration needed for the decaying tower, the new intervention is pulled away from the façade. The methodology of approach proposes a freestanding structure whereby delineating its sensitivity towards the tower's heritage value. With this, two internal streets are created between the tower and the addition. ${ }^{19}$

Figure 8.4.1: Pulp

Tower axonometric, showing existing building and new interventions.

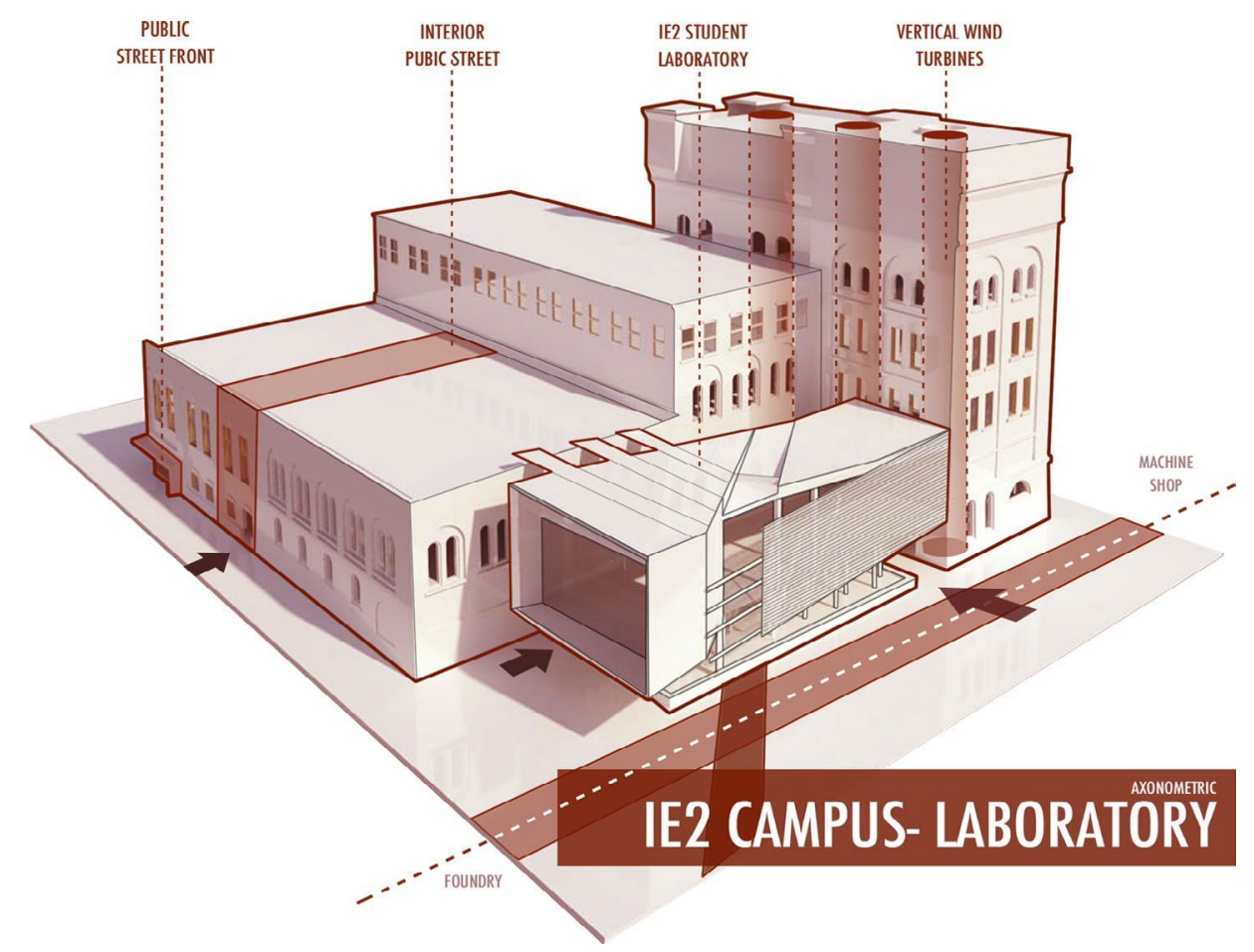

19 Figure 8.4.1 demonstrates the utilization of newly formed interventions and traces that begin to construct the boundaries of the campus. These connections and pathways begin to inform how the design uses the spaces in and around the Pulp Tower. These traces allude to the form of Clergue's phantom pathways.

Chapter 8: Consolidating the Void: Institute of Energy and Environmental Studies 
The Institute of Energy and Environmental Studies facility intends to provide an armature of green building systems, such as vertical wind turbines to employ unique academic tactics for learning spaces. The concept of the building is driven by this idea of the living laboratory, described in the Campus Growth Report. (Common) As prescribed by the college, the students will be exposed to a hands-on approach of the program. In lieu of this living laboratory, the facility will incorporate student curriculum with building techniques and constructions for the design of new laboratory spaces. In this particular intervention, the grey water system is used as a point of departure that begins to inform the architectural space of the laboratory facility. At the ground and public level, piping for the grey water system is exposed and mixed with structural columns to manifest "the forest". Water being utilized in laboratory processes will then be recycled into the grey water filtration system below. Whereby the design methodology allows for an open public gathering at the base and student spaces from above (refer to Figure 8.4.2). The surface of the volume within the interior street is transparent to allow insight into the relationship between laboratory and grey water system. Thus, what students will be studying and processing in the laboratory is directly related to the energy efficiency of the building.

The distinct form of the intervention presents a new symbol for the campus. Primarily, the design will employ both literal and metaphorical expressions of environmental intentions in its architectural composition. The forest begins to articulate the passage and connection sustainable energy industries place towards nature; serving as a field for which the two sectors can merge. The canopy sets the stage for activity and events to create not only a locus for students, but a centre of gravity for those passing from one end of the site to the other. The forest is meant to draw the public into the campus boundary, fortifying the tower's pull as a central communal hub. At night, during communal events and gatherings, the canopy acts as a beacon, which engenders curiosity 
from a distance. The illumination of the canopy is reflected in a pool of water at the base of the forest, whereby the pipes stretch in the reflection to mimic the tower. The design inherits the idea of diverse landscapes that are cherished in the Algoma Region and provides a unique space for the public. As individuals move past this constructed landscape, flecks of the old sandstone construction in the background play with the delicate balance of the newly constructed space (Figure 8.4.3). The campus extension is neither exclusive nor detached from the site's activities; rather, it remains permeable and interacts with the constantly evolving public event.

Figure 8.4.2:

Perspective section of Pulp Tower and Student Laboratory, grey water system process.

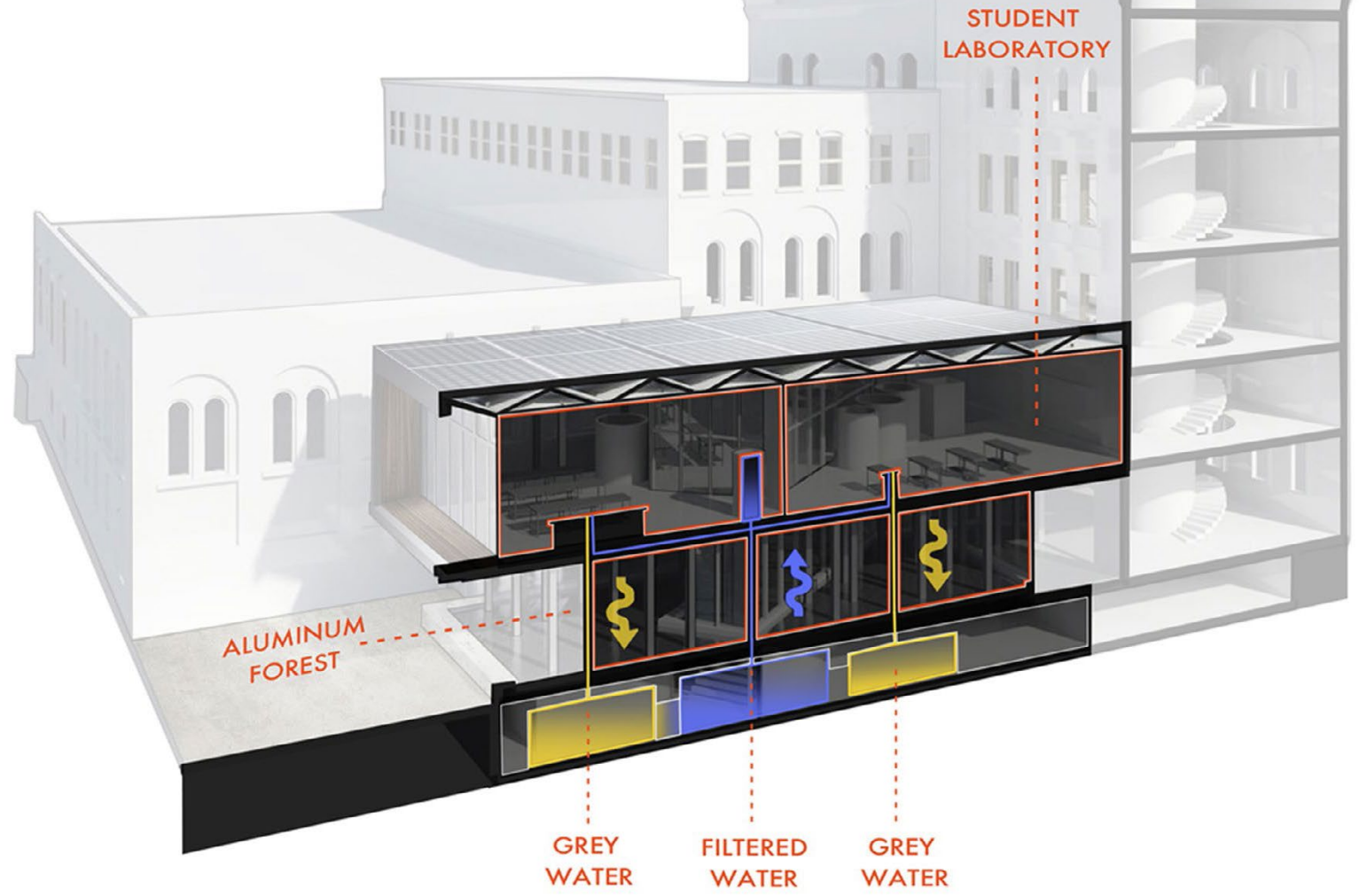

The strategy for this intervention utilizes a grey water system that is exposed by the architectural composition and acts as a means for educating students while creating unique spaces for the community. In the student laboratory and private laboratory spaces, water piping is connected with a grey water system that leads water down through the artificial forest. The water is then filtered and cleaned in the machine room located on the basement level and redirected back to the laboratories (as seen in Figure 8.4.2). For this reason, pipes are exposed under the laboratory volume, uncovering the inner system and creating an added educational value. 







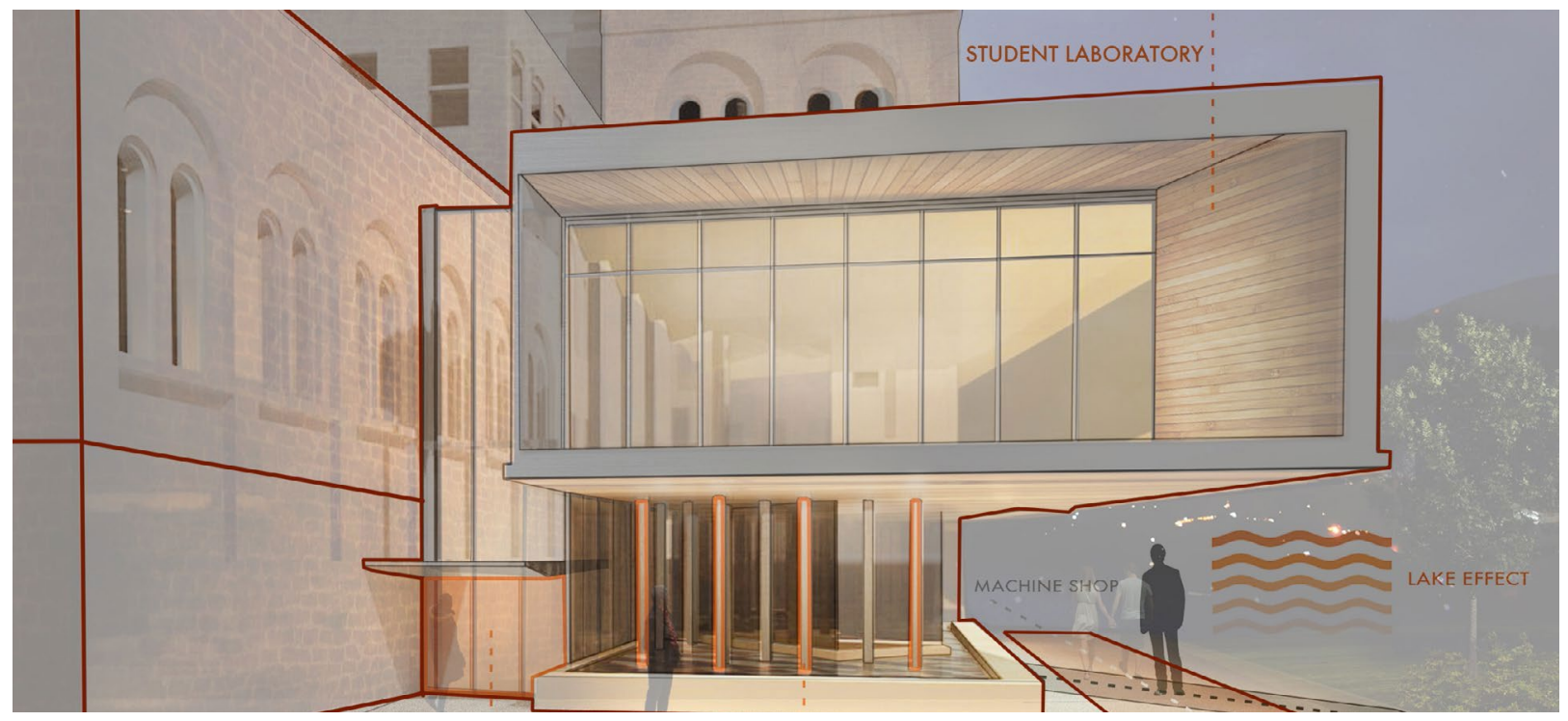

Figure 8.4.4:

Student laboratory perspective, design strategy diagram.
The space in which the forest rests was conditioned by the need to respect the original pathways and guidelines set by Clergue. For this reason, the campus boundary extends out over the pathway, creating the presence needed for a campus gateway. This cantilevered space runs the entire perimeter of the southern face, creating a sheltered corridor while resolving at the base to form the forest. ${ }^{20}$ The simplicity of the form articulates and integrates the two volumes of solid space above and open below. The result of such interior streets and public egress is to interconnect interior and exterior spaces, which trigger diverse activities and generate an informal opportunity for learning that creates a narrative between space and community. The profile of the building at the south is enclosed by a similar hinged sunscreen system used in the Biomass Facility.

The horizontally mounted blades of the façade gently move with the wind. For the college, this articulated façade serves as a means to viewing directly the faculty of wind generated energy. With this, students are able to

20 The forest also serves as means of shielding the interior streets from cold lake effect winds during winter seasons, as denoted in Figure 8.4.4.

Chapter 8: Consolidating the Void: Institute of Energy and Environmental Studies 
comprehend that the wind turbines generate more energy when the facade becomes illuminated and active. There is a direct correlation between outside environmental activity, and energy generation while also becoming a spectacle for those passing by. The façade not only regulates internal luminosity but also re-directs the sunlight towards the center of the square between the Institute of Energy and Environmental Studies facility and Biomass Facility. A rippling of

Figure 8.4.5: Insitute of Energy and Environmental Studies, southern perspective rendering. light onto the square resonates (as seen in Figure 8.4.5) and injects life onto what had once been a dense assemblage of industrial buildings.

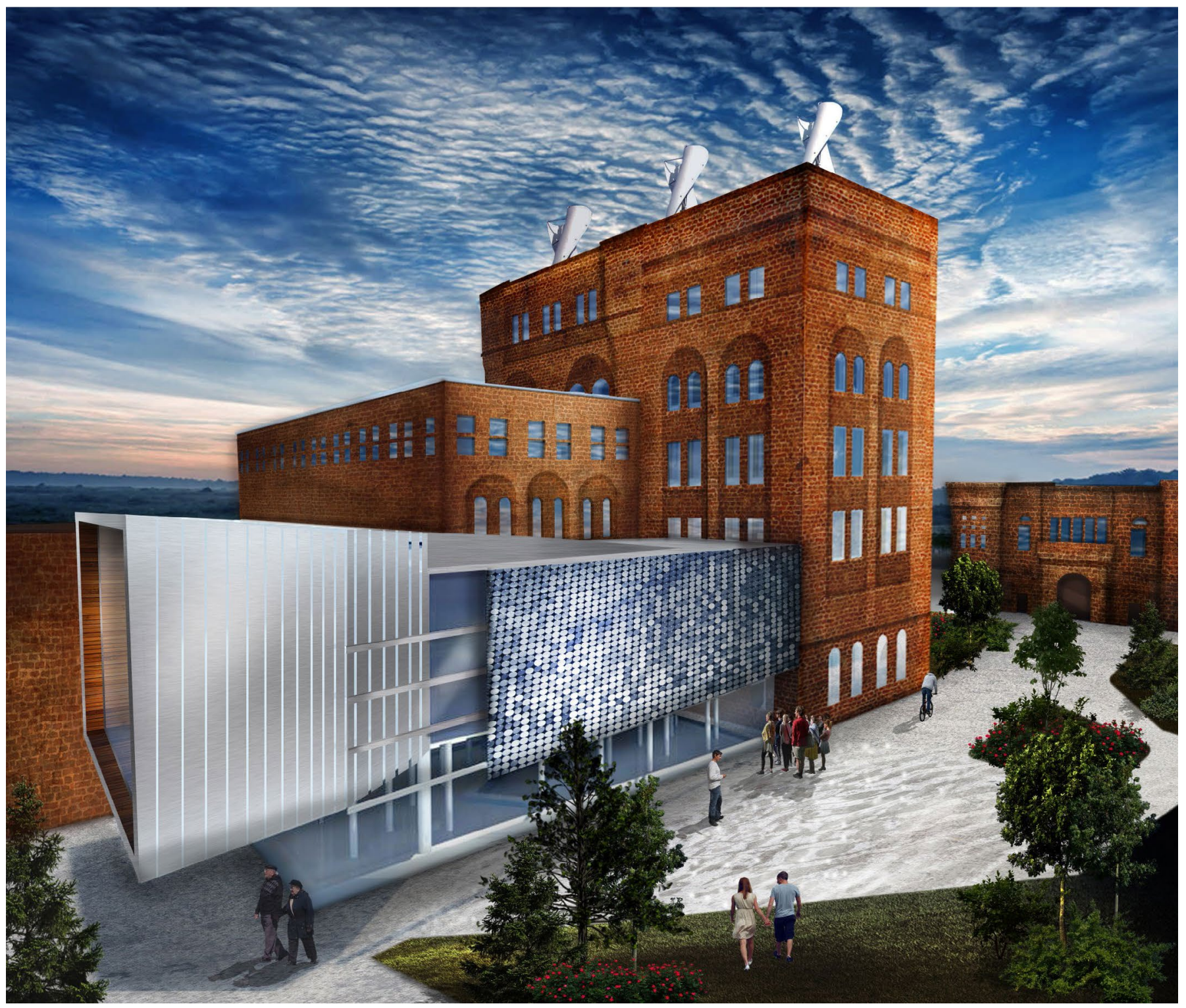


The methodology of this thesis has risen from the challenges faced with maintaining industrial heritage and addressing issues of gentrification in postindustrial developments that do not consider the past. As the St. Mary's Paper Mill has evidently become a symbol of the citizens and workers, conserving its former essence was essential for the development of a continuous dialogue with the community. The integration of past pride from a flourishing industry provided a means for infusing the voids of deindustrialization and bankruptcy by unearthing the enduring networks of Clergue's empire. Where history is concerned, the ruin allows space for the fruition of new progress and invention through an end in production that gives rise to carefully considered reiterations of past places. Through research and my own personal encounters, we understand that the voiding of such an empire and disuse of space may inhibit individuals from reconnecting with post-industrial landscapes as a result of traumatic encounters with recent deindustrialization. A glimpse of the past and its perseverance in contemporary modes of living is therefore a necessity for reintegrating the community into an ongoing tale and memory of post-industrial spaces. Through a mirror event, images of incompleteness are dismantled by reflections of the ruin's ambiguous state to embrace progress and advancement. Such images of former corporeal incarnations dissemble feelings of loss; the conception of life is transposed with renewed faith. This reflectivity yearns for the return of values that are evoked through experiencing the ruin in new light. Informed by the reflection of phantom forms, understanding its historicity and reclaiming the pride of achievement, the thesis also manifests strategies to enhance social, economic and communal stability. 
The traces of former industrial processes and networks enrich the architectural environment as it activates an empathetic association with the surrounding context and community. Newly erected architecture is able to cultivate lessons of past vestiges to instruct the furthering of historical and cultural experiences as part of the site's regeneration. The foundational components, such as existing infrastructure and service pathways, allow for the process of invention and integration that begin to direct the built form of the Biomass Facility and surrounding landscape. This integration of such existing channels promotes the use of space and begins to consolidate economic and social needs. The program considers the resources left by industry to generate the creation of jobs and support local economy that can now consider sustainability and stability as driving features for the redevelopment of such a site. The interconnectivity of the mill's former grid once again seeps out into the city, and is made evident through the re-authorship of phantom matrixes to revisit the site's autobiography. The accessibly of machine and man are reunited in new light, with a heightened consideration of communal and social requirements. The ruin therefore provides an indispensible and prime venue for the continuation of contemporary modes of living that induce familiarity and history of place. The de-industrialized image provides a unique capacity to bridge the gaps of a discontinuous narrative with the community by allowing alternate interpretations to reflect adaptive positions and fill the void of function within the city.

The prerogative for utilizing the Pulp Tower as a communal center had been initially for its strength as a landmark on site. The project is ultimately channeled towards assessing the visceral characteristics and qualities of the exiting space with regards to its history and culture. In aspiring to uncover the evolutionary nature of the industrial process within this particular edifice, my intention is to heighten the user's consciousness of their surroundings without displacing the existing networks that are inherent of the space. Indeed, the evocative presence 
of the past indicates that the building is not simply an object that may be represented, but it is itself a mechanism of representation. (Wigley, 163) The most unearthed remains of a building, through conservation, can evoke the whole; preserving the skeleton of a built space testifies to the ghostly presence of the past. (Crinson, 18) The methodology that has been developed relies on the re-framing of contemporary modes towards the regeneration of phantom forms and passages that are being augmented by calculated measurements of destruction. What happens through architecture both constructs and instructs society and the memories found within it. We inhabit it, as well as it inhabits us. We must recognize post-industrial sites as an artifact of construction, a monument; its heritage inaugurates the intimacy of our economy, our familial, historical and political economy. Characteristics that evoke the dimensions of temporality, morality and culture must be resuscitated for the ruin to empower it as an architecture of resistance in modernization. These are places of demise and of rebirth. We understand them as icons within the city, taking it for nature itself. 
Figure 2.1.2: Clutter from abandoned foundry building, 2013.

By author

Figure 2.1.3: Machine shop interior, St. Mary's Paper Site. 2013.

By author

Figure 3.1.1: Pulp Tower during demolition, 2013.

By author

Figure 3.1.2: St. Mary's Paper workers celebrating. Date unknown.

Scanned image, provided by Riversedge Development Co.

Figure 5.1.1: Site demolition, with Pulp Tower in the background. 2013.

By author

Figure 5.1.2: View of former St. Mary's Paper Mill from International Bridge. 2013.

By author

Figure 5.2.1: Essar Steel and the St. Mary's River, 2013.

By author

Figure 5.2.2: Map of Sault Ste. Marie's downtown core and western section.

By author

Figure 5.2.3: Master plan of new and old site fabric.

By author

Figure 6.1.1: Past plan of the Laird and Henderson Mill Site (St. Mary's Paper Mill),1938.

Scanned site plan from St. Mary's Paper engineering department.

Figure 6.1.2: Retaining wall and existing foundation along the riverside. 2013.

By author 
Figure 6.1.3: Site typography and existing buildings.

By author

Figure 6.1.4: Biomass Facility massing and info-graphic of biomass industrial process. 28 By author

Figure 6.2.1: Biomass Facility axonometric and site connections.

By author

Figure 6.2.2: Biomass Facility perspective by night. Northern elevation.

By author

Figure 6.2.3: Biomass Facility perspective section.

By author

Figure 6.2.4: Biomass Facility, basement floor plan. Highlighted section of area (found above). By author

Figure 6.2.5: Biomass Facility, ground floor plan. Highlighted section of area (found above). By author

Figure 6.2.6: Biomass Facility, second floor plan. Highlighted section of area (found above). By author

Figure 6.2.7: Biomass Facility perspective by night. East elevation.

Figure 6.2.8: Southern perspective of Biomass Facility. Façade shines onto existing foundation of previous industrial building. By author

Figure 7.1.1: City map of west-central core and St. Mary's Paper site.

By author

Figure 7.1.2: Phytoremediation processes in nature.

Phytoremediation Technologies Used for Remediating Polluted Water, Soil, or Air. Digital image. Edited by author Http://systemsbiology.usm.edu/BrachyWRKY/WRKY/Phytoadaptation.html. N.p., n.d. Web.

Figure 7.1.3: Biomass Facility roof system section with park and Hub trail pathway above. By author

Figure 7.1.4: Levels of contamination within roof system and clean water storage. By author

Figure 7.1.5: Detail of decontamination process in the Biomass Facility roof system. By author 
Figure 7.1.6: Axonometric detail of roof system structure and water storage containment. By author

Figure 7.1.7: Roof system chart of dimensions and plant types.

By author

Figure 8.1.1: West façade of Pulp Tower, St. Mary's Paper Mill. 2013.

By author

Figure 8.1.2: Soup Kitchen community event in Machine Shop. St. Mary's Paper mill, 2013. By author

Figure 8.1.3: Social risk index demographic map.

By author. Reference to the Social Services Administration Board Study (Hoffman)

Figure 8.1.4: Physical Health \& Well Being demographic map.

By author. Reference to the Social Services Administration Board Study (Hoffman)

Figure 8.1.5: Communication \& General Knowledge demographic map.

By author. Reference to the Social Services Administration Board Study (Hoffman)

Figure 8.1.6: Pulp Tower axonometric section.

By author

Figure 8.2.1: Pulp Tower evolution from 1901 to 2014.

By author

Figure 8.2.2: Pulp Tower basement and first floor plan.

By author

Figure 8.2.3: Front entrance canopy of Pulp Tower, public library entrance. By author

Figure 8.2.4: Interior public corridor perspective, public library staircase. By author

Figure 8.2.5: Pulp Tower second floor plan.

By author

Figure 8.2.6: Pulp Tower third floor plan.

By author

Figure 8.2.7: Multi-use and Density diagram for programs within Pulp Tower. 
Figure 8.3.1: Voids left by digester tanks in Pulp Tower.

By author

Figure 8.3.2: Perspective section of Pulp Tower and Student Laboratory, wind turbine function. By author

Figure 8.3.3: Pulp Tower exhibit and wind turbine rendering.

By author

Figure 8.4.1: Pulp Tower axonometric, showing existing building and new interventions. By author

Figure 8.4.2: Perspective section of Pulp Tower and Student Laboratory, grey water system process. By author

Figure 8.4.3: Student laboratory perspective rendering. Eastern view.

By author

Figure 8.4.4: Student laboratory perspective, design strategy diagram.

By author

Figure 8.4.5: Insitute of Energy and Environmental Studies, southern perspective rendering. By author 
Bibliography

Ashraf, M., Munir A. Qzturk, and M. S. A. Ahmad. Plant Adaptation and Phytoremediation. Dordrecht: Springer, 2010. Print.

ASLA. "Shanghai Houtan Park: Landscape as a Living System Shanghai, China." ASLA 2010 Professional Awards. American Society of Landscape Architects, n.d. Web. <http://www.asla.org/2010awards/006.html>.

Berens, Carol. Redeveloping Industrial Sites: A Guide for Architects, Planners, and Developers. Hoboken, NJ: John Wiley \& Sons, 2011.

"Bioenergy from Biomass." Natural Resources Canada (NRC). N.p., 4 Dec. 2013. Web. <http://www.nrcan.gc.ca/forests/industry/biomass-bioenergy-bioproducts/13323>.

"Bio Mass Power Plant / Matteo Thun \& Partners" 09 Sep 2013. ArchDaily. $<$ http://www.archdaily.com/?p=423318>

Boyer, M. Christine. The City of Collective Memory: Its Historical Imagery and Architectural Entertainments. Cambridge, MA: MIT, 1994. Print.

Common, Robert. Institutional Vision, Proposed Mandate Statement and Priority Objectives. The Ministry of Training, Colleges and Universities. Sault College, n.d.Web.<https://www.saultcollege.ca/Services/Corporate/ pdf/2012\%20Sault\%20College\%20Strategic\%20Mandate\%20Agreement. $p d f>$.

Canada Pulp and Paper Association (CPPA). "The Soo": Visit of the Canadian Pulp and Paper Association, Technical Se. Sault Ste. Marie: Canada Pulp and Paper Association, 1920. Print.

Cheung, C.K. "CH2 Energy Harvesting Systems: Economic Use and Efficiency." Diss. Deakin University, n.d. Print.

Cowie, Jefferson and J. Heathcott, eds. 2003. Beyond the Ruins: The Meaning of Deindustrialization. Ithaca: ILR Press.

Crinson, Mark. Paul, Tyrer. Urban Memory: History and Amnesia in the Modern City. London: Routledge, 2005. 
Davidoff, Alexander. "Potential environmental and health impacts of soil contaminated with heavy metal and deposited in a landfill near Lake Erie". 26 June 2008

Edensor, Tim. Industrial Ruins: Spaces, Aesthetics, and Materiality. Oxford [U.K.: Berg, 2005. Print.

EFB. "Enviromental Advantages." European Federation Of Green Roof Associations. N.p., n.d. Web. <http://www.efbgreenroof.eu/verband/fachbei/fa01_englisch.html>.

Hettiarachchi, Ganga M. Phytoremediation: Protecting the Environment with Plants. Tech. Kansas State University, Aug. 2012. Web. <http://www.ksre.ksu. edu/bookstore/pubs/mf3067.pdf>.

Hoffman, Kristen, and Steve Zuppa. 2011 Best Start Network Report. Tech. Sault Ste. Marie: Social Services Administration Board, 2011. Print.

Hollerung, John. Phytoremediation: A General Overview. Diss. lowa State University. Print.

Kahn, Ned. "Articulated Cloud." Ned Kahn Studios. N.p., 2012. Web. <http:// nedkahn.com/portfolio/articulated-cloud/>

Klein, Kerwin Lee. From History to Theory. Berkeley: University of California, 2011.

Mah, Alice. Industrial Ruination, Community, and Place: Landscapes and Legacies of Urban Decline. Toronto: University of Toronto, 2012. Print.

PKF. Gateway Site: Attraction Development Business Plan. Rep. Sault Ste. Marie: n.p., 2012. Print. Final Draft Report.

Quaak, P., Harrie Knoef, and Hubert E. Stassen. Energy from Biomass a Review of Combustion and Gasification Technologies. Washington, D.C.: World Bank, 1999. Print. (QUAAK)

Ramachandran, V. S. The Tell-tale Brain: A Neuroscientist's Quest for What Makes Us Human. New York: W.W. Norton, 2011. Print.

Real Estate Carrick Limited. Carrick Park: In the Centre of "the Soo" Montreal: Real Estate Carrick Limited, 1920. Scan.

Rossi, Aldo, and Peter Eisenman. The Architecture of the City. Cambridge, MA: MIT, 1982.

Sarma, Herman. Metal Hyperaccumulation in Plants: A Review Focusing on Phytoremediation Technology. Digital image. Science Alert. Http://www.scialert. net/fulltext/?doi=jest.2011.118.138\&org=11, n.d. Web. 
SSMIC. "St. Marys River Remedial Action Plan." Sault Ste. Marie Innovation Centre 2014.Web.<http://www.ssmic.com/index.cfm?fuseaction=content\&menuid=52\&pageid $=1188>$.

Virilio, Paul. The Original Accident. Cambridge: Polity, 2007.

Wigley, Mark. The Architecture of Deconstruction: Derrida's Haunt. Cambridge, MA: MIT, 1993. 
Extended Bibliography

Eisenman, Peter, Jean-Francois Bedard, and Alan Balfour. Cities of Artificial Excavation: The Work of Peter Eisenman, 1978-1988. Montreal: Canadian Centre for Architecture, 1994. Print.

Lefebvre, Henri. 1991. The Production of Space. Oxford: Blackwell.

Merleau-Ponty, Maurice, and C. Smith. 1989. Phenomenology of Perception. London: Routledge.

Trigg, Dylan. 2009. "The Place of Trauma: Memory, Haunting and the Temporality of Ruins." Memory Studies: 87-101. 